\title{
JiSEA
}

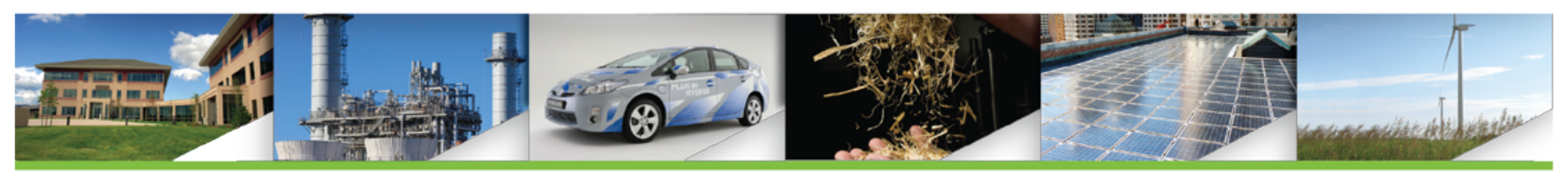

\section{Controlling Methane Emissions in the Natural Gas Sector: A Review of Federal \& State Regulatory Frameworks Governing Production, Gathering, Processing, Transmission, and Distribution}

\author{
Elizabeth Paranhos and Tracy G. Kozak \\ Energy Innovation Partners \\ William Boyd \\ Energy Innovation Partners and \\ University of Colorado - Boulder \\ James Bradbury \\ U.S. Department of Energy \\ Office of Energy Policy and Systems Analysis \\ Daniel C. Steinberg \\ National Renewable Energy Laboratory \\ Douglas J. Arent \\ Joint Institute for Strategic Energy Analysis
}

The Joint Institute for Strategic Energy Analysis is operated by the Alliance for Sustainable Energy, LLC, on behalf of the U.S. Department of Energy's National Renewable Energy Laboratory, the University of Colorado-Boulder, the Colorado School of Mines, the Colorado State University, the Massachusetts Institute of Technology, and Stanford University.

Technical Report

NREL/TP-6A50-63416

April 2015

Contract No. DE-AC36-08GO28308 


\section{Controlling Methane Emissions in the Natural Gas Sector: A Review of Federal \& State Regulatory Frameworks Governing Production, Gathering, Processing, Transmission, and Distribution}

Elizabeth Paranhos and Tracy G. Kozak Energy Innovation Partners

William Boyd

Energy Innovation Partners and

University of Colorado - Boulder

James Bradbury

U.S. Department of Energy

Office of Energy Policy and Systems Analysis

Daniel C. Steinberg

National Renewable Energy Laboratory

Douglas J. Arent

Joint Institute for Strategic Energy Analysis

Prepared under Task No. DOCC.LT23

The Joint Institute for Strategic Energy Analysis is operated by the Alliance for Sustainable Energy, LLC, on behalf of the U.S. Department of Energy's National Renewable Energy Laboratory, the University of Colorado-Boulder, the Colorado School of Mines, the Colorado State University, the Massachusetts Institute of Technology, and Stanford University.
The Joint Institute for Strategic Energy Analysis 1617 Cole Boulevard Golden, Colorado 80401 303-275-3000 • www.jisea.org
Technical Report

NREL/TP-6A50-63416

April 2015

Contract No. DE-AC36-08GO28308 


\section{NOTICE}

This report was prepared as an account of work sponsored by an agency of the United States government. Neither the United States government nor any agency thereof, nor any of their employees, makes any warranty, express or implied, or assumes any legal liability or responsibility for the accuracy, completeness, or usefulness of any information, apparatus, product, or process disclosed, or represents that its use would not infringe privately owned rights. Reference herein to any specific commercial product, process, or service by trade name, trademark, manufacturer, or otherwise does not necessarily constitute or imply its endorsement, recommendation, or favoring by the United States government or any agency thereof. The views and opinions of authors expressed herein do not necessarily state or reflect those of the United States government or any agency thereof.

Available electronically at http://www.osti.gov/scitech

Available for a processing fee to U.S. Department of Energy and its contractors, in paper, from:

U.S. Department of Energy

Office of Scientific and Technical Information

P.O. Box 62

Oak Ridge, TN 37831-0062

phone: 865.576.8401

fax: 865.576.5728

email: reports@adonis.osti.gov

Available for sale to the public, in paper, from:

U.S. Department of Commerce

National Technical Information Service

5285 Port Royal Road

Springfield, VA 22161

phone: 800.553 .6847

fax: 703.605.6900

email: orders@ntis.fedworld.gov

online ordering: http://www.ntis.gov/help/ordermethods.aspx

Cover Photos: (left to right) PIX 04135, iStock 22779761, PIX 16933, PIX 15648, PIX 08466, PIX 21205

NREL prints on paper that contains recycled content. 


\section{Acknowledgments}

This report was funded by the U.S. Department of Energy (DOE) Office of Energy Policy and Systems Analysis (EPSA). The authors would like to thank Judi Greenwald, Bryan Mignone, and Elke Hodson from EPSA for their support of this research. The report benefited from the input, review, and feedback from a number of experts. In particular, the authors would like to thank Elisabeth Blaug, Federal Energy Regulatory Commission (FERC); Tomás Carbonell, Environmental Defense Fund (EDF); Garvin Heath, National Renewable Energy Laboratory (NREL); Elke Hodson, DOE; Adrian Down, DOE; Jeff Logan, NREL; Virginia Palacios, EDF; Gian Porro, NREL; Robert Smith, U.S. Department of Transportation (DOT); Suzanne Waltzer, U.S. Environmental Protection Agency (EPA); and Monique Watson, FERC, for their reviews of the report. These reviews serve to make this report as technically sound as possible, however, any remaining errors or omissions are those of the authors. Furthermore, the views and opinions of authors expressed herein do not necessarily state or reflect those of the reviewers, their associated institutions, or the United States government or of any institution thereof. 


\section{Foreword}

\section{Natural Gas and our Transforming Energy Economy}

Unconventional natural gas, and specifically shale gas, is reshaping the U.S. energy sector. In 2011, the Joint Institute for Strategic Energy Analysis (JISEA) published its first major report in a series of studies on natural gas and the U.S. energy sector. Titled Natural Gas and the Transformation of the U.S. Energy Sector: Electricity, the report provides a new methodological approach to estimate natural gas related greenhouse gas emissions, tracks trends in regulatory and voluntary industry practices, and explores various electricity futures.

Since then, our work has examined additional critical topics related to the role of natural gas in our energy economy, including potential synergies between natural gas and renewable energy in the power and transportation sectors; and the state of knowledge about emissions of natural gas systems compared to other fuel sources. Our ongoing work in this space will explore economic, environmental, and systems impacts of natural gas development and use.

As the natural gas landscape continues to shift in the United States and globally, JISEA believes that bringing objective views and analytical expertise to bear on issues critical to our energy system transformation can help move discussion forward on a productive path. It is part of our mission to provide leading-edge, objective, high-impact research and analysis to inform global energy investment and policy decisions. This report is part of our growing portfolio of natural gas research and reflects our commitment to "getting gas right." We look forward to your feedback and thank you for your interest in our work.

Doug Arent

Executive Director, Joint Institute for Strategic Energy Analysis 


\section{Acronyms}

\begin{tabular}{|c|c|}
\hline ANPRM & Advanced Notice of Proposed Rulemaking \\
\hline BLM & Bureau of Land Management \\
\hline CARB & California Air Resources Board \\
\hline CCRM & capital cost recovery mechanism \\
\hline $\mathrm{CIG}$ & Colorado Interstate Gas Co. \\
\hline CTG & Control Technique Guideline \\
\hline DOI & U.S. Department of the Interior \\
\hline EA & Environmental Assessment \\
\hline EIS & Environmental Impact Statement \\
\hline EPA & United States Environmental Protection Agency \\
\hline FERC & Federal Energy Regulatory Commission \\
\hline FLPMA & Federal Land Policy and Management Act \\
\hline GAO & Government Accountability Office \\
\hline GHG & greenhouse gas \\
\hline GHGRP & Greenhouse Gas Reporting Program \\
\hline GPTC & Gas Piping Technology Committee \\
\hline HAP & hazardous air pollutant \\
\hline $\mathrm{HCA}$ & high-consequence area \\
\hline HLPSA & Hazardous Liquid Pipeline Safety Act of 1979 \\
\hline IFF & Incentive Fixed Fuel \\
\hline IMP & integrity management plan \\
\hline LAUF gas & lost and unaccounted-for gas \\
\hline LDAR & leak detection and repair \\
\hline LDC & local distribution company \\
\hline LDS & leak detection system \\
\hline LNG & liquefied natural gas \\
\hline MLA & Mineral Leasing Act \\
\hline NEPA & National Environmental Policy Act \\
\hline NESHAP & $\begin{array}{l}\text { National Emission Standards for Hazardous Air } \\
\text { Pollutants }\end{array}$ \\
\hline NG & natural gas \\
\hline NGA & Natural Gas Act of 1938 \\
\hline NGPSA & Natural Gas Pipeline Safety Act of 1968 \\
\hline NOI & notice of inquiry \\
\hline NPR & Notice of Proposed Rulemaking \\
\hline NREL & National Renewable Energy Laboratory \\
\hline NRRI & National Regulatory Research Institute \\
\hline NSPS & New Source Performance Standard \\
\hline PGA & purchased-gas adjustment \\
\hline PHMSA & Pipeline and Hazardous Materials Safety Administration \\
\hline PUC & public utility commission \\
\hline RMP & Resource Management Plan \\
\hline SCADA & supervisory control and data acquisition \\
\hline UGRB & Upper Green River Basin \\
\hline VOC & volatile organic compound \\
\hline
\end{tabular}




\section{Executive Summary}

The United States is the world's largest producer of natural gas ${ }^{1}$ and is home to the most extensive infrastructure for transporting natural gas. That infrastructure includes over 480,000 natural gas and condensate wells ${ }^{2}$ and associated equipment, over 2.1 million miles of distribution pipelines, approximately 300,000 miles of onshore natural gas transmission pipelines, ${ }^{3}$ and 230,000 miles of gathering pipelines. ${ }^{4}$

Methane accounts for roughly $10 \%$ of anthropogenic greenhouse gas (GHG) emissions, with one quarter of these methane emissions coming from the natural gas sector. ${ }^{5}$ Given the substantial contribution of methane leakage to climate change, measuring and controlling methane emissions have been identified in the President's Climate Action Plan as key components of U.S. efforts to reduce GHG emissions. In March 2014, the Obama administration announced its Strategy to Reduce Methane Emissions, ${ }^{6}$ including more details on interagency efforts to curb this GHG from oil and natural gas systems. More recently, the Administration announced a new goal to cut methane emissions in the oil and gas sector by 40-45\% from 2012 levels by $2025 .{ }^{7}$ Though the Administration aims for all current federal initiatives to make significant progress toward this goal, it acknowledges that additional actions will be needed over the coming decade. ${ }^{8}$

Historically, federal and state regulation of the natural gas industry has not emphasized minimizing the climate impacts of methane leakage. Rather, methane emission reductions from this sector have typically occurred as a co-benefit of policies that target air pollution (such as smog) and improve safety. In general, policy strategies that reduce system leakage for any of the above purposes also conserve natural gas, which can result in savings for consumers in addition to climate benefits. On the other hand, new regulations can carry administrative costs for governments and investment costs for industry that need to be balanced against fuel savings or other co-benefits.

\footnotetext{
${ }^{1}$ Energy Information Administration. "International Energy Statistics." http://www.eia.gov/cfapps/ipdbproject/IEDIndex3.cfm?tid=3\&pid=26\&aid=1.

${ }^{2}$ Energy Information Administration. "U.S. Natural Gas Number of Gas and Gas Condensate Wells." http://www.eia.gov/dnav/ng/hist/na1170 nus 8a.htm.

${ }^{3}$ U.S. Dept. of Transportation, The State of National Pipeline Infrastructure, 1 (2011), http://opsweb.phmsa.dot.gov/pipelineforum/docs/Secretarys\%20Infrastructure\%20Report_Revised\%20per \%20PHC_103111.pdf; PHMSA, Gathering Pipelines: Frequently Asked Questions, http://www.phmsa.dot.gov/portal/site/PHMSA/menuitem.6f23687cf7b00b0f22e4c6962d9c8789/?vgnextoi $\underline{\mathrm{d}=4351 \mathrm{fd} 1 \mathrm{a} 874 \mathrm{c} 6310 \mathrm{VgnVCM} 1000001 \mathrm{ecb} 7898 \mathrm{RCRD} \& v g n e x t c h a n n e l=f 7280665 \mathrm{~b} 91 \mathrm{ac0} 010 \mathrm{VgnVCM} 100}$ 0008049a8c0RCRD\&vgnextfmt=print.

${ }^{4} 76$ Fed. Reg. 53,086 (Aug. 25, 2011).

${ }^{5}$ Assuming a Global Warming Potential for methane of 25. Source: U.S. Environmental Protection Agency. "Inventory of U.S. Greenhouse Gas Emissions and Sinks: 1990-2012."April 2014. http://www.epa.gov/climatechange/ghgemissions/usinventoryreport.html.

${ }^{6}$ Executive Office of the President. "Climate Action Plan: Strategy to Reduce Methane Emissions." March, 2014. http://www.whitehouse.gov/blog/2014/03/28/strategy-cut-methane-emissions.

${ }^{7}$ Executive Office of the President. "FACT SHEET: Administration Takes Steps Forward on Climate Action Plan by Announcing Actions to Cut Methane Emissions.” http://www.whitehouse.gov/the-pressoffice/2015/01/14/fact-sheet-administration-takes-steps-forward-climate-action-plan-anno-1.

${ }^{8}$ Id.
} 
This report provides an overview of the regulatory frameworks governing natural gas supply chain infrastructure siting, construction, operation, and maintenance. Information was drawn from a number of sources, including published analyses, government reports, in addition to relevant statutes, court decisions and regulatory language, as needed. The scope includes all onshore facilities that contribute to methane emissions from the natural gas sector, focusing on three areas of state and federal regulations: (1) natural gas pipeline infrastructure siting and transportation service (including gathering, transmission, and distribution pipelines), (2) natural gas pipeline safety, and (3) air emissions associated with the natural gas supply chain. In addition, the report identifies the incentives under current regulatory frameworks to invest in measures to reduce leakage, as well as the barriers facing investment in infrastructure improvement to reduce leakage. Policy recommendations regarding how federal or state authorities could regulate methane emissions are not provided; rather, existing frameworks are identified and some of the options for modifying existing regulations or adopting new regulations to reduce methane leakage are discussed. Key conclusions of the report are as follows:

\section{Regulation of Natural Gas Pipeline Siting and Transportation Service:}

Federal and state regulation of natural gas pipeline siting and transportation service have given only limited attention to direct and indirect GHG emissions from natural gas transmission and distribution pipeline infrastructures.. In particular, for pipeline transportation service, the traditional cost-of-service approach to setting rates for pipelines has typically treated methane leaks under the broad category of lost and unaccounted for gas, or LAUF gas, which also includes theft, metering errors and other factors, as a cost of service to be passed on to consumers. The Federal Energy Regulatory Commission (FERC), however, has proposed a new policy to enable a cost-recovery mechanism for investments in pipeline modernization, though on a case-by-case basis. The new policy, if adopted, could have beneficial effects on efforts by pipeline companies to reduce LAUF gas. Most states have already adopted similar mechanisms to encourage local distribution companies to invest in accelerated pipeline replacement programs.

\section{Pipeline Safety Regulations:}

To date, federal pipeline safety regulations have exclusively focused on the risk that gas pipeline leaks and ruptures pose to public safety, with no consideration of the threat that non-hazardous methane leaks pose to the environment. As a result, there are numerous gaps and limitations with respect to the coverage, the specificity of requirements and the enforcement of federal pipeline safety regulations. The Pipeline and Hazardous Materials Safety Administration (PHMSA), is planning to propose improvements to the federal pipeline safety laws, which could help to reduce methane emissions from natural gas infrastructure by expanding the scope of requirements under federal safety standards. In addition, most states have put safety standards in place that go beyond minimum federal requirements. Lastly, a desire to conserve their product, reduce litigation risk and/or increase customer confidence may motivate some companies to go beyond regulatory requirements. 


\section{Federal and State Air Pollution Requirements:}

The current federal regulatory framework for air pollution does not require controls for methane emissions directly. Most methane emissions from older equipment, sources downstream of processing plants, and other select sources across all segments, are currently not covered by federal or state air pollution standards. However, the administration recently announced ${ }^{9}$ that the Environmental Protection Agency (EPA) will soon propose the first ever federal regulations on methane emissions from "new and modified oil and gas production sources, and natural gas processing and transmission sources." States have already begun to address gaps in current federal requirements. A small number of states directly regulate methane emissions, including requirements for new and existing sources concurrently under the same authorities. However, requirements for emissions sources downstream of processing plants - such as compressor stations, pneumatic controllers, and pipeline and equipment leaks -- are notably lacking in state clean air measures.

\section{Federal Permitting Requirements:}

Current Bureau of Land Management (BLM) policies and requirements for oil and gas activities on federal and tribal land are decades old and there is considerable room to reduce emissions through the strengthening of these standards. The President's Methane Strategy commits the BLM to propose "updated standards to reduce venting and flaring from oil and gas production on public lands." It is not clear, however, whether these standards will take the form of a revision to the current policy or a wholly new rule. A limitation to any BLM requirements is that they apply to leases on federal and tribal lands and rights-of-way, which represented roughly 16 percent of total U.S. production of natural gas in FY 2013. ${ }^{10}$

Historically, most federal and state regulatory agencies have not been charged with taking steps to minimize emissions of greenhouse gases such as methane. Yet, there are many cases where the current regulatory frameworks and the authorities granted to agencies with jurisdiction over natural gas pipelines and other facilities provide ample opportunity to reduce and prevent methane emissions. Moreover, state and federal air pollution regulators recently have begun to regulate methane emissions directly. Through economic, safety, waste prevention, and environmental requirements, the existing federal and state agencies involved in regulation of the natural gas industry, including FERC, PHMSA, EPA, BLM, state public utility commissions (PUCs), state environmental and other agencies, have a wide array of existing authorities that could be leveraged to minimize emissions from the natural gas system.

\footnotetext{
${ }^{9}$ http://www.whitehouse.gov/the-press-office/2015/01/14/fact-sheet-administration-takes-steps-forwardclimate-action-plan-anno-1.

${ }^{10} \mathrm{http}: / / \mathrm{www} . e i a . g o v / a n a l y s i s /$ requests/federallands/
} 


\section{Table of Contents}

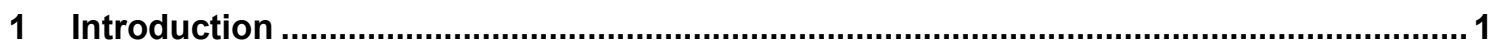

2 Federal and State Regulation of Pipeline Siting and Transportation Service ................4

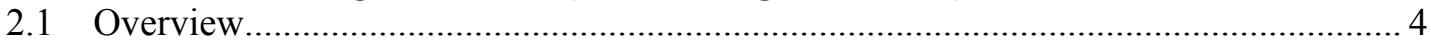

2.2 Regulation of Natural Gas Pipeline Siting and Transportation Service.......................... 6

2.2.1 Federal Energy Regulatory Commission Regulation of Interstate Natural Gas

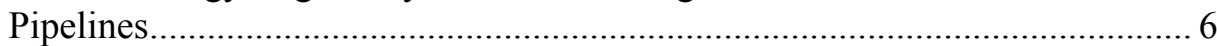

2.2.2 State Regulation of Gathering, Intrastate Transmission, and Distribution Pipeline Transportation Service.................................................................. 11

2.3 Regulatory Treatment of Fuel Usage and LAUF Gas Under Federal and State Regulation of Pipeline Transportation Service ............................................................... 14

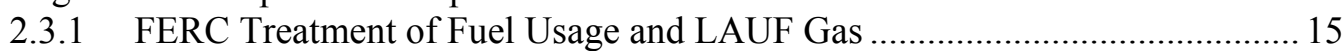

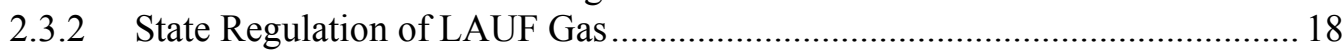

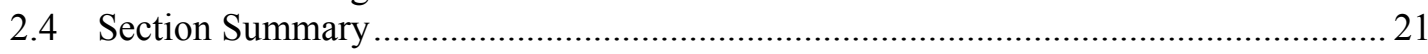

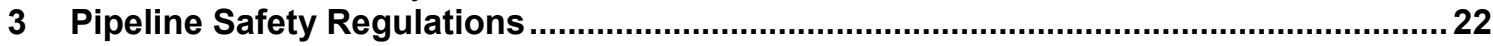

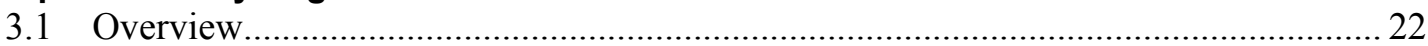

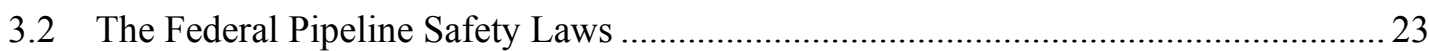

3.2.1 Consideration of Environmental Impacts of Methane from Leaking Pipelines25

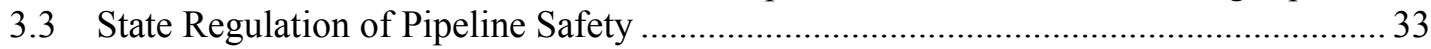

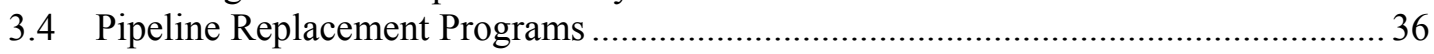

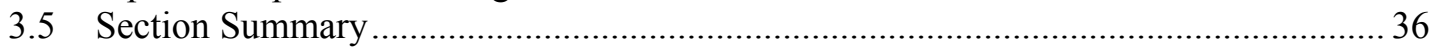

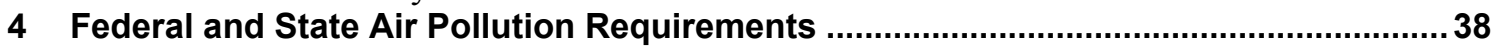

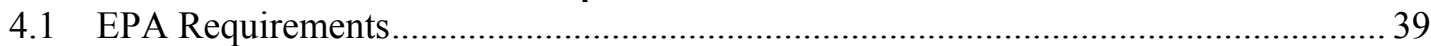

4.1.1 New Source Performance Standards........................................................... 39

4.1.2 EPA National Emission Standards for Hazardous Air Pollutants........................ 41

4.1.3 Reporting Requirements for GHG Emissions .............................................. 41

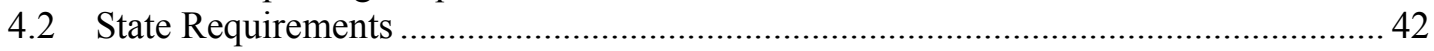

4.2.1 Leak Detection and Repair Requirements for Equipment Leaks.................... 42

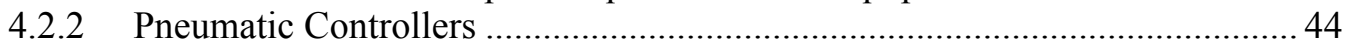

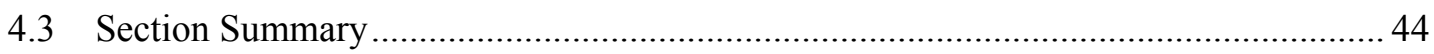

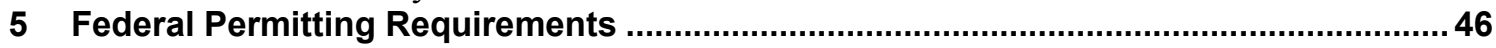

5.1 Overview of Bureau of Land Management Requirements .......................................... 46

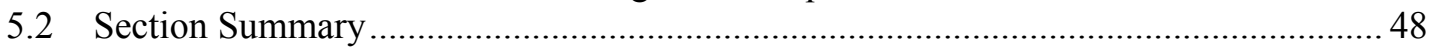

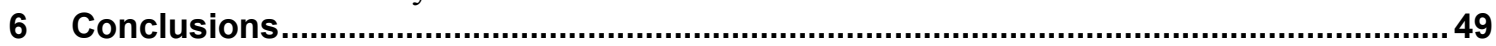

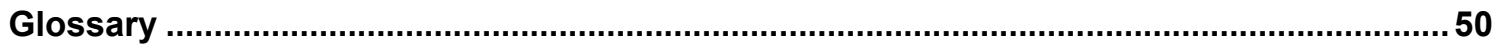

Appendix A: FERC Experiments with Incentive Rates to Reduce Pipelines' Fuel Use and

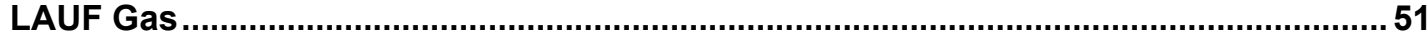

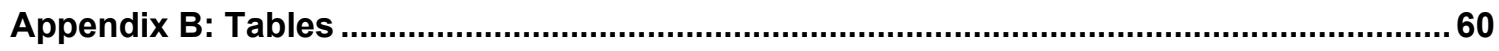




\section{Introduction}

Methane $\left(\mathrm{CH}_{4}\right)$ accounts for roughly $10 \%$ of anthropogenic greenhouse gas (GHG) emissions, with one quarter of these methane emissions coming from the natural gas sector. ${ }^{11}$ These emissions occur across the entire natural gas supply chain, from production to transportation and distribution (Figure 1). When measured over a 100 year time frame, methane is over 25 times as effective at trapping heat in the atmosphere as an equivalent mass of carbon dioxide. ${ }^{12}$ The United States Environmental Protection Agency's (EPA) Greenhouse Gas Inventory report estimates that 7.7 million metric tons (193 million metric tons $\mathrm{CO}_{2}$ equivalent, or $\mathrm{MMT} \mathrm{CO}_{2} \mathrm{e}$ ) of methane were emitted from the oil and natural gas systems in 2012, the vast majority of which (6.19 million metric tons (155 million metric tons $\mathrm{CO}_{2}$ equivalent) came from natural gas systems. ${ }^{13}$ This report focuses primarily on regulatory frameworks governing methane emissions from onshore natural gas systems.

\section{U.S. Anthropogenic Methane Emissions, 2012}
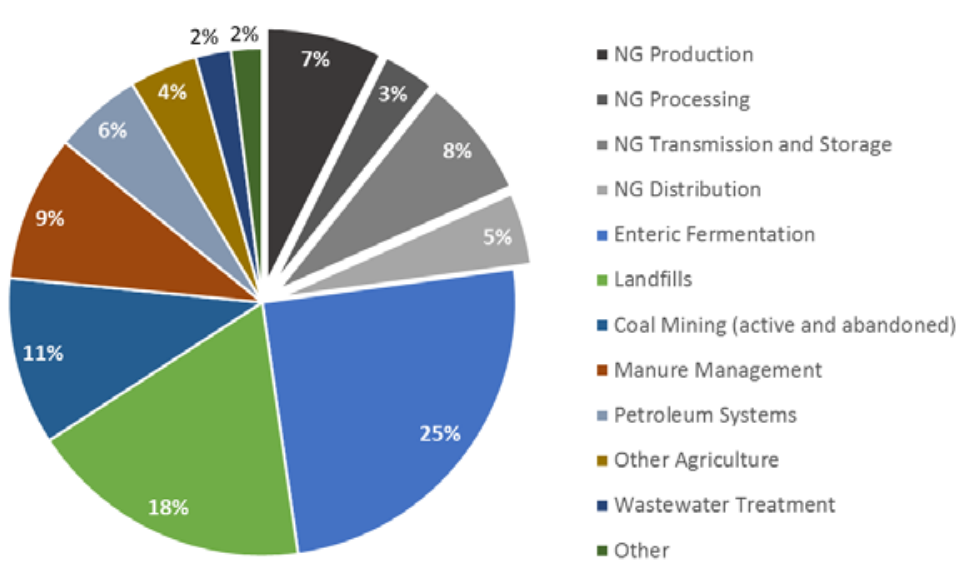

Figure 1. Inventory of methane emissions from anthropogenic sources Natural gas (NG) sector emissions from all segments amount to roughly $23 \%$ of total U.S. methane emissions. ${ }^{14}$

Considerable public scrutiny has focused on methane emissions from the production stage of the natural gas supply chain, and this is where the majority of methane emission

\footnotetext{
${ }^{11}$ U.S. Environmental Protection Agency, Inventory of U.S. Greenhouse Gas Emissions and Sinks: 19902012, ES-13 (Apr., 2014).

${ }^{12}$ For analytical and reporting purposes, the Environmental Protection Agency assumes that methane has a Global Warming Potential (GWP) of 25. However, the most recent science assessment report by the Intergovernmental Panel on Climate Change estimates that the GWP for methane is 34 for fossil $\mathrm{CH}_{4}$. Intergovernmental Panel on Climate Change. "Climate Change 2013: The Physical Science Basis." Chapter 8. 2013. https://www.ipcc.ch/pdf/assessment-report/ar5/wg1/WG1AR5 Chapter08_FINAL.pdf.

${ }^{13}$ Inventory of U.S. Greenhouse Gas Emissions and Sinks: 1990-2012, Energy section, Table 3-2 (April 2014). Emissions include leaks and vented emissions and some combustion-related emissions

${ }^{14}$ U.S. Environmental Protection Agency, supra note 11.
} 
reductions have occurred in recent years. ${ }^{15}$ From 2005 to 2012, however, methane emissions from the processing and transmission and storage segments increased by $13 \%{ }^{16}$

Measuring and controlling methane emissions has been identified in the President's Climate Action Plan ${ }^{17}$ as a key component of U.S. efforts to reduce GHG emissions. In March 2014, the administration announced its Strategy to Cut Methane Emissions, including details on interagency efforts to curb methane emissions from oil and natural gas systems. ${ }^{18}$ More recently, the Administration announced a new goal to cut methane emissions in the oil and gas sector by $40-45 \%$ from 2012 levels by $2025 .{ }^{19}$ Though the Administration aims for all current federal initiatives to make significant progress toward this goal, it acknowledges that additional actions will be needed over the coming decade. $^{20}$

The regulatory frameworks governing the various aspects of the natural gas supply chain are dynamic and multi-layered. This report focuses on four different areas of state and federal regulations, each of which may directly or indirectly pertain to natural gas system emissions:

1. Regulation of natural gas transmission and distribution pipeline siting and transportation service

2. Regulation of natural gas pipeline safety

3. Regulation of air emissions associated with the natural gas supply chains ${ }^{21}$

4. Regulation of oil and gas development on federal lands.

Depending on the particular regulatory framework, regulators treat natural gas emissions as an economic or permitting issue in the context of pipeline siting, transportation service regulation, and federal permitting, as a safety issue in the context of pipeline safety regulations, and as an environmental issue in the context of environmental regulations dealing with air quality. In general, policy strategies that reduce system leakage for any of the above purposes also conserve natural gas, which can result in savings for consumers in addition to climate benefits. ${ }^{22}$ On the other hand, new regulations can carry administrative costs for governments and investment costs for companies that need to be

\footnotetext{
15 The U.S. GHG Inventory estimates that methane emissions from NG systems dropped by $13 \%$ between 2005 and 2012. Methane emissions from the production segment have dropped by $38 \%$ over this same time period.

${ }^{16}$ U.S. EPA. Inventory of U.S. Greenhouse Gas Emissions and Sinks: 1990-2012, (Apr., 2014).

${ }^{17}$ President's Climate Action Plan, Strategy to Reduce Methane Emissions, 7 (Mar. 2014).

${ }^{18} \mathrm{http}: / / w w w . w h i t e h o u s e . g o v / \mathrm{blog} / 2014 / 03 / 28 /$ strategy-cut-methane-emissions.

19 http://www.whitehouse.gov/the-press-office/2015/01/14/fact-sheet-administration-takes-steps-forwardclimate-action-plan-anno-1,

${ }^{20} I d$.

${ }^{21}$ Within the production segment, many state and federal environmental regulations apply to both natural gas and oil operations, and as such the below discussion of regulations governing emissions from the production segment generally applies to both natural gas and oil.

${ }^{22}$ Warner, E., D. Steinberg, E. Hodson and G. Heath. "Potential Cost-Effective Opportunities for Methane Emissions Abatement.” NREL/TP-6A50-62818. Golden, CO, USA: Joint Institute for Strategic Energy Analysis. 2015. (Forthcoming)
} 
balanced against potential fuel savings or other co-benefits. This report identifies some of the challenges and opportunities associated with efforts to further reduce emissions across the natural gas supply chain. Information for this study was drawn from a number of sources, including published analyses, government reports, in addition to relevant statutes, court decisions, and regulatory language, as needed. 


\section{Federal and State Regulation of Pipeline Siting and Transportation Service}

\subsection{Overview}

The United States has the world's most extensive infrastructure for transporting natural gas. That infrastructure includes over 2.1 million miles of distribution pipelines, approximately 300,000 miles of onshore natural gas transmission pipelines,${ }^{23}$ and 230,000 miles of gathering pipelines. ${ }^{24}$ These various pipelines are constructed of different materials, which pose differing risks of leaks and failures.

Roughly $9 \%$ of all distribution main pipelines are made of leak-prone (cast-iron, baresteel, and early vintage plastic) materials, though states are actively working with utilities to replace these pipelines. ${ }^{25}$ Cast or wrought iron pipelines were originally constructed to transport manufactured gas beginning in the 1870s and 1880s and used extensively through the 1940s ${ }^{26}$ The degradation-prone nature of iron alloys, the old age of the pipelines, and outdated pipe-joint design pose increased risks with continued use of such pipelines. Steel has been used extensively since the 1950s. The age and lack of protective coating typically increases leak and failure risk of bare steel pipelines compared to some other pipelines. Plastic pipelines for gas distribution became prevalent in the early 1970s. Older vintage plastic pipelines are at risk of brittle failures (modern plastic pipelines are designed to avoid such failures). ${ }^{27}$

Most U.S. natural gas pipelines that are made of leak-prone materials are located within distribution systems, with relatively few located within transmission systems ${ }^{28}$ (figure 2 shows a breakdown of emissions by supply chain segment). There is relatively little information regarding the integrity (and even the location) of much of the pipeline infrastructure within the gathering segment. ${ }^{29}$ About half of the existing natural gas

\footnotetext{
${ }^{23}$ U.S. Dept. of Transportation, The State of National Pipeline Infrastructure, 1 (2011), http://opsweb.phmsa.dot.gov/pipelineforum/docs/Secretarys\%20Infrastructure\%20Report_Revised\%20per \%20PHC_ 103111.pdf; PHMSA, Gathering Pipelines: Frequently Asked Questions, http://www.phmsa.dot.gov/portal/site/PHMSA/menuitem.6f23687cf7b00b0f22e4c6962d9c8789/?vgnextoi $\mathrm{d}=4351 \mathrm{fd} 1 \mathrm{a} 874 \mathrm{c} 6310 \mathrm{VgnVCM} 1000001 \mathrm{ecb} 7898 \mathrm{RCRD} \& v g n e x t c h a n n e l=f 7280665 \mathrm{~b} 91 \mathrm{ac} 010 \mathrm{VgnVCM} 100$ $0008049 \mathrm{a} 8 \mathrm{c} 0 \mathrm{RCRD} \& \mathrm{vgnextfmt}=$ print.

2476 Fed. Reg. 53,086 (Aug. 25, 2011).

${ }^{25}$ American Gas Foundation, Gas Distribution Infrastructure: Pipeline Replacement and Upgrades (July 2012).

${ }^{26}$ U.S Department of Transportation, Pipeline and Hazardous Materials Safety Administration (PHMSA).

"Cast and Wrought Iron Inventory",

http://opsweb.phmsa.dot.gov/pipeline _replacement/cast iron inventory.asp, accessed February 9, 2015.http://opsweb.phmsa.dot.gov/pipeline replacement/cast iron inventory.asp.

${ }^{27}$ U.S Department of Transportation, Pipeline and Hazardous Materials Safety Administration (PHMSA), "Pipeline Materials" http://opsweb.phmsa.dot.gov/pipelineforum/pipeline-materials/index.html Accessed February 9, 2015.

${ }^{28}$ According to EPA, roughly half of methane emissions from distribution systems are from pipeline leaks; meanwhile less than $5 \%$ of methane emissions form the transmission and storage sectors are from leaking pipelines. (U.S. EPA. 2014. Inventory of U.S. Greenhouse Gas Emissions and Sinks: 1990-2012.)

${ }^{29}$ U.S. Government Accountability Office. "Collecting Data and Sharing Information on Federally Unregulated Gathering Pipelines Could Help Enhance Safety.” March 22, 2012. Accessed January 16, 2015, at http://www.gao.gov/products/GAO-12-388.
} 
transmission pipelines and gathering systems were built in the 1950s and 1960s, and about $12 \%$ was built before $1950 .{ }^{30}$ One quarter of the nation's gas distribution pipelines was built in the $1940 \mathrm{~s}$ and $1950 \mathrm{~s}$, and about $7 \%$ before $1950 .^{31}$

A March 2014 report from ICF International estimates that an additional 850 miles of interstate transmission pipeline and 13,850 miles of new gathering lines will be needed every year until 2035 in order to keep pace with the projected development of natural gas supplies. ${ }^{32}$ Moreover, there are still about 31,000 miles of cast iron main natural gas distribution lines and about 57,000 miles of bare steel main pipelines in the United States that will eventually need to be replaced. ${ }^{33}$

\footnotetext{
${ }^{30}$ PHMSA Website, Pipeline Incidents and Mileage Report, https://opsweb.phmsa.dot.gov/pipelineforum/f acts-and-stats/incidents-and-mileage-report/. 
Production, Gathering and Boosting

(49 $\mathrm{MMtCO}_{2} \mathrm{e} \mathrm{yr}^{-1}[32 \%]$ )

1) Drilling and Well Completion

2) Producing Wells

3) Gathering Lines

4) Gathering and Boosting Stations

Processing $122 \mathrm{MMtCO}_{2} \mathrm{e} \mathrm{vr}^{-1}$

[14\%]):

5) Gas Processing Plant

Transmission and Storage $\mathbf{1 5 2}$

$\left.\mathrm{MMtCO}_{2} \mathrm{e} \mathrm{yr}^{-1}[34 \%]\right)$

6) Transmission Compressor Stations

7) Transmission Pipeline

8) Underground Storage

Distribution (31 $\mathrm{MMtCO}_{2}{\left.\mathrm{e} \mathrm{r}^{-1}[20 \%]\right)}^{2}$

9) Distribution Mains

10) Regulators and Meters for:

a. City Gate

b. Large Volume Customers

c. Residential Customers

d. Commercial Customers

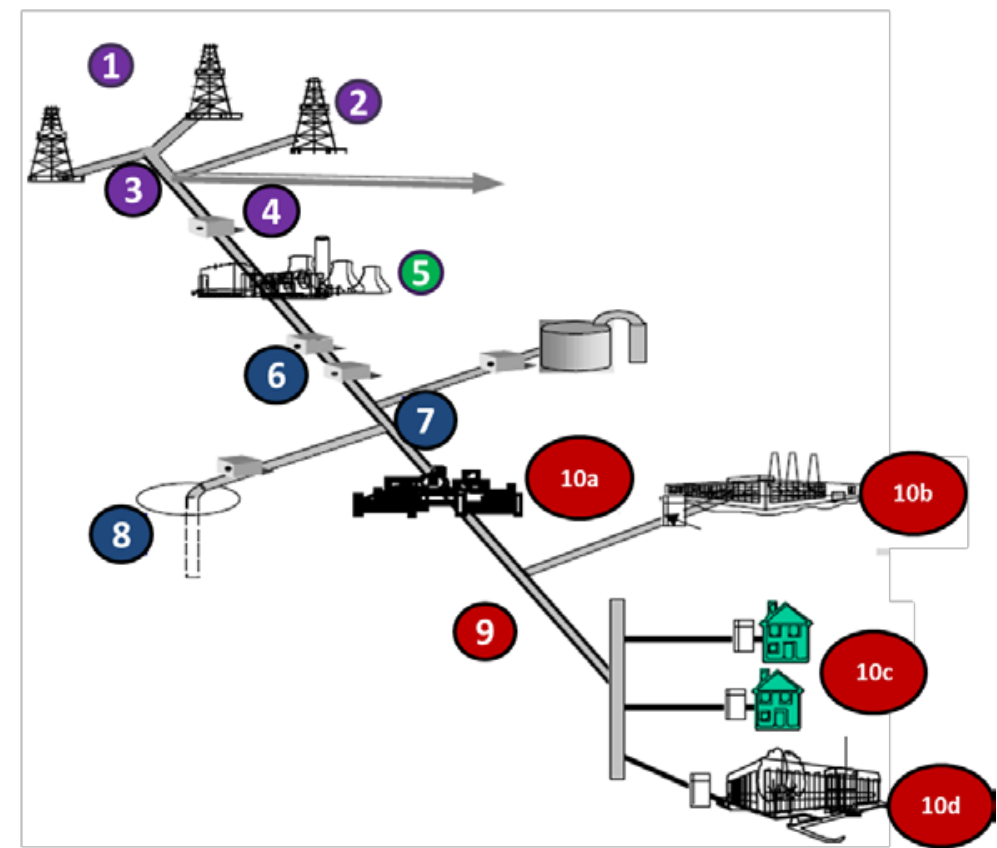

Figure 2. Methane emissions in 2011 from the natural gas supply chain ( $\mathrm{MMtCO}_{2} \mathrm{e} / \mathrm{yr}$ ) and contributions to total emissions (\%)

\subsection{Regulation of Natural Gas Pipeline Siting and Transportation Service}

The states and the federal government are responsible for different aspects of natural gas pipeline siting and transportation service regulation. In general, FERC has jurisdiction over the siting of interstate natural gas pipelines and over ratemaking for transportation service provided by those interstate pipelines. The states have jurisdictions over siting and ratemaking for upstream gathering lines, intrastate pipelines, and downstream local distribution systems.

\subsubsection{Federal Energy Regulatory Commission Regulation of Interstate Natural Gas Pipelines}

Under the Natural Gas Act (NGA) of 1938, FERC has primary responsibility for the siting of interstate natural gas pipelines and for regulating transmission and wholesale sales of natural gas in interstate commerce. ${ }^{35}$ This section discusses each of these regulatory responsibilities in turn.

\section{FERC Interstate Pipeline Siting Authority}

Section 7 of the NGA requires a natural gas company to obtain from FERC a Certificate of Public Convenience and Necessity (Certificate) before a company can transport natural gas in interstate commerce or construct, acquire, extend, or operate any facilities for such

\footnotetext{
${ }^{34}$ This figure is adapted from EPA report 430-R-13-011, Global Mitigation of Non- $\mathrm{CO}_{2}$ Greenhouse Gases: 2010-2030 (2013), with data from EPA report 430-R-14-003, Inventory of U.S. GHG Emissions and Sinks: 1990-2012 (2014).

${ }^{35}$ Natural Gas Act $\S 7,15$ U.S.C. $\S 717 \mathrm{c}, I d$. at $\S 4,15$ U.S.C. $\S 717 \mathrm{f}$.
} 
transportation. ${ }^{36}$ The application for such a certificate of public convenience and necessity (Certificate Application) is a comprehensive document that describes the proposed project, its need, and potential environmental impacts. After the Certificate Application is submitted, FERC prepares an Environmental Assessment (EA) or an Environmental Impact Statement (EIS) analyzing the environmental issues of the proposed project as per requirements of the National Environmental Policy Act (NEPA).

If FERC determines that the project is in the public convenience and necessity, it will issue a Certificate authorizing construction and operation of the new interstate natural gas facility. As discussed below, FERC's siting authority represents an opportunity for the applicant, stakeholders, and FERC to consider, where relevant, methane emissions early in the decision making process.

\section{Pre-Filing Process}

FERC has established a collaborative pre-application process that gives landowners, government agencies, and other interested stakeholders the opportunity to review project information and an anticipated schedule, and to identify issues or concerns before a Certificate Application is filed with FERC or other permit applications are made. ${ }^{37}$ This phase of project development is referred to as the Pre-Filing Process.

As part of this process, the project sponsor hosts a series of public open houses or informal public informational sessions in the areas potentially affected by the proposal. Representatives from FERC normally participate in these meetings. As part of its environmental review under NEPA, FERC may also hold public scoping meetings in the project area. ${ }^{38}$ Through this solicitation of stakeholder input, the project sponsor can incorporate proposed alternatives and environmental mitigation measures into the project design included in the Certificate Application. If FERC approves pre-filing, it will issue to the developer a pre-filing docket number establishing an official public record associated with the proposed pipeline project. ${ }^{39}$

\section{Certificate Application}

Under the NGA, FERC may only provide a Certificate for a pipeline project if it determines that the applicant is:

"[A]ble and willing properly to do the acts and to perform the service proposed and to conform to the provisions of this chapter and the requirements, rules, and regulations of the Commission thereunder, and that the proposed service, sale, operation, construction, extension, or

\footnotetext{
36 15 U.S.C. $\S 717 \mathrm{f}(\mathrm{c})(1)(\mathrm{A})$.

3718 C.F.R. 157.21 .

38 C.F.R. $157.21(\mathrm{~g})(2)$.

${ }^{39}$ Federal Energy Regulatory Commission, "Guidance: FERC Staff NEPA Pre-Filing Process for Natural Gas Projects," 2004, http://www.fws.gov/habitatconservation/gas_prefiling_FERC_staff_NEPA_guidance_2004.pdf
} 
acquisition, to the extent authorized by the certificate, is or will be required by the present or future public convenience and necessity."

Among other things, the Certificate Application contains a description of the new facilities, need for the project, detailed maps, schedules, and various environmental reports. This information details the various studies and analyses that have been conducted to determine what effect construction and operation could potentially have on the environment and community.

FERC requires applicants for Certificates to include an environmental report analyzing the project's likely environmental impacts. The environmental report includes thirteen resource reports, one of which analyzes the project's estimated air quality impacts. Specifically, the report must include, among other things, a description of "existing air quality, including background levels of nitrogen dioxide and other criteria pollutants which may be emitted above EPA-identified significance levels." ${ }^{41}$ In addition, the report must also provide an estimate of the project's likely impact on air quality and, in particular, "the emission rate of nitrogen oxides from existing and proposed facilities." 42 FERC regulations do not require applicants to estimate the project's GHG emissions as part of the environmental report, though there are no statutory requirements preventing FERC from doing so in the future. FERC routinely requests from the applicant additional information on air quality including emissions of criteria pollutants, GHGs, and hazardous air pollutants from construction and operation of the project, as well as air quality impact analyses of compressor stations and liquefied natural gas facilities.

\section{FERC Environmental Reviews}

After the company submits its Certificate Application, FERC must conduct an environmental review under NEPA before issuing a Certificate authorizing a pipeline project. ${ }^{43}$ NEPA requires federal agencies to prepare an EIS for all "major federal actions significantly affecting the quality of the human environment." ${ }^{44}$ FERC's NEPA regulations require preparation of an EIS for major pipeline construction projects including, but not limited to, where those projects use rights-of-way in which there is no existing natural gas pipeline. ${ }^{45}$ For other pipeline projects, FERC prepares an environmental assessment (EA) with a level of detail appropriate for the complexity of the project.

In addition to the direct effects of a project on air quality, the EA or EIS also must examine the cumulative impact of the project on air quality, when added to the air quality impacts of existing and reasonably foreseeable development in the region. ${ }^{46}$ FERC environmental assessments often include a section on climate change with some version of the following language:

${ }^{40} 15$ U.S.C. $\S 717 \mathrm{f}(\mathrm{e})$.

${ }^{41} 18$ C.F.R. $380.12(\mathrm{k})(1)$.

42 C.F.R. $380.12(\mathrm{k})(3)(\mathrm{i})$.

${ }^{43} 42$ U.S.C. $\$ 4321$ et seq.

${ }^{44} 42$ U.S.C. $\S 4332(2)$.

${ }^{45} 18$ C.F.R. $380.6(\mathrm{a})(3)$.

${ }^{46} 40$ C.F.R. 1508.7. 
Currently there is no standard methodology to determine how the Projects' relatively small incremental contribution to GHGs would translate into physical effects on the global environment. However, the emissions would increase the atmospheric concentration of GHGs, in combination with past and future emissions from all other sources, and contribute incrementally to climate change that produces the impacts previously described.

Although we cannot accurately determine the Projects' incremental addition to the impacts of climate change on the environment, we do not expect the relatively minor amount of $\mathrm{CO}_{2}$ eq produced by the Projects to result in significant cumulative impacts related to climate change. ${ }^{47}$

With respect to NEPA reviews, FERC's analyses of the potential climate impacts of proposed natural gas projects have consistently focused on those impacts associated with constructing and operating the project, and have concluded that gas production and consumption activities are not caused by the pipeline transportation. Nevertheless, where production and consumption activities lie within what staff has identified as the region of potential cumulative impacts, FERC has included those facilities in its cumulative impact analysis.

In December, 2014, The White House Council on Environmental Quality (CEQ) issued revised draft guidance on how GHG emissions and climate impacts should be considered in the context of NEPA reviews. The guidance is not yet final (the public comment period was open through February 26, 2015); therefore, time will tell how FERC will ultimately interpret and apply this guidance to methane emissions from natural gas systems. ${ }^{48}$

\section{Ratemaking for Natural Gas Pipeline Transportation Service}

In addition to charging FERC with responsibility for the approval and siting of interstate natural gas pipelines, the NGA also requires that FERC set "just and reasonable" rates for pipeline transportation service, whether through contract or under a FERC-approved tariff. ${ }^{49}$ The Supreme Court has held that the just and reasonable standard does not require any specific methodology or formula for establishing rates; all that matters is whether the "end result" of the ratemaking exercise is "just and reasonable."50

Ratemaking is thus not a precise undertaking; rates are generally expected to fall within a "zone of reasonableness" that balances the interests of ratepayers with investors, allowing the pipeline to access the capital markets and continue as a viable business. ${ }^{51}$

\footnotetext{
${ }^{47}$ FERC, Tioga Area Expansion and Sabinsville to Morrisville Projects Environmental Assessment, Docket No. CP12-19-000 (Nov. 2012). See also FERC East Side Expansion Project Environmental Assessment, Docket No. CP14-17-000 (Aug. 2014); FERC Environmental Assessment Ohio Pipeline Energy Network Project, Texas Eastern Transmission, Docket No. CP14-68-000 (Aug. 2014); Texas Eastern Appalachia to Market 2014 Project, Docket No. CP13-84-000 (Sept. 2013).

${ }^{48} \mathrm{http}$ //www.whitehouse.gov/administration/eop/ceq/initiatives/nepa/ghg-guidance

${ }^{49}$ Natural Gas Act $\$ 4,15$ U.S.C. $\$ 717$ c.

${ }^{50}$ FPC v. Hope Natural Gas Co., 320 U.S. 591, 602 (1944) (“Under the statutory standard of "just and reasonable' it is the result reached not the method employed which is controlling.").

${ }^{51}$ Colorado Interstate Gas Co. v. FPC, 324 U.S. 581, 589 (1945); Permian Basin Area Rate Cases, 390 U.S. 747, 767 (1968).
} 
During the 1980s and 1990s, FERC restructured the natural gas pipeline industry. ${ }^{52}$ Specifically, under Order 636, FERC unbundled the sale and marketing of natural gas from the transportation of natural gas, moving to an open-access model that required pipeline companies to offer transportation service under tariffs or contracts approved by FERC. ${ }^{53}$

Traditionally, FERC has followed a "cost-of-service" approach to setting pipeline rates. Under this approach, which is sometimes known as "rate-of-return regulation," FERC will set rates at a level that provides sufficient revenue to allow the pipeline to recover its reasonable operating costs together with a return on its rate base (the capital invested in the pipeline company's assets) to ensure that creditors and shareholders are fairly compensated for their investment. ${ }^{54}$

Sections 4 and 5 of the NGA provide the framework for establishing pipeline rates for interstate transport of natural gas. In a general Section 4 rate case, the pipeline company submits proposed rates according to rules provided by FERC. ${ }^{55}$ A pipeline company can file a general Section 4 rate case anytime, provided the pipeline company did not previously agree to different terms in a settlement. In practice, however, since FERC eliminated the triennial restatement of rates filing requirement in Order No. 636, there has been a decline in general Section 4 rate case filings. ${ }^{56}$ In evaluating the proposed rates, FERC evaluates the pipeline company's cost of service, sometimes called the revenue requirement, which is the amount of revenue the pipeline company will need in order to cover the fixed and variable costs of providing service. ${ }^{57}$ Pursuant to Section 5 of

\footnotetext{
${ }^{52}$ See Paul W. MacAvoy, The Natural Gas Market: Sixty Years of Regulation and Deregulation 16-17 (2000). Congress had initiated the decade's long effort to de-regulate wellhead sales of natural gas in 1978 with the Natural Gas Policy Act. This effort culminated in the Wellhead Decontrol Act of 1989.

${ }^{53}$ Pipeline Service Obligations and Revisions to Regulations Governing Self-Implementing Transportation; and Regulation of Natural Gas Pipelines After Partial Wellhead Decontrol, Order No. 636, FERC Stats. \& Regs. ๆ 30,939, order on reh'g, Order No. 636-A, FERC Stats. \& Regs. ๆ 30,950, order on reh'g, Order No. 636-B, 61 FERC \61,272 (1992), order on reh'g, 62 FERC \ 61,007 (1993), aff'd in part and remanded in part sub nom. United Distribution Cos. v. FERC, 88 F.3d 1105 (D.C. Cir. 1996), order on remand, Order No. 636-C, 78 FERC $\$$ 61,186 (1997).

${ }^{54}$ See, e.g., North Carolina Utilities Comm'n v. FERC, 42 F.3d 659, 661 (D.C. Cir. 1994).

${ }^{55} 15$ U.S.C. $\$ 717 \mathrm{c}$.

${ }^{56}$ Revisions to Forms, Statements, and Reporting Requirements for Natural Gas Pipelines, Order No. 710 , FERC Stats. \& Regs. ๆ 31,267 (2008). Before Order 636, FERC performed a review of many pipeline companies' rates at least once every 3 years. Order 636 eliminated this regular triennial rate review. After Order 636, FERC conducts reviews when the pipeline companies file for new rates. Furthermore, under Section 5 of the Natural Gas Act, FERC - on its own initiative or upon the complaint of a distribution company, a municipality, or a state authority - can still review a pipeline company's rates at any time to determine whether they are just and reasonable. U.S. GAO Report to Congressional Requesters, Natural Gas: Costs, Benefits and Concerns Related to FERC's Order 636 (Nov. 1993).

${ }^{57}$ In a general Section 4 rate case, FERC reviews all of a pipeline's rates and services, and the pipeline must demonstrate that the new rates it proposes to charge are just and reasonable. In contrast, a limited Section 4 filing occurs when pipelines file to add new services and establish new rates. FERC policy permits pipelines to recover fuel costs in periodic limited Section 4 filings and has also allowed pipelines to use limited Section 4 proceedings to establish a hurricane surcharge to recover costs related to damage resulting from events outside the pipeline's control. See, e.g., Chandeleur Pipe Line Co., 117 FERC 9 61,250 (2006) (allowing Chandeleur to use a limited Section 4 filing to establish surcharge to recover costs related to damage from Hurricane Katrina).
} 
the NGA, FERC may also require prospective changes to rates charged by a pipeline if the pipeline's existing rates are shown to be no longer just and reasonable. FERC can initiate a Section 5 proceeding on its own motion or upon complaint from an interested party. FERC or the complainant has the burden of demonstrating that the currently effective rates of the pipeline are no longer just and reasonable and of establishing just and reasonable rates.

Key components of cost-of-service include 1) the rate base (generally, the capital invested in physical and other durable assets, such as pipelines and compressors); 2) operating and maintenance costs (costs of operating and maintaining the physical pipeline system); 3) the rate of return; 4) administrative and general expenses (salaries, wages, office supplies); 5) depreciation; and 6) taxes. Once determined, the total revenue requirement is then translated into actual rates through the rate design process, which classifies different costs into reservation and usage charges and defines rates for different classes of service. ${ }^{58}$ In general, "prudent" investments in rate base and "prudent" expenditures for operating and maintenance are recoverable under traditional cost-ofservice ratemaking. ${ }^{59}$

FERC has experimented with alternatives to the traditional model of cost-of-service ratemaking for pipelines companies. Specifically, pursuant to a 1996 policy statement on alternative approaches to ratemaking for natural gas pipeline companies, FERC considers proposals to use incentive rates (see Appendix A) on a case-by-case basis. ${ }^{60}$ To date, as discussed in more detail below, only a handful of pipeline companies have proposed and received incentive rates.

\subsubsection{State Regulation of Gathering, Intrastate Transmission, and Distribution Pipeline Transportation Service}

\section{State Siting of Gathering, Intrastate Transmission, and Distribution Pipelines}

Responsibility for siting intrastate pipelines, including intrastate transmission lines, gathering lines, and distribution pipelines, varies significantly among states and often involves multiple federal, state, and local stakeholders. ${ }^{61}$ Unlike the process for siting interstate pipelines, which is led by FERC, in most states there is no single state agency responsible for siting or conducting environmental reviews. ${ }^{62}$ In many instances, companies do not need to acquire pre-authorization from a state agency before

\footnotetext{
${ }^{58}$ Darryl Tietjen, Tariff Development I: The Basic Ratemaking Process (2008).

59 The so-called "prudent investment standard" holds that only those investments prudently made will be eligible for inclusion in rate base and thus recoverable in rates. Likewise, the "prudent expenditure standard" holds that only those operating and maintenance costs that are prudent or reasonable will be eligible for recovery in rates. See Charles F. Philips, Jr. The Regulation of Public Utilities 257, 340-41 (1993).

${ }^{60}$ See Alternatives to Traditional Cost-of-Service Ratemaking for Natural Gas Pipelines; Regulation of Negotiated Transportation Services of Natural Gas Pipelines, 74 FERC \ 61,076, order granting clarification, 74 FERC \ 61,194 (1996).

${ }^{61}$ GAO Report, Pipeline Permitting: Interstate and Intrastate Natural Gas Permitting Processes Include Multiple Steps, and Time Frames Vary (Feb. 2013), http://www.gao.gov/assets/660/652225.pdf. ${ }^{62} I d$.
} 
constructing an intrastate pipeline, although they may need to comply with local zoning requirements and state and federal environmental requirements. ${ }^{63}$

The Government Accountability Office (GAO) surveyed the intrastate pipeline siting process in 11 states in 2013. In the majority of states reviewed (California, Colorado, Delaware, Oklahoma, Pennsylvania, and Texas), no single agency is responsible for siting or conducting environmental reviews. ${ }^{64}$ In North Dakota and New York, the Public Service Commission retains authority over the siting of gas pipelines. In Rhode Island, the Energy Facility Siting Board has authority over siting, whereas in Florida siting is left to the Department of Environmental Protection. ${ }^{65}$

Because most states do not have a lead state siting agency, the decision as to where to locate a pipeline is left up to the company subject to whatever federal, local, or environmental restraints may exist. Local governments may restrict the siting of pipelines pursuant to zoning authorities, or impose conditions on the siting. ${ }^{66}$ In some instances operators must obtain permits from state environmental agencies in order to ensure protection of sensitive lands or resources. Federal agencies may also become involved in those instances where an intrastate pipeline crosses an area subject to federal jurisdiction, such as endangered species habitat.

In addition to obtaining siting permits, where required, operators also must acquire access to land in order to construct pipelines. For the most part, the process of acquiring rightsof-way takes the form of negotiated agreements between the pipeline company and landowner. In some instances, companies may resort to eminent domain proceedings where negotiations fail. Eminent domain procedures vary by state, but ability to condemn land through eminent domain usually involves two issues: whether the project serves a public purpose under state law (and whether private companies can be granted this authority), and if so, determining how landowners will be justly compensated for the property being taken. ${ }^{67}$ In Texas, the legislature has granted the right of eminent domain and the authority to "lay and maintain" pipeline on certain lands and waters to gas corporations. ${ }^{68}$ While eminent domain is generally thought of as a government right, the Texas courts have upheld the legislature's granting of this right to gas corporations under

\footnotetext{
${ }^{63}$ For instance, the City of Fort Worth adopted Ordinance 18449-02-2009, which amended in its entirety the provisions of the City's Code pertaining to gas drilling and oil production. Included in this portion of the City Code are technical and permitting requirements for gas pipelines. The pipelines that are subject to these requirements include — but are not limited to - production lines, gathering lines, and transmission lines, regardless of where they are laid in the city. Under the City's Code, the City's Gas Drilling Review Committee must review proposed pipelines before a construction permit can be issued for the pipeline. Pipeline Safety Trust, The State of Natural Gas Pipelines in Fort Worth (Oct. 2010), http://www.fwlna.org/documents/FWFinal.pdf

${ }^{64}$ GAO Report, Pipeline Permitting, supra note 61 at 23-25.

${ }^{65} I d$. at Table 2, p. 23.

${ }^{66}$ See e.g., Fort Worth Ordinance, supra note 63. See also Boulder County, Colorado Zoning Code Article 4 (subjecting gathering lines and flow lines part of new oil and gas development and located on the same parcel or parcels as the well head, pumping units, tanks and/or treaters to Development Plan Review).

${ }^{67}$ Kevin C. Abbott \& Melissa M. Taylor, Condemnation in the Natural Gas Industry: Who Can Take What, When, and How Much Will It Cost? 32 Energy \& Min. L. Inst. 10 (2011).

${ }^{68}$ See Neblett, Robert B., et al, Issues Commonly Arising in Texas Utility Condemnations, http://images.jw.com/com/publications/789.pdf.
} 
the rationale that transporting gas from places of production to places of sale serves a public purpose. The one exception to this is pipelines transporting "sour" gas, which is high in hydrogen sulfide. The Texas Railroad Commission has retained authority over the siting of sour gas pipelines due to the risks that exposure to this gas poses to human health.

\section{Ratemaking for Natural Gas Systems by States}

The jurisdiction of a state PUC (or its equivalent) applies to certain economic, operational, safety, and other aspects of gathering systems, intrastate pipelines, and distribution pipelines. Intrastate pipelines, which are prevalent in states such as Texas, Louisiana, and Oklahoma, are regulated by the state PUC or its equivalent, most often on a cost-of-service basis. Local distribution systems are also regulated by state PUCs, typically as a monopoly franchise under a cost-of-service approach. State regulations of gathering facilities (e.g., gathering lines and boosting stations) typically address the safety and infrastructure concerns involved in the design, construction, installation, testing and operation of gathering facilities but historically have not entailed rate regulation.

The vast majority of residential and commercial customers in the United States receive service from regulated local distribution companies (LDCs) serving exclusive franchise territories. Large industrial customers and electric utilities typically receive a significant portion of their gas directly from the interstate pipelines, but many of these entities also receive service from LDCs. Rates for gas service provided by LDCs are generally determined under a cost-of-service model similar to that described above and are subject to a "just and reasonable" standard. Cost-of-service rates include charges associated with lost and unaccounted-for gas (LAUF gas), the details of which are discussed in the next section. Costs incurred for infrastructure improvements generally must be considered prudent (e.g., as required by safety or environmental regulations) in order to be passed on to ratepayers.

A significant number of states have been experimenting with revenue decoupling and with various types of incentive rates (see Appendix A). ${ }^{69}$ A number of states have also adopted accelerated pipeline replacement programs for their local distribution systems and have adjusted their ratemaking approaches to accommodate these programs; as of 2013, 38 states had infrastructure cost recovery mechanisms in place. ${ }^{70}$ As discussed in more detail below, each mechanism accommodates the specific circumstances of the LDC and the particular statutory guidance, policies, and precedents of the jurisdiction.

\footnotetext{
${ }^{69}$ Revenue decoupling is a means of breaking the link between (or "decoupling") the amount of natural gas sold by a utility and the revenue the utility collects, to eliminate the utility's incentive to increase profits by increasing sales. This is usually achieved by the utility and the regulator agreeing on a fixed amount of revenue that the utility is entitled to receive, and subsequently allowing the utility to make periodic price adjustments between rate cases in order to achieve the authorized level of revenue. For further information, see Sandy Glatt and Myka Dunkle, Natural Gas Revenue Decoupling Regulation, U.S. Dept. of Energy (2010).

${ }^{70}$ American Gas Association, 2014, “The Declining Trend in Natural Gas Emissions Efforts Underway that will Continue that Trend."

https://www.aga.org/sites/default/files/the_declining_trend_in_natural_gas_emissions_04_17_14_final.pdf.
} 
For example, many PUCs oversee both safety and rate regulation, providing states relatively broad authority to establish cost-recovery mechanisms for infrastructure investment programs, even without new legislative action.

\subsection{Regulatory Treatment of Fuel Usage and LAUF Gas Under Federal and State Regulation of Pipeline Transportation Service}

The federal and state regulatory frameworks governing the rates, terms, and conditions of natural gas pipeline transportation service generally treat natural gas that is used by the pipeline operator as fuel and natural gas that is leaked or vented to the atmosphere through the same basic approach.

Natural gas that is used as fuel by rate-regulated pipeline operators ${ }^{71}$ — primarily for compression, to help move it across the country through pipelines - is a cost of service that is recoverable in rates. Likewise, natural gas "losses" from various components of the natural gas pipeline system (inter- and intrastate pipelines, and local distribution systems) are treated under the broad category of LAUF gas and included as a basic cost of service by pipeline companies and LDCs.

Although the definition of LAUF gas varies across jurisdictions, the definition generally includes gas that is lost or unaccounted for as a result of leaks, routine venting, metering and accounting errors, or theft. ${ }^{72}$ In effect, the difference between the gas that is "metered into" the system and the gas that is "metered out" of the system is included in the broad category of LAUF gas. ${ }^{73}$ Measurement and tracking of LAUF gas is challenging ${ }^{74}$ and estimates of the total amount of LAUF gas vary. ${ }^{75}$

Federal and state regulations for pipelines and local distribution systems generally treat fuel usage and LAUF gas as a variable cost to be passed along to ratepayers, with some

\footnotetext{
${ }^{71}$ As noted above, gathering lines are not rate regulated..

${ }^{72}$ Ken Costello, Lost and Unaccounted-for Gas: Practices of State Utility Commissions, Report No. 13-06, NRRI (June 2013).

${ }^{73}$ Given these challenges, there is strong need for a common definition and standard metrics for LAUF gas. Currently, definitions vary, even among utilities within a single jurisdiction. Measurement is uneven and inconsistent. Multiple causes and annual variability also compound the challenge of defining a standard metric for the problem. And, of course, different utilities have vastly different infrastructures in terms of age, material, etc., that contribute to wide variations among utilities in terms of their ability to track and control LAUF gas.

${ }^{74}$ The major factors affecting LAUF gas are: pipe leakage, measurement error (which can include temperature and pressure differences, heat value conversion and meter inaccuracies), accounting error, third party damage, cycle billing (timing mismatch between gas receipts and deliveries), stolen gas and blowdown (released gas into the atmosphere during maintenance, inspections or emergency procedures). Ken Costello, NRRI presentation , Lost-and-Unaccounted-for Gas: State Utility Commission Practices (2013).

${ }^{75}$ Based on information submitted to the EIA, one study estimated the total value of LAUF gas from the distribution segment during the years from 2000 to 2011 to be at least $\$ 20$ billion. America Pays for Gas Leaks, a report prepared for Sen. Edward J. Markey (Aug. 2013). This figure is based on lost and unaccounted for gas reported to EIA, multiplied by the average city gate price, and adjusted for inflation. An EIA official recommended to the authors of the Markey report using the average city gate price because it reflects the price the distribution company paid for the gas from the transmission company.
} 
variation in the method allowed for cost recovery. Under this general approach, pipeline companies have little direct incentive to improve system efficiencies to reduce fuel usage or avoid emissions to reduce LAUF gas. However, pipeline companies operating in competitive markets have an indirect incentive to reduce fuel and LAUF costs (e.g., to attract customers through reduced rates), though cost recovery for investments in system upgrades can be uncertain. Accordingly, both FERC and a handful of state regulatory commissions have experimented with alternative, incentive-based rates in an effort to improve pipeline performance, including reductions in fuel usage and LAUF gas.

\subsubsection{FERC Treatment of Fuel Usage and LAUF Gas}

FERC "has recognized that unaccounted-for gas is a variable cost which by definition cannot be attributed to any particular service or part of an integrated system. ${ }^{, 76}$ LAUF gas is typically viewed as an inevitable aspect of natural gas transportation, leading to straightforward and largely uncontested recovery of these costs by natural gas pipelines under the general framework of rate regulation discussed above. Because LAUF is an aggregated metric that includes natural gas losses, meter error, theft, and other factors, there is typically no way for a company to know which portion of LAUF gas is associated with system losses versus other factors.

Natural gas transmission companies generally require that customers contribute a small percentage of the volumes of natural gas tendered for transportation service to provide fuel for compressors and to make up for LAUF gas (i.e., "fuel retention"). Each pipeline states the percentage of natural gas it retains in its open access tariff. ${ }^{77}$ These percentages have ranged from a fraction of a percent to as high as $13 \% .^{78}$

Since its ANR Pipeline Co. Order of 2005, FERC has given pipelines two options to recover fuel and unaccounted-for gas in their tariffs: ${ }^{79}$

1. The fixed percentage option, which involves establishing a fixed-fuel retention percentage in a general Section 4 rate case ${ }^{80}$ and leaves that percentage

\footnotetext{
${ }^{76}$ Texas Gas Transmission Corp., 106 FERC $\$ 61,211$ (2004), citing Mississippi River Transmission Corp., 104 FERC $\$ 61,068$ (2003).

${ }^{77}$ Fuel Retention Practices of Natural Gas Companies, FERC Stats. \& Regs. ๆ 35,556 (2007); terminated, FERC Stats. \& Regs. 135,560 (2008).

${ }^{78}$ FERC Fuel NOI.

${ }^{79}$ ANR Pipeline Co., 110 FERC $\uparrow 61,069$ (2005), order on reh'g and compliance filing, 111 FERC $\ 61,290$ (2005) (ANR Pipeline).

${ }^{80}$ As noted, pipelines can file a general Section 4 rate case at any time. FERC reviews all of a pipeline's rates and services, and the pipeline must demonstrate that the new rates it proposes to charge are just and reasonable. "Limited" Section 4 filings occur when pipelines file to add new services and establish new rates. FERC policy permits pipelines to recover fuel costs in periodic limited Section 4 rate filings and has also allowed pipelines to use limited Section 4 proceedings to establish a hurricane surcharge to recover costs related to damage resulting from events outside the pipeline's control. See, e.g., Chandeleur Pipe Line Co., 117 FERC 9 61,250 (2006) (allowing Chandeleur to use a limited Section 4 filing to establish surcharge to recover costs related to damage from Hurricane Katrina)..
} 
unchanged until the pipeline files its next Section 4 rate case (or until a Section 5 case $^{81}$ is filed); and

2. The fuel tracker with true-up option, which involves including in its tariff a tracker mechanism that allows the pipeline to periodically adjust its fuel retention percentage outside of a Section 4 rate case and to "true up" any over- or underrecoveries of fuel. ${ }^{82}$

Because FERC did not follow the ANR Order with any formal policy statement or rule on fuel retention, however, it has enforced the "two-option" ANR policy only on a caseby-case basis. Thus, notwithstanding the ANR Order, according to the FERC Fuel Notice of Inquiry (FERC FUEL NOI), a number of pipelines also operate using a third option: fuel trackers without any true-up mechanism. ${ }^{83}$ At the time of the FERC Fuel NOI, there were three different approaches to fuel retention for fuel use and LAUF gas among interstate pipelines:

1. Fixed percentage ( 24 out of 70 pipelines)

2. Tracker without true-up (8 out of 70 pipelines)

3. Tracker with true-up (38 out of 70 pipelines). ${ }^{84}$

The fixed percentage option provides some incentives to reduce LAUF gas in that any such reductions would accrue to the benefit of the pipeline until the next Section 4 rate case. Since the FERC Fuel NOI, some fixed fuel percentage pipelines are converting to tracker and true-up mechanisms. ${ }^{85}$ A potential emission reduction benefit of fuel trackers is that they require pipeline companies to quantify the precise amount of LAUF gas that they can recover through rates. But this approach, when used in combination with true-up mechanisms, also may dilute incentives for pipelines to reduce the amount of LAUF gas, given that the true-up mechanism will always allow the pipeline to get full cost recovery.

\section{Notice of Inquiry}

In 2007, FERC issued its FERC Fuel NOI seeking comments on its policy regarding fuel retention practices (for fuel use and LAUF gas) by natural gas pipeline companies. ${ }^{86}$ In doing so, FERC sought to "provid[e] pipelines [with] a greater incentive to reduce their fuel use and lost gas and [to] minimiz[e] pipeline over-recoveries of these costs," and

\footnotetext{
${ }^{81}$ Pursuant to Section 5 of the NGA, FERC may also require prospective changes to rates charged by a pipeline if the existing rates are shown to no longer be just and reasonable. FERC can initiate a Section 5 proceeding on its own motion, or upon complaint from an interested party. FERC or the complainant has the burden of demonstrating that the currently effective rates of the pipeline are no longer just and reasonable, and of establishing just and reasonable rates. See Natural Gas Act, Section 515 U.S.C. §717d. ${ }^{82}$ FERC Fuel NOI, FERC Stats. \& Regs. $\uparrow 35,560$ at $\mathrm{P} 3$.

${ }^{83}$ See FERC Fuel NOI, at P 9 (indicating that eight pipelines continued to operate with such a mechanism). ${ }^{84} \mathrm{Id}$.

${ }^{85}$ See, e.g., Ozark Gas Transmission, L.L.C., 136 FERC 91 61,079, at PP 4 and 6 (2011); and Tennessee Natural Gas Pipeline Co., LLC, 137 FERC 9 61,182, at P 12 (2011).

${ }^{86}$ Fuel Retention Practices of Natural Gas Companies , FERC Stats. \& Regs. ๆ 35,556 (2007); terminated, FERC Stats. \& Regs. $\mid$ 35,560 (2008).
} 
pointed to the wide range of retention percentages for fuel and LAUF gas in pipeline tariffs. $^{87}$

From 2000-2005, a number of pipeline customers, or shippers, began to raise concerns that the gas retained by some pipelines for fuel and LAUF requirements was excessive and was leading to significant over-recovery and excessive profits. At the time, rising gas prices meant that pipeline charges for fuel and LAUF made up a significant percentage of the overall costs of transporting natural gas. (see Appendix A for a more detailed discussion).

The NOI thus sought comment on whether the Commission's current fuel retention policy should be modified, "both for the purpose of providing pipelines a greater incentive to reduce their fuel use and LAUF and for the purpose of minimizing pipeline over-recoveries of these costs." During the comment period, most of the commenting parties noted that including some form of incentive mechanism in a tracker with true-up mechanism could encourage greater efficiency, but the parties generally agreed that the Commission should consider such mechanisms on a case-by-case basis. ${ }^{88}$

At roughly the same time that FERC issued its NOI on fuel retention practices, it also initiated a separate proceeding on information and reporting requirements, which led to a formal rulemaking that culminated in Order $710 .{ }^{89}$ Among the changes were new reporting requirements that required natural gas companies to provide detailed information regarding the acquisition and disposition of fuel use and LAUF gas. As discussed below, FERC cited Order 710's improved reporting and transparency provisions in its decision to terminate the fuel retention NOI.

\section{Termination of Notice of Inquiry}

FERC terminated the Fuel Retention Notice of Inquiry in 2008, stating that it would continue to develop its fuel retention policies on a case-by-case basis. ${ }^{90}$ In terminating the NOI, FERC listed four main legal and practical constraints that prevented it from moving forward with a one-size-fits-all approach to pipeline fuel retention practices. First, FERC found that the fixed percentage provides an incentive for pipelines to invest in efficiency improvements and therefore accords with their general rate-making policy for open access pipelines, which aims to minimize costs and maximize service during the time period between Section 4 rate cases (that is, during the time of "regulatory lag"). Second, FERC did not find a sufficient legal basis for a generic action under Section 5.

Specifically, FERC did not view the concerns about over-recovery as sufficient to find that all fixed percentage rates, including those agreed to in settlements between pipelines and their customers, were unjust and unreasonable. Third, FERC also found that revisions to reporting requirements - under Order 710 — made tracking any over-recoveries easier.

\footnotetext{
${ }^{87}$ Id.

${ }^{88}$ Fuel Retention Practices of Natural Gas Companies, Notice Terminating Proceeding, 125 FERC 961,213 (2008).

${ }^{89}$ Revisions to Forms, Statements, ands Reporting Requirements for Natural Gas Pipelines, Order No. 710 , 73 Fed. Reg. 19,389 (April 10, 2008).

${ }^{90}$ Fuel Retention Practices of Natural Gas Companies, Notice Terminating Proceeding, 125 FERC $₫ 61,213$ (2008).
} 
FERC concluded that with this new information, shippers would be better able to use the Section 5 complaint process to address fuel cost over-recovery by a pipeline. ${ }^{91}$ Finally, FERC acknowledged the need to improve the efficiency of existing pipelines, and the merits of incentive mechanisms in doing so, but agreed with the general sentiment expressed by most of the parties to the proceeding that fuel savings incentive mechanisms should be developed through individual proceedings on a case-by-case basis. ${ }^{92}$ (See Appendix A for a more detailed discussion.)

Given the diversity of physical and market conditions in the interstate natural gas pipeline industry and given its general lack of experience with incentive mechanisms, FERC clearly preferred a more flexible, case-by-case approach to fuel retention based on the feedback it received during the Fuel Retention NOI proceeding. In the six years since it terminated that proceeding, FERC has continued to experiment on a case-by-case basis with fuel-sharing mechanisms and other incentive-based approaches, gaining valuable experience in the process (see Appendix A). As the importance of natural gas in the U.S. economy grows and in the face of the substantial increases in pipeline throughput expected as the shale gas revolution proceeds, FERC is revisiting its approach to costrecovery for infrastructure investments. ${ }^{93}$

\subsubsection{State Regulation of LAUF Gas}

Like FERC, state PUCs or their equivalents generally assume that LAUF gas is a reasonable and unavoidable cost-of-service, with varying approaches to cost recovery. A recent survey by the National Regulatory Research Institute (NRRI) documents the following ratemaking approaches to LAUF gas:

1. Deferral accounts

2. Targeted LAUF-gas percentage in base rates

3. In-kind gas

4. Pass through of costs via a purchased-gas adjustment (PGA) mechanism

\footnotetext{
${ }^{91}$ Notice of Termination at 7. FERC has presided over several Section 5 rate proceedings targeting potential over-recovery by pipeline companies of LAUF gas costs. Section 5 proceedings instituting investigations and setting hearings for over-recovery of LAUF gas include: Viking Gas Transmission Company (Docket No. RP13-185-000) (2012); Natural Gas Pipeline Company of America LLC (Docket No. RP10-147-000) (2009); Kinder Morgan Interstate Gas Transmission LLC (Docket No. RP11-1494000) (2010).

${ }^{92} I d$., at 8 .

${ }^{93}$ On November 20, 2014, FERC issued a Proposed Policy Statement on Cost Recovery Mechanisms for Modernization of Natural Gas Facilities, 149 FERC 161,146 (2014), for comment. In this proposed Policy Statement, FERC "seeks to provide greater certainty concerning the ability of interstate natural gas pipelines to recover the costs of modernizing their facilities and infrastructure to enhance the efficient and safe operation of their systems. The proposed Policy Statement explains the standards the Commission would require interstate natural gas pipelines to satisfy in order to establish simplified mechanisms, such as trackers or surcharges, to recover costs associated with replacing old and inefficient compressors and leakprone pipes and performing other infrastructure improvements and upgrades to enhance the efficient and safe operation of their pipelines." Initial comments on the proposed Policy Statement are due on January 26, 2015, and reply comments are due on February 26, 2015.
} 


\section{Combined base-rate/PGA recovery. ${ }^{94}$}

The NRRI survey notes a recent trend among state commissions of shifting treatment of LAUF gas from base rates to PGA mechanisms. ${ }^{95}$ Commissions normally review LAUF gas as part of their audits of LDCs' gas purchasing practices, either in a rate case review or in PGA reconciliation case, but the issue rarely receives much attention. ${ }^{96}$ As with the use of trackers plus true-up mechanisms under the FERC regulations, the use of PGA mechanisms to recover the costs associated with LAUF gas creates no direct incentive for LDCs to improve performance in a manner that will reduce LAUF gas.

Thirty-eight states have policies that provide cost-recovery for distribution utility investments in pipeline replacement projects. ${ }^{97}$ Some state PUCs have used their traditional ratemaking authority to approve these programs, establishing the terms and conditions under a generally applicable statutory provision. Other state PUCs have specific legislative authority to approve such programs. The terms, conditions, and cost recovery mechanisms of these programs vary by state.

In response to the perennial problem of "regulatory lag" (the time between when costs are incurred and when cost recovery begins), several jurisdictions have also adopted alternative infrastructure cost recovery mechanisms that provide for more timely recovery of pipeline replacement and upgrade costs. These include infrastructure cost trackers, infrastructure base rate surcharges, and deferred regulatory assets: ${ }^{98}$

1. Cost trackers are implemented through tariff riders or adjustments to the base rates set forth in LDC rate schedules. Infrastructure cost trackers incorporate a number of design elements that establish the calculation of recoverable costs, the timing of including accumulated costs in rates, applicable customer classes, method of recovery including whether the costs are recovered through customer charges or delivery charges, and any other applicable recovery provisions. Cost trackers include "true-up" provisions that prevent over- or under-recovery that results from variations in costs or throughput levels from those used to calculate the rate. ${ }^{99}$

2. Infrastructure base rate surcharges involve the calculation of a fixed incremental change to base rates in order to accommodate the recovery of specified infrastructure investments. Infrastructure base rate surcharges are similar in many respects to cost trackers, particularly with respect to the ability to provide more

\footnotetext{
${ }^{94}$ Costello, supra note 72 at 17-18. Similar to purchased gas costs, the base rates of many utilities include historical or projected LAUF-gas costs with any deviations recoverable in a purchased gas agreement.

${ }^{95} \mathrm{Id}$., at 18.

${ }^{96} I d$.

${ }^{97}$ Natural Gas Utilities Take Steps to Further Reduce Emissions, AGA website (June. 2014), http://www.aga.org/Newsroom/news-releases/2014/Pages/Natural-Gas-Utilities-Take-Steps-to-FurtherReduce-Emissions.aspx.

${ }^{98}$ American Gas Foundation, Gas Distribution Infrastructure: Pipeline Replacement and Upgrades (July 2012).

${ }^{99} \mathrm{Id}$.
} 
timely cost recovery, but are fixed over a longer period, providing greater certainty with respect to rate impacts. ${ }^{100}$

3. Deferred regulatory asset mechanisms defer investment costs associated with eligible infrastructure replacement and improvements. These mechanisms treat these costs as regulatory assets to be amortized and recovered over a future period, typically when new base rates are established in a rate case. No recovery occurs until the new base rates are implemented. ${ }^{101}$

While these approaches have been effective at significantly reducing inventories of cast iron, bare steel, and other leak-prone pipelines within natural gas distribution networks, it is estimated that it will still take several more decades for many utilities to replace all of the leak prone-pipes within their distribution systems. ${ }^{102}$ Moreover, these cast iron mains tend to be located in heavily-populated, urban areas, making pipe replacement more challenging and costly. ${ }^{103}$

Finally, a handful of state PUCs have adopted special regulatory incentive mechanisms for reducing LAUF gas. New York, for example, utilizes a targeted incentive mechanism to address LAUF gas that caps cost recovery within a range of values, outside of which the LDC receives either a penalty or a reward. ${ }^{104}$ In Texas, the Railroad Commission allows LDCs to expense a maximum of five percent of its LAUF gas for distribution systems in a test year and intrastate pipelines to expense three percent for transmission systems in a test year. ${ }^{105}$ And in Pennsylvania, the PUC issued a final rule in April 2013 establishing a uniform definition of LAUF gas and standard metrics for natural gas distribution system losses for Pennsylvania's distribution companies. ${ }^{106}$ The new rule states that LDCs must reduce distribution system losses in accordance with specified percentages. $^{107}$

${ }^{100} \mathrm{Id}$.

${ }^{101} \mathrm{Id}$.

${ }^{102}$ American Gas Foundation, Gas Distribution Infrastructure: Pipeline Replacement and Upgrades (July 2012).

${ }^{103}$ PHMSA website, https://opsweb.phmsa.dot.gov/pipelineforum/reports-and-research/cast-iron-pipeline/.

${ }^{104}$ New York State Department of Public Service, Staff White Paper on Lost and Unaccounted for (LAUF) Gas, http://documents.dps.ny.gov/public/Common/ViewDoc.aspx?DocRefId=\%7B0413ECDDC194-46DE-8B04-AFDB3FBBE404\%7D. Such an approach recognizes "the inherent uncertainty and natural variability in gas measurement" and uses two standard deviations from the target level to set the lower and upper bounds of the range. $I d$.

${ }^{105}$ Railroad Commission of Texas Natural Gas Rate Review Handbook (Oct. 2012), http://www.rrc.state.tx. us/forms/publications/RateHandbook2012.pdf. All lost and unaccounted for gas is presumed "lost" unless a utility can provide evidence in a ratemaking proceeding that the unaccounted for gas represented company uses, liquids extraction or meter errors. The Commission may allow greater than five percent lost gas if special circumstances can be shown by the utility. 16 TEX. ADMIN. CODE $\$ 7.5525$ (2002).

${ }^{106} 52$ PA. CODE $§ 59.111$. LAUF gas is defined as the difference between total amount of gas supplies delivered to the distribution company and the amount of gas that the distribution company subsequently delivers to its retail, commercial and industrial customers, adjusted for company use, temperature, pressure variations or other allowed variables.

${ }^{107}$ Id. Beginning with the first subsequent Purchased Gas Cost or Gas Cost Rate filing after August 11, 2014, LAUF gas is capped at five percent in the first year and decreases by $0.5 \%$ every year in the subsequent years until it reaches three percent. $I d$. In Pennsylvania, LAUF is handled in Purchased Gas 


\subsection{Section Summary}

FERC's authority to site new interstate transmission pipelines, coupled with its oversight of rates charged by pipeline companies, present opportunities to improve the gas transmission system and reduce methane emissions. Most notably, by allowing pipeline companies to recover their costs associated with improvements in their pipeline infrastructure, FERC can accelerate efforts to further reduce methane emissions from the existing pipeline system.

Other opportunities to address methane emissions through regulation of pipeline transportation service include adjusting existing regulatory frameworks to incentivize reduction of LAUF gas. Under the traditional cost-of-service approach to setting rates for natural gas transportation service, the value of LAUF gas and fuel usage is typically passed through as a cost to ratepayers. This means that pipeline companies operating in competitive markets have some incentive to reduce costs associated with fuel usage and natural gas emissions because these efforts can lead to a reduction in associated charges that are passed on to customers. However, there are few direct incentives under the traditional cost-of-service framework for pipeline operators to reduce leaked gas or fuel usage.

To address this problem, FERC and a handful of state utility commissions have adopted incentive rates in specific cases to encourage better pipeline performance, including infrastructure upgrades and reductions of LAUF gas. Under the just and reasonable standard, however, FERC and the state commissions are somewhat limited in terms of how far they can go in requiring reductions of fuel usage or LAUF gas. Ultimately, the investments made in system efficiency improvements or reducing LAUF gas will need to be judged as reasonable and prudent in terms of their impacts on the rates charged to natural gas consumers. To the extent that the costs associated with such investments outweigh the benefits that accrue to customers (e.g., for improved safety, reliability, or the environment), they are unlikely to be recoverable as prudently incurred costs.

However, infrastructure improvements that address certain externalities and are required under other regulatory frameworks, such as pipeline safety or environmental regulations, would merit treatment as a basic cost-of-service in pipeline service regulation. For more discussion of this issue, see sections 3 and 4 of this paper.

Cost or Gas Cost Rate proceedings relating to gas cost rates. The PGC or GCR mechanisms are not part of base rate cases. 


\section{Pipeline Safety Regulations}

\subsection{Overview}

In addition to the federal and state laws governing rate regulations for natural gas transport, specific federal and state laws address pipeline safety. Methane emissions from leaking pipelines, compressor stations, and poorly maintained or operated equipment pose risks of serious accidents. Historically, most serious incidents (i.e., injuries or fatalities) associated with natural gas pipelines have occurred along distribution pipelines (Figure 3). According to the Pipeline \& Hazardous Materials Safety Administration (PHMSA), the frequency of incidents on distribution pipeline mains made of cast iron is more than four times greater than for mains made of other materials. Also, $38 \%$ of the cast iron main incidents caused a fatality or injury compared to only $20 \%$ of the incidents on other types of mains. ${ }^{108}$ This record is in contrast with gathering lines, which have the fewest reported incidents, no fatalities on record, and only 10 injuries reported since record-keeping began in $1994 .{ }^{109}$

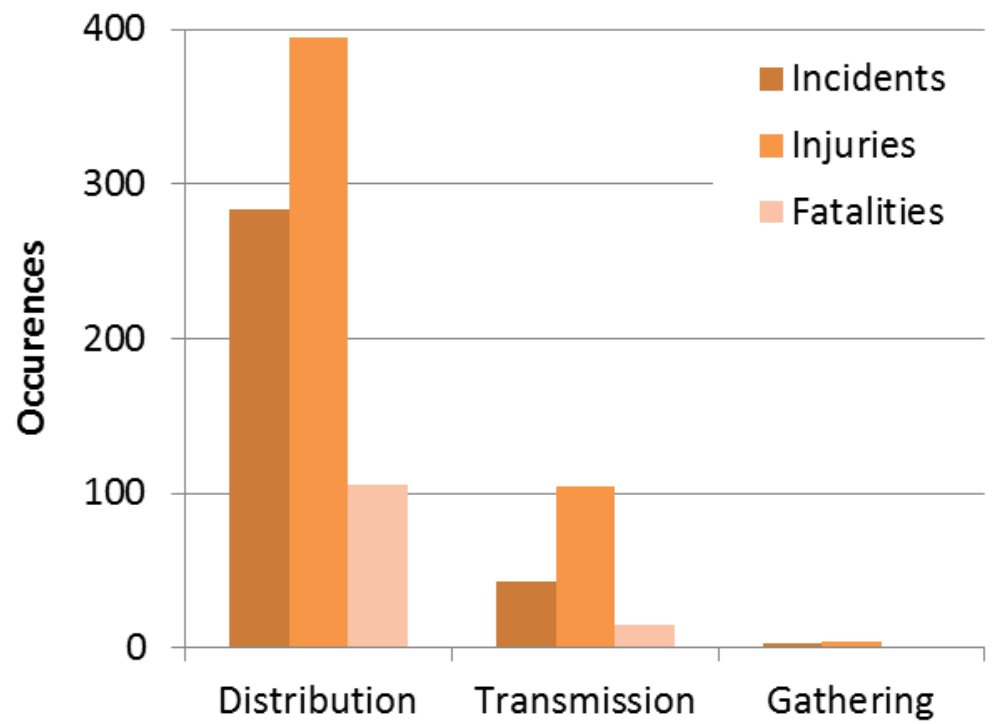

Figure 3. Total Number of reported incidents, fatalities and injuries for U.S. natural gas pipelines, from 2004 through $2013 .^{110}$

\footnotetext{
${ }^{108}$ U.S. Dept. of Transportation website, PHMSA, Cast and Wrought Iron Inventory, http://opsweb.phmsa. dot.gov/pipeline replacement/cast iron inventory.asp.

${ }^{109}$ U.S. Dept. of Transportation website, PHMSA, Pipeline Incidents Reports, http://www.phmsa.dot.gov/p ipeline/library/datastatistics/pipelineincidenttrends. Only a small potion of gathering lines are subject to reporting requirements; however, so the data likely significantly underestimate the number of incidents that have occurred on gathering lines. See Government Accountability Office. "Collecting Data and Sharing Information on Federally Unregulated Gathering Pipelines Could Help Enhance Safety." GAO-12-388. July, 2012.

${ }^{110}$ Pipeline and Hazardous Materials Safety Administration. "Pipeline Serious Incidents 20 Year Trend." https:/hip.phmsa.dot.gov/analyticsSOAP/saw.dll?Portalpages.
} 
A 2010 pipeline explosion in San Bruno, California resulted in heightened public scrutiny regarding the scope and enforcement of our nation's pipeline safety rules, and led to the passage of The Pipeline Safety, Regulatory Certainty, and Job Creation Act of 2011. This Act directed the Department of Transportation to re-examine many of its requirements including the expansion of Integrity Management Plans (IMPs) for transmission lines and to investigate further opportunities for leak reduction. ${ }^{111}$ In addition, in 2011 the National Transportation Safety Board recommended PHMSA require all operators of transmission and distribution natural gas pipelines to equip their pipeline monitoring systems with tools to assist in recognizing and pinpointing the location of leaks. ${ }^{112}$

There is broad recognition that updates to our pipeline safety laws are needed, which creates potential opportunities for enhanced methane mitigation. While not all leaks lead to an explosion, ${ }^{113}$ leaks pose a threat to pipeline integrity, and in some instances can be leading indicators for the possibility of a major accident. ${ }^{114}$ Accordingly, the promulgation of robust leak detection and repair requirements that ensure frequent, reliable detection of leaks from all pipeline segments is a fundamental prerequisite to improving pipeline safety. It is also a common, highly effective practice for reducing the types of non-hazardous leaks that do not pose an immediate safety threat but do contribute to climate change. Despite the fact that the goals of pipeline safety and emissions reduction are complementary, historically the primary focus of the federal pipeline safety laws has been on preventing major pipeline accidents that pose an imminent risk to people and property, not minimizing emissions that contribute to climate change, and the current requirements largely reflect this focus. However, PHMSA has signaled the possibility of extending certain safety regulations that, if finalized, could improve the detection and remediation of non-hazardous methane emissions from a significant number of natural gas pipelines, including older, exempt pipelines and certain gathering lines not currently subject to federal oversight.

\subsection{The Federal Pipeline Safety Laws}

To date, the climate impacts resulting from methane releases due to pipeline leaks has not been a factor PHMSA considers when promulgating natural gas pipeline standards. The

\footnotetext{
${ }^{111}$ Pipeline Safety, Regulatory Certainty and Job Creation Act of 2011, Pub. L. No. 112-90, 125 Stat. 1904 (2012) (requiring PHMSA submit a report to Congress on leak detection systems and requiring PHMSA evaluate whether or not to extend its integrity management requirements for transmission lines to those located outsider high consequence areas).

${ }^{112}$ Nat'l Transportation Safety Board, Pipeline and Hazardous Materials Safety Administration, Recommendation P-11-10 (2011).

${ }^{113}$ See e.g., AGA testimony on Natural Gas Pipeline Safety Act (noting that "most gas leaks do not result in an explosion or fire, because the natural gas is vented into the atmosphere at which point it is nonflammable and non-explosive." Reauthorization of Pipeline Safety Programs: Hearing Before the Subcommittee on Surface Transportation of the Committee on Commerce, Science, and Transportation U.S. Senate, 102nd Cong. 102-266 (1991).

${ }^{114}$ See e.g., statement by Cynthia L. Quarterman, PHMSA Administrator and Sen. Dianne Feinstein, Pipeline Safety: Assessing the San Bruno, California Explosion and Other Recent Accidents, Hearing Before the Subcomm. on Surface Transportation and Merchant Marine Infrastructure, Safety, and Security of the Comm. on Commerce, Science, and Transportation United States S., $111^{\text {th }}$ Congress (2010).
} 
Pipeline Safety Laws ${ }^{115}$ provide the Department of Transportation with broad rulemaking authority to issue minimum safety standards for natural gas and hazardous liquid pipelines and pipeline facilities. ${ }^{116}$ The goal of the pipeline safety laws is to "provide adequate protection against risks to life and property posed by pipeline transportation and pipeline facilities..." ${ }^{117}$ Minimum standards must be practicable and designed to meet the need for pipeline safety and protection of the environment. ${ }^{118}$ In setting standards, PHMSA must consider a number of factors including the reasonableness of the standard, appropriateness for the particular type of facility, relevant available safety and environmental information, and the reasonably identifiable costs and benefits of the requirement, based on a risk assessment. ${ }^{119}$ The guiding principle for pipeline safety regulations is risk management, ${ }^{120}$ and the aim of most requirements is either the prevention or mitigation of pipeline accidents.

The Department of Transportation has delegated to PHMSA the responsibility to ensure the safe transportation and distribution of natural gas. ${ }^{121}$ PHMSA has established minimum safety standards for all pipelines, other than certain gathering lines located in rural areas operating at low pressures (non-regulated gathering lines). PHMSA exercises jurisdiction over all interstate distribution, ${ }^{122}$ transmission pipelines, and "regulated" gathering lines, which operate at specified pressures located in proximity to populated areas. ${ }^{123}$ In 2011, PHMSA found that only 20,150 of the 230,000 miles of gathering lines in the country were subject to its regulations. ${ }^{124}$ In addition, PHMSA exercises jurisdiction over intrastate pipelines where a state has not been delegated enforcement and inspection authority. ${ }^{125}$ PHMSA has delegated enforcement and inspection authority over intrastate and interstate pipelines to all but two states: Hawaii and Alaska. ${ }^{126}$

\footnotetext{
${ }^{115}$ The "Pipeline Safety Laws" refers to a set of statutes which provide the framework for the Federal pipeline safety program. The focus of this paper is on the Natural Gas Pipeline Safety Act of 1968 as amended (NGPSA), and subsequent statutes related to natural gas pipelines, which authorize the Department to regulate pipeline transportation of natural (flammable, toxic, or corrosive) gas and other gases as well as the transportation and storage of liquefied natural gas (LNG). This act, and subsequent statutes related to natural gas and hazardous liquid pipeline safety, have been recodified as 49 U.S.C. Chapter 60101 et seq. In addition, the Pipeline Safety, Regulatory Certainty, and Job Creation Act of 2011 significantly amended existing natural gas and hazardous liquid pipeline safety laws and authorized the appropriation of funds to support the pipeline safety activities of PHMSA through 2015.

${ }^{116} 49$ U.S. Code. $§ 60102$ et seq. Safety standards may apply "to the design, installation, inspection, emergency plans and procedures, testing, construction, extension, operation, replacement and maintenance of pipeline facilities." Id. at $\S 60102$ (a)(2). See also M. Diamond, et al., Pipeline Safety: An Overview of the Legal Framework, the Regulation of Gas Gathering, and How Current and Future Regulation May Affect Producers, 34 Energy \& Min. L. Inst. 5, 163 (2013). Pipeline facilities include gas pipeline and hazardous liquid pipeline facilities as well as rights-of-way, facilities, buildings or equipment used in the transport or treating of gas during transportation. 49 U.S.C. $\S 60101$ (a).

11749 U.S.C. $\$ 60102(a)$.

${ }^{118} I d$. at 49 U.S.C. $\S 60102(\mathrm{~b})$.

${ }^{119} \mathrm{Id}$.

${ }^{120}$ See 74 Fed. Reg., 53,086 (Aug. 25, 2011).

${ }^{121}$ Diamond, et al., supra note 116 at $\$ 5.02$.

${ }^{122}$ The service territories of distribution companies can, in some cases, cross state lines.

12371 Fed. Reg. 13289 (Mar. 15, 2006).

${ }^{124} 76$ Fed. Reg. 53,086, 53,101.

${ }^{125}$ Diamond, et al., supra note 116 at 161.

${ }^{126} \mathrm{Id}$.
} 
Accordingly, PHMSA is responsible for inspecting intra- and interstate pipelines in Hawaii and Alaska and ensuring compliance with its regulations, whereas all other states are the primary enforcers of federal and state pipeline safety requirements for intrastate pipelines.

A notable gap in PHMSA's historical mission authority is the so-called "grandfather clause." This clause allows pre-1970 pipelines to continue to operate at the highest actual operating pressure to which they were subjected in the five years prior to July 1, 1970, exempts them from post-construction hydrostatic pressure testing and certain design requirements applicable to newer pipelines, and allows the use of certain materials manufactured prior to $1970 .{ }^{127}$ The 2011 Act narrows this exemption somewhat, however, by requiring PHMSA to promulgate regulations requiring testing of transmission lines in areas where pipeline releases could have greater consequences, socalled high consequence areas (HCAs), that were not previously tested and that operate above $30 \%$ of their specified minimum yield strength. ${ }^{128}$ Additionally, in a 2011 Advanced Notice of Proposed Rulemaking (ANPRM), PHMSA signaled the possibility of removing these exemptions, although the agency has yet to take any additional action related to this notice. ${ }^{129}$

\subsubsection{Consideration of Environmental Impacts of Methane from Leaking Pipelines}

The Pipeline Safety Laws require PHMSA design safety standards to protect the environment, consider environmental information when setting standards, and consider "the reasonably identifiable or estimated benefits expected to result from implementation or compliance with the standard" and "the reasonably identifiable or estimated costs expected to result from implementation or compliance with the standard."130 These provisions authorize PHMSA to consider environmental factors, such as the amount of methane leaked from pipelines, and the social benefits and costs (including the social cost of carbon) of standards designed to minimize leaks. ${ }^{131}$ Federal agencies, including the Department of Transportation and EPA estimate the social benefits and costs of regulatory actions that have an impact on cumulative global carbon dioxide emissions using the social cost of carbon. ${ }^{132}$

Nevertheless, as noted above, the focus of the natural gas federal pipeline safety laws is on the prevention of those types of leaks ("hazardous" leaks) that pose a risk to human health and property, rather than those that contribute to climate change. PHMSA

12749 C.F.R. § 192.619(a)(3), (c).

${ }^{128}$ The Pipeline Safety, Regulatory Certainty and Job Creation Act of 2011, Pub. L. No. 112-90, 125 Stat. 1904 (2012); See also S. Olenchuk, et al., Potential Impact of New Safety Laws on PHMSA's Regulatory Initiatives, 239 Pipeline \& Gas Journal 4, (April 2012), http://www.pipelineandgasjournal.com/potentialimpact-new-pipeline-safety-laws-phmsa $\% \mathrm{E} 2 \% 80 \% 99$ s-regulatory-initiatives?page $=5$.

${ }^{129} 76$ Fed. Reg. 53,086, at 53,099-53,100 (Aug. 25, 2011).

13049 U.S. Code. $\S 60102(b)(2)(D),(E)$.

${ }^{131}$ Technical Support Document: Technical Update of the Social Cost of Carbon for Regulatory Impact Analysis - Under Executive Order 12866.

http://www.whitehouse.gov/sites/default/files/omb/assets/inforeg/technical-update-social-cost-of-carbonfor-regulator-impact-analysis.pdf

${ }^{132}$ EPA website, http://www.epa.gov/climatechange/EPAactivities/economics/scc.html. 
historically has not considered information relating to the amount of methane leaked from gas pipelines, the climate impacts associated with such non-hazardous leaks, nor the climate benefits that could accrue from reducing such leaks. Rather, PHMSA has primarily limited its consideration of the environmental impacts (such as damage to wetlands) of a pipeline release to rulemakings involving the regulation of hazardous liquid pipelines. Notably, Congress has made clear its concern for the adverse environmental impacts that can result from an accident involving a hazardous liquids pipeline although it has not done so with respect to the climate impacts of methane releases from gas pipelines. ${ }^{133}$ Per the language in the Pipeline Safety Laws directing PHMSA to consider "environmental information" when setting federal pipeline standards and to design safety standards in order to "protect the environment", PHMSA has authority to consider the amount of methane leaked from natural gas pipelines, and the impact such leaks have on the environment, when promulgating safety standards.

\section{Leak Inspection and Repair Requirements}

Requirements that operators deploy reliable technologies capable of detecting leaks of all sizes under various operating conditions, coupled with expeditious mandatory repair timeframes, are critical elements of leak mitigation. ${ }^{134}$ PHMSA requires operators of all pipeline facilities to perform some type of inspection to identify leaking equipment. As currently implemented, these regulations are designed to minimize the risk of pipeline accidents that could cause imminent harm to people and property. Accordingly, the frequency and specificity of monitoring varies significantly depending on pipeline characteristics and location. PHMSA's most robust requirements currently apply to those pipelines located closest to densely populated areas, and to hazardous leaks, although it has signaled the possibility of expanding its pipeline integrity management rules to additional miles of pipeline. ${ }^{135}$ Requiring additional miles of pipelines to be subject to

\footnotetext{
${ }^{133}$ See, e.g. 49 C.F.R. §195.6. Congress historically has not directed PHMSA to consider methane emissions' contribution to climate change when promulgating gas pipeline standards. The legislative history for the 2011 Act reflects concern regarding natural gas leaks in the context of natural gas pipeline explosions including a February 2011 natural gas explosion in Allentown,

Pennsylvania that led to five fatalities and extensive property damage and a 2010 San Bruno, CA explosion, which led to eight fatalities and extensive property damage. The legislative history makes scant reference to climate change or increased atmospheric methane levels that result from natural gas leaks in pipelines. See also Reauthorization of Pipeline Safety Programs: Hearing Before the Subcommittee on Surface Transportation of the Committee on Commerce, Science, and Transportation U.S. Senate, $102^{\text {nd }}$ Cong. 102-266 (1991) and S. Rep. No. 102-152 (1991). (Legislative history for the NGPSA indicates a greater concern with the environmental threats posed by hazardous liquid pipelines such as impacts to wetlands and rivers than natural gas pipelines); See statement of John D. Kobasa, ANR Pipeline Co., representing INGAA, Senate Subcommittee hearing transcript (1991) (testifying that natural gas leaks posed negligible threats as "natural gas is environmentally benign, and being lighter than air, dissipates upon release to the atmosphere.").

${ }^{134}$ See, e.g. EPA and state leak detection and repair requirements discussed in Section XX). To qualify as a "leak detection and repair" program, operators must be required to inspect routinely for leaks and to repair leaks promptly. Programs that do not contain both of these elements are not true "LDAR" programs. PHMSA's current regulations do not qualify as full-fledged LDAR programs as they do not couple rigorous repair requirements with inspections. As such, they are referred to here as "leak inspection and repair" requirements.

${ }^{135} 76$ Fed. Reg. 53,086; 78 Fed. Reg. 46,560.
} 
frequent inspections and scheduled, prompt repairs would assist in reducing methane emissions from pipeline segments.

PHMSA specifies leak repair times in only certain instances. Specifically, operators of all regulated pipelines except Type B gathering lines must repair all "hazardous" leaks promptly and "replace, repair, or remove from service" each segment of pipeline that is unsafe. ${ }^{136}$ Note, however, that PHMSA does not define what constitutes hazardous or unsafe. According to PHMSA, most operators rely on guidelines published by the Gas Piping Technology Committee (GPTC) ${ }^{137}$ in determining how quickly to respond to a detected leak. Pursuant to these guidelines, the risk a leak poses to human health or property is the determinant factor determining how quickly a leak must be repaired. See Table B-1, Appendix B, which details the GPTC guidelines.

In addition, operators of transmission pipelines located in HCAs and Type A gathering lines pipelines must take "prompt" action to address pipeline anomalies that pose a threat to pipeline integrity. ${ }^{138}$ Per this requirement, operators must repair "immediately" certain types of explicitly enumerated anomalies, while others must be repaired within one year of detection. ${ }^{139}$ The schedule prioritizes remedial actions according to the threat that the condition poses to pipeline integrity. As a general rule, those leaks or conditions that are hazardous to human health or property must be repaired immediately, while less hazardous leaks may be repaired on a longer timetable.

One common element to all leak inspection and repair requirements is that operators have considerable discretion in determining how to conduct inspections and how quickly to fix all non-hazardous leaks. For example, visual patrols may be conducted by walking, driving by, or flying over pipelines. ${ }^{140}$ PHMSA requires operators of distribution pipelines and transmission pipelines carrying non-odorized gas to conduct periodic leakage surveys using "leak detector equipment" but nowhere defines what types of leak detection equipment must be used nor provides performance standards such equipment must meet. Transmission, Type A regulated gathering lines, and distribution line operators must conduct periodic leak surveys. The regulations afford operators significant discretion in determining how best to conduct such inspections, including what equipment to use. According to a recent report prepared by Kiefner \& Associates and commissioned by PHMSA (the Kiefner report), ${ }^{141}$ most natural gas pipeline operators

\footnotetext{
13649 C.F.R. $\S 192.703$.

${ }^{137}$ The GPTC is a group made up of representatives from the natural gas industry, National Association of Pipeline Safety Representatives (NAPSR), PHMSA, and the National Transportation Safety Board. Since 1970 , the GPTC has provided guidance to the natural gas industry. The primary purpose of the GPTC is to assist operators in complying with the performance requirements of the Federal pipeline safety regulations through publishing the "Guide for Transmission and Distribution Piping Systems." The Guide includes the current Federal pipeline safety regulations together with recommended practices developed by the members of the GPTC.

${ }^{138} I d$. at $\$ 192.933$.

${ }^{139} \mathrm{Id}$.

${ }^{140} I d$. at $\S 195.412$

${ }^{141}$ The Kiefner report responded to a request from PHMSA for a study of leak detection systems (LDS) for hazardous liquid and natural gas pipelines. The report includes the following: (1) An assessment of past incidents to determine if additional LDS may have helped to reduce the consequences of the incident. (2) A
} 
rely on supervisory control and data acquisition (SCADA) systems to identify leaks. ${ }^{142}$ These systems are designed to monitor pressure and flow and are capable of identifying pipeline ruptures but not as proficient at detecting small leaks. ${ }^{143}$

The Kiefner report highlights the various benefits that implementation of an effective leak detection program can achieve. According to the report, the most important step an operator can take to mitigate accidents and reduce leaks is to prevent them from occurring in the first place. ${ }^{144}$ Accordingly, preventative actions such as providing adequate training for controllers and "strict enforcement of safety and maintenance programs" are the most important actions operators can take to prevent accidents and leaks. ${ }^{145}$ The second most important step is implementing an effective leak detection program. Leak detection programs can help operators identify a leak early in its life and ideally determine its location, which then allows for prompt remedial actions. The report notes the significant advantages to quickly locating and repairing leaks, including increased public confidence and increased value of the pipeline asset. ${ }^{146}$

Despite the clear safety, environmental, and economic benefits that operators can achieve by deploying an effective leak detection and repair program, the Kiefner report found that leak detection standards and requirements for natural gas pipelines lag behind those applicable to liquid pipelines. The report notes that while there are several industryrecommended best practices for leak detection on liquids pipelines, there are none for gas pipelines. ${ }^{147}$ The report similarly notes that liquids pipeline operators are required to install continuous pipeline monitoring, whereas gas pipeline operators are not, and as a result, many gas pipelines are not equipped with continuous leak detection systems. ${ }^{148}$ However, PHMSA has funded several research projects to learn more about leak detection systems for the various pipelines. A table summarizing PHMSA-funded research projects can be found in Table B-6 of Appendix B.

The following sections provide details of the specific leak inspection and repair requirements for gathering, transmission, and distribution lines as well as other pipeline facilities. States are primarily responsible for ensuring operators comply with safety standards through delegation agreements with PHMSA.

review of installed and currently available LDS technologies along with their benefits, drawbacks, and their retrofit applicability to existing pipelines. (3) A study of current LDS being used by the pipeline industry. (4) A cost-benefit analysis of deploying LDS on existing and new pipelines. (5) A study of existing LDS standards to determine what gaps exist and if additional standards are required to cover LDS over a larger range of pipeline categories. Dr. David Shaw, et al., Kiefner \& Associates, Final Report, Leak Detection Study, Introduction (Dec. 10, 2012).

${ }^{142}$ Dr. David Shaw, et al., Kiefner \& Associates, Final Report, Leak Detection Study, 2-4 (Dec. 10, 2012).

${ }^{143} I d$.

${ }^{144}$ Shaw, supra note 142 at 4-4.

${ }^{145} \mathrm{Id}$.

${ }^{146} \mathrm{Id}$. at $4-5$.

${ }^{147}$ Id.

${ }^{148} \mathrm{Id}$. 


\section{Requirements for Distribution Pipelines}

Distribution pipelines are subject to the most comprehensive set of leak inspection requirements of all pipelines and facilities under PHMSA's jurisdiction. All operators of distribution lines must prepare IMPs and use "leak detection equipment" when conducting periodic leakage surveys. The fact that local distribution companies (LDCs) are subject to the most robust set of leak inspection and repair requirements can be understood, in part, by the fact that distribution pipelines are located closest to population centers where the potential impact of an accident on human health and property is the greatest (Figure 3). In addition, because distribution pipelines operate at lower pressure than transmission lines, they tend to leak before they rupture. ${ }^{149}$ The key actions distribution pipeline operators must take to identify and repair leaking pipeline include conducting periodic visual patrols, periodic leak surveys using "leak detector equipment," developing IMPs, ${ }^{150}$ and repairing all hazardous leaks promptly. ${ }^{151}$

IMPs are designed to help operators gain critical information about the state of their pipelines, such as age, material, and leak history that operators can use to form a plan for maintaining pipeline integrity and safety. A key goal of an IMP is to identify and mitigate problems, such as leaks, before they lead to accidents. Specifically, distribution operators must: ${ }^{152}$

1. Periodically, on a schedule determined by the operator, monitor pipeline conditions in order to gain knowledge about their facilities, including data on leak history

2. Identify threats, including leaks; PHMSA specifically notes that "leak repair history and incident reports" ${ }^{\text {"153 }}$ can provide important information to help in identifying threats

3. Analyze risks that result from these threats in order to help identify those parts of the systems most in need of actions to address and mitigate them

4. Evaluate and prioritize risks

5. Identify and implement measures to address risks. According to PHMSA an "effective leak management program is the major component of mitigating risk" 154

6. Continuously re-evaluate pipelines

7. Report the number of Class 1 hazardous leaks either eliminated or repaired (or total number of leaks if all leaks are repaired when found). ${ }^{155}$

\footnotetext{
${ }^{149}$ PHMSA Office of Pipeline Safety, presentation on Distribution Integrity Management (July 2010). http://www.phmsa.dot.gov/staticfiles/PHMSA/flash/chapter1.html.

15049 C.F.R. $\S 192.721, \S 192.723$. $\$ 192$ Subpart P. Master meters and small LPGs are exempt. Id. at $\S 192.1003$.

${ }_{151} 49$ C.F.R. $\S 192$.

${ }^{152} I d$. at $\S 192.703$.

${ }^{153}$ PHMSA, Distribution Integrity Management Webcast (July 2010), http://www.phmsa.dot.gov/staticfiles/PHMSA/flash/chapter1.html. 
In addition, operators of distribution systems must conduct patrols and leakage surveys, with increased frequency requirements for those located in business districts. The general frequency of patrolling distribution mains is determined by a subjective assessment of "the severity of the conditions which could cause failure or leakage, and the consequent hazards to public safety." 156 For distribution mains in places or on structures where anticipated physical movement or external loading could cause failure or leakage, PHMSA requires patrols at least four times a year in business districts. ${ }^{157}$ For leakage surveys, distribution mains located in business districts are subject to annual leakage surveys using leak detector equipment. ${ }^{158}$ For the specific patrol and leakage survey requirements, see Table B-2, Appendix B. Operators of distribution systems are required to check and service valves annually and to take prompt remedial action to correct any inoperable valves. ${ }^{159}$

\section{Requirements for Transmission Pipelines}

The leak inspection requirements for transmission lines differ depending on pipeline characteristics and location. The most frequent patrols and leakage surveys (quarterly) are required for those pipelines located closest to populated areas while the least frequent (annual) are required for those located farthest from populated areas ${ }^{160}$ (see Table B-3, Appendix B). Operators of transmission lines carrying odorless gas must utilize leak detection equipment when conducting leak surveys, but this requirement does not apply to lines carrying gas with odor. ${ }^{161}$ As noted above, operators have considerable flexibility in choosing the types of leak detection equipment they utilize as the regulations neither specify precise technologies nor standards that leak detection equipment must meet (e.g., whether the equipment is capable of detecting leaks of a certain size within a certain distance from a pipeline facility). Like LDCs, operators of all transmission lines, regardless of location, are required to promptly repair all hazardous leaks. ${ }^{162}$ Operators of transmission pipelines are required to make permanent repairs to pipelines "as soon as feasible," unless the problem is discovered pursuant to an IMP, in which case a more detailed repair timeline is required. ${ }^{163}$ Operators of transmission lines must also annually inspect valves that might be required in an emergency and take prompt remedial action to correct any inoperable valves. ${ }^{164}$

Operators of transmission pipelines located in HCAs must develop an IMP. ${ }^{165}$ The IMP requirements for transmission lines share many of the same characteristics as those that

\footnotetext{
${ }^{155} \mathrm{Id}$. at $\S 192.1007$.

${ }^{156} I d$. at $\$ 192.721$.

${ }^{157} \mathrm{Id}$.

${ }^{158} I d$. at $\S 192.723$. A leakage survey with leak detector equipment must be conducted outside business districts as frequently as necessary, but at least once every 5 calendar years at intervals not exceeding 63 months. Id.

${ }^{159} I d$. at $\$ 192.747$.

${ }^{160}$ Id. at $\S 192.705$ (patrol requirements); $§ 192.706$ (leak survey requirements).

${ }^{161} I d$. at $\$ 192.706$.

16249 C.F.R. $\S 192$.

16349 C.F.R. $\$ 192.711$.

16449 C.F.R. $\$ 192.745$.

${ }^{165} I d$. at $\S 192.763$. The implementation standards for transmission pipeline IMPs are contained in 49

C.F.R. $\$ 192.907$. This provision directs operators to follow the requirements of the IMP subpart in the
} 
apply to distribution lines. In particular, IMPs for transmission lines must also rely on comprehensive risk analysis to identify additional measures to prevent a pipeline release. Installing a computerized monitoring and LDS is one potential measure operators could consider to comply. ${ }^{166}$ One important difference between IMP requirements for transmission and distribution lines is that transmission IMPs are only required for pipelines located within HCAs, whereas all LDCs must implement IMPs. According to PHMSA, only $6.4 \%$ of the total length of transmission lines is located within HCAs. ${ }^{167}$

Some of the language in transmission line IMPs is vague and vulnerable to variable compliance. For example, the provision regarding actions to respond to integrity issues requires "prompt" action, which is not defined in the regulations. The same provision allows 180 days for an operator to determine if a condition presents a potential threat. "Immediate repair" is required in certain instances, but again, the regulations contain ample subjectivity, directing immediate repair for "an indication or anomaly that in the judgment of the person designated by the operator to evaluate the assessment results requires immediate action." "168 The transmission IMP regulations outline additional measures operators may take to prevent and mitigate risk, but these are vague and subjective. For example, the IMP regulations require operators to install automatic shutoff valves or remote control valves if the operator determines, based on a risk analysis, that such valves would be an efficient means of adding protection to an HCA in the event of a gas release. ${ }^{169}$

PHMSA has recognized the utility of IMPs for preventing and mitigating pipeline leaks and accidents and in 2011 issued an ANPRM considering changes to its IMP requirements. ${ }^{170}$ With this notice, PHMSA signaled the possibility of expanding and strengthening the IMP requirements by extending them to pipelines located outside HCAs, requiring transmission lines to be equipped with remotely or automatically controlled valves, and adding more prescriptive requirements to prevent and mitigate pipeline releases including requiring the use of computerized monitoring and leak detection systems. ${ }^{171}$ Last year, PHMSA signaled its interest in going forward with a proposal to extend and strengthen the IMP requirements. Specifically, PHMSA issued a Notice of Proposed Rulemaking (NPR) wherein it requested comment on a number of issues involving IMP requirements, class locations, and the extension of IMP requirements beyond HCAs. ${ }^{172}$

regulations and also the guidelines contained in the American Society of Mechanical Engineers' (ASME) $\mathrm{B} 31.8 \mathrm{~S}$ where specified. The regulation specifies that an operator may follow an equivalent standard or practice only when the operator demonstrates the alternative provides an equivalent level of safety to the public and property. In the event of a conflict between the IMP subpart and ASME B31.8S, the requirements in the IMP subpart control.

16676 Fed. Reg. 53,086 53089 (Aug. 25, 2011).

${ }^{167}$ Id. at 53,088.

16849 C.F.R. $\S 192.933$.

${ }^{169} \mathrm{Id}$. at $\$ 192.935$.

${ }^{170} 76$ Fed. Reg. 53,086 (Aug. 25, 2011).

${ }^{171} \mathrm{Id}$. at 53,086.

17278 Fed. Reg. 46,560 (Aug. 1, 2013). 


\section{Requirements for Gathering Lines}

Operators of "regulated" gathering lines are subject to the least stringent leak inspection and repair requirements of the three types of pipelines covered by PHMSA. Lines with specified operating parameters located close to densely-populated areas are subject to the same patrol and leak survey requirements as transmission lines (Type A lines). Operators of these Type A gathering lines must repair all hazardous leaks promptly. ${ }^{173}$ Type B lines are those located in more remote areas and operating at lower pressures only need to comply with construction, maintenance, and operational requirements in order to prevent corrosion and excavation damage. ${ }^{174}$ IMPs are not required for gathering lines, regardless of proximity to populated areas. ${ }^{175}$ See Table B-4, Appendix B.

PHMSA has noted, however, that the use and increasing number of higher pressure, larger gathering lines to transport shale gas may necessitate a change to the current requirements for gathering lines. ${ }^{176}$ Importantly, PHMSA's 2011 ANPRM includes a proposal that would increase PHMSA oversight of gathering lines. ${ }^{177}$ As proposed in the 2011 ANPRM, PHMSA is considering subjecting gathering lines to the IMP requirements. PHMSA recognizes "recent developments in the field of gas exploration and production, such as shale gas, indicate that the existing framework for regulating gas gathering lines may no longer be appropriate." ${ }^{178}$ In addition to the idea of extending IMP requirements to gathering lines, PHMSA is also considering establishing a new, risk-based regime of safety requirements for large-diameter, high-pressure gas gathering lines in rural locations, and requiring the submission of annual incident and safety-related conditions for gathering lines. ${ }^{179}$ These additional requirements for gathering lines would aid in addressing methane leakage from a large quantity of previously unregulated pipelines.

\section{Requirements for Other Pipeline Facilities}

PHMSA has also issued limited leak inspection requirements for compressors and pressure-limiting and regulating stations that may reduce the incidence of non-hazardous

\footnotetext{
17349 C.F.R. $\S 192$.

17471 Fed. Reg. 13292 (Mar. 15, 2006).

17571 Fed. Reg. 13291 (Mar. 15, 2006).

${ }^{176}$ PHMSA, Gathering Pipelines: Frequently Asked Questions, http://phmsa.dot.gov/portal/site/PHMSA/m enuitem.6f23687cf7b00b0f22e4c6962d9c8789/?vgnextoid=4351fd1a874c6310VgnVCM1000001ecb7898 RCRD\&vgnextchannel=f7280665b91ac010VgnVCM1000008049a8c0RCRD\&vgnextfmt=print.

17776 Fed. Reg. 53,086, 53,100 (Aug. 25, 2011); See also, U.S. Government Accountability Office, Oil and Gas Transportation: Department of Transportation Is Taking Actions to Address Rail Safety, but Additional Actions Are Needed to Improve Pipeline Safety (Aug. 2014).

17876 Fed. Reg. 53,086, 53,100.

17976 Fed. Reg. 53,086, 53,101.
} 
methane leaks. ${ }^{180}$ Compressors are used to help transport gas over long distances to endusers. Compressors are normally located every 40 to 100 miles, depending on terrain features. ${ }^{181}$ Potential sources of emissions at compressor stations include various equipment leaks and venting during maintenance and routine operation. ${ }^{182}$

Per PHMSA requirements, operators must replace or repair defective or inadequate compressor equipment ${ }^{183}$ and monitor for gas leaks likely to cause explosions. ${ }^{184} \mathrm{At}$ pressure-limiting and regulating stations, PHMSA requires operators to conduct annual inspections to determine if equipment, including pressure relief devices ${ }^{185}$ and valves, ${ }^{186}$ are in good mechanical condition and adequate from the standpoint of capacity and reliability of the operation. ${ }^{187}$ PHMSA also requires distribution systems to be equipped with telemetering or recording pressure gauges to monitor gas pressure. ${ }^{188}$ PHMSA does not require the operators of compressor stations and pressure-limiting and regulating stations to take any specific action to remediate equipment leaks, as opposed to equipment venting at compressors, however.

\subsection{State Regulation of Pipeline Safety}

The Pipeline Safety Statutes permit states to regulate, inspect, and enforce pipeline safety requirements for intrastate pipelines pursuant to a certification program. Through this delegation, states have primary inspection and enforcement authority over gathering, intrastate transmission and distribution pipelines. ${ }^{189}$ Concerns over some aspects of this delegation of power have recently surfaced, however. An audit report from the Inspector General of PHMSA found the state delegation program lacking, both in terms of policies and procedures for managing the state pipeline safety programs and oversight of the state

\footnotetext{
${ }^{180} 49$ C.F.R. 192, Subpart D, Subpart M. "Pressure limiting station" and "pressure regulating station" are not defined in Part 192. However, they are defined in the widely accepted Industry document, the ANSI B31.8 Code. See PHMSA Interpretation \#PI-88-002 (1988).

From ASME B31.8, 2003 edition:

803.323 Pressure regulating station consists of equipment installed for automatically reducing and regulating the pressure in the downstream pipeline or main to which it is connected. Included are piping and auxiliary devices such as valves, control instruments, control lines, the enclosure, and ventilation equipment.

803.324 Pressure limiting station consists of equipment that under abnormal conditions will act to reduce, restrict, or shut off the supply of gas flowing into a system to prevent the gas pressure from exceeding a predetermined value. While normal pressure conditions prevail, the pressure limiting station may exercise some degree of control of the flow of the gas or may remain in the wide open position. Included in the station are piping and auxiliary devices, such as valves, control instruments, control lines, the enclosure, and ventilating equipment, installed in accordance with the pertinent requirements of this Code.

${ }^{181}$ PHMSA website, http://primis.phmsa.dot.gov/comm/FactSheets/FSPumpStations.htm.

${ }^{182} \mathrm{ICF}$, supra note 11 , at 2-4.

18349 C.F.R. $\S 192.731$.

${ }^{184} I d$. at $\S 192.736$ (requiring a fixed gas detection and alarm system at compressor stations, with some exceptions, as detailed in the code section).

${ }^{185} I d$. at $\S 192.744$.

${ }^{186} I d$. at $\S 192.745$.

${ }^{187} \mathrm{Id}$. at $\S 192.739$. Note, instrumented inspections not required.

${ }^{188} \mathrm{Id}$. at $\$ 192.741$.

${ }^{189}$ B. McCown \& D. Theiss, Safeguarding the Energy Pipeline Transportation System \& the Pipes Act of 2006, 3 TEX. J. OIL GAS \& ENERGY L. 22, 43 (2008).
} 
pipeline safety programs. ${ }^{190}$ The report includes recommendations to PHMSA for improving the program.

The Natural Gas Pipeline Safety Act of 1968 (NGPSA) authorizes the imposition of civil and criminal penalties, as well as corrective action by PHMSA that can include suspended or restricted use of the pipeline facility in the event the facility "is or would be hazardous to life, property, or the environment." ${ }^{191}$ Some have noted that the threat of penalties for safety violations may not incentivize compliance with safety regulations as these make up a limited share of the total costs that a pipeline operator could incur in the event of a major pipeline accident. ${ }^{192}$ The threat of a shutdown order from PHMSA may be more likely to influence operator behavior ${ }^{193}$ because it would impose significantly more costs than the penalties authorized under NGPSA. Public perception also influences operator behavior and promotes compliance or over-compliance. ${ }^{19}$

Certified states may also adopt more stringent state standards provided such standards are not inconsistent with federal requirements. ${ }^{195}$ PHMSA provides states with grants to fund up to $80 \%$ of the costs associated with state pipeline safety programs and may also provide grants for programs intended to prevent damage to pipeline facilities. ${ }^{196}$ In 2013 , 46 states, the District of Columbia, and Puerto Rico received over \$46 million in Pipeline Safety Base grants. Between 2008 and 2013, funding for these grants more than doubled. ${ }^{197}$

Grants are based on performance standards - the amount of funding depends on the adequacy of state certification and interstate agency programs. ${ }^{198}$ Specifically, PHMSA considers the following factors:

1. Adequacy of state operating practices

2. Quality of state inspections, investigations, and enforcement/compliance actions

3. Adequacy of state recordkeeping

4. Extent of state safety regulatory jurisdiction over pipeline facilities

5. Qualifications of state inspectors

\footnotetext{
${ }^{190}$ Office of Inspector General Audit Report, PHMSA'S State Pipeline Safety Program Lacks Effective Management and Oversight (May 2014).

${ }^{191} 49$ U.S.C. $\$ 60112(d)(1)$. The NGPSA authorizes administrative civil penalties up to $\$ 200,000$ per violation per day and up to $\$ 2$ million for a related series of violations. PHMSA also may refer claims to the Attorney General who can result in both civil and criminal penalties. It may also order operators to remedy conditions that pose a less imminent pipeline integrity risk to public safety, property or the environment. 49 U.S.C. $\S 60122(1)(a)$.

192 P.W. Parfomak, Keeping America's Pipelines Safe and Secure: Key Issues for Congress, 27 (Mar. 13, 2012).

193 Id.

${ }^{194}$ GAO, supra note 177 , at 24.

19549 U.S.C. $\$ 60104(\mathrm{c})$.

19649 U.S.C. $\$ 60107(\mathrm{a})$.

${ }^{197}$ Office of Inspector General Audit Report, PHMSA'S State Pipeline Safety Program Lacks Effective Management and Oversight (May 2014).

${ }^{198}$ Diamond et al., supra note 116 , at 170 .
} 


\section{Number of state inspection person-days}

7. State adoption of applicable federal pipeline safety standards

8. Any other factor the Administrator deems necessary to measure performance. ${ }^{199}$

To maintain its inspection and enforcement authority, the state must certify compliance with federal requirements annually. ${ }^{200}$

In many respects, most states go beyond federal requirements for pipeline safety. Of the fifty states with certified pipeline safety programs, all but three (Montana, , South Dakota, and Utah) have adopted safety initiatives that are more stringent than federal regulations. ${ }^{201}$ For the most part, these programs focus on more extensive requirements for the use of valves, odorant, damage prevention, and operating pressure. ${ }^{202}$ Only seven states (California, Colorado, Ohio, Oklahoma, Pennsylvania, North Dakota, and Texas) have requirements that go beyond federal standards for gathering lines. Of these, Ohio, Oklahoma, North Dakota, Pennsylvania, and Texas exercise jurisdiction over rural gathering lines not subject to PHMSA's requirements. ${ }^{203}$

Thirty-four states and the District of Columbia have leak inspection standards that go beyond federal requirements. ${ }^{204}$ Kansas, Michigan, New Hampshire, and Washington have some of the most robust leak standards, generally requiring more frequent leak surveys, more prompt repair times, and enhanced reporting requirements. ${ }^{205}$ California recently passed legislation that requires the PUC to develop rules "for the most technologically feasible and cost-effective avoidance, reduction, and repair of leaks and leaking components in PUC-regulated pipeline facilities within a reasonable time after discovery..."206 The law directs the PUC to require LDCs to report how they control leaks, a list of the leaks detected by grade, an estimate of the amount of gas lost due to leaks, and a list of leaks being monitored or repaired. Importantly, the bill requires the PUC adopt rules intended to minimize methane leaks to further the dual goal of safety and GHG reduction consistent with federal pipeline safety laws and California's GHG reduction targets. ${ }^{207}$

19949 C.F.R. § 198.13(c).

${ }^{200} \mathrm{Id}$.

${ }^{201}$ Nat'l Ass'n of Pipeline Safety Reps., Compendium of State Pipeline Safety Requirements \& Initiatives Providing Increased Public Safety Levels compared to Code of Federal Regulations, $2^{\text {nd }}$ Ed. (2013).

${ }^{202} I d$.

${ }^{203} I d$. at 52, 57-58, 67-69, 247, 250, 254-255, 276, 281-282; GAO, Oil and Gas Transportation, Department of Transportation is Taking Actions to Address Rail Safety, but Additional Actions are Needed to Improve Pipeline Safety (August 2014), 23; 59 P.S. § 3218.5.

${ }^{204}$ All but Alabama, Alaska, Hawaii, Idaho, Louisiana, Mississippi, Montana, Nebraska, Nevada, North Dakota, Oklahoma, South Dakota, Utah, Vermont, and West Virginia.

${ }^{205}$ Id. at 115-118, 120-121, 153-154, 156-158, 163, 188, 190, 199-201, 206-207, 302, 304, 308-310, 312.

${ }^{206}$ Anne C. Mulkern, E\&E, CALIFORNIA: Law orders changes to cut methane leaks from pipelines, Sept. 23, 2014. The bill is California Senate Bill No. 1371.

${ }^{207}$ California Senate Bill No. 1371 (noting that the California Global Warming Solutions Act of 2006 requires the State Air Resources Board to adopt regulations to require the reporting and verification of emissions of greenhouse gases and to monitor and enforce compliance with the reporting and verification program, and requires the state board to adopt a statewide GHG emissions limit equivalent to the statewide GHG emissions level in 1990, to be achieved by 2020). 
For the most part, state PUCs (or their equivalents) are the state agencies responsible for implementing pipeline safety programs. ${ }^{208}$ In a few instances, the PUC shares responsibility with other state agencies. For example, the Arkansas Oil and Gas Commission oversees gathering lines that are unaffiliated with a natural gas utility operating within Arkansas; ${ }^{209}$ in Connecticut, the Department of Energy and Environmental Protection is the state's pipeline safety agency; and in Louisiana pipeline safety is managed by the Department of Natural Resources. ${ }^{210}$

\subsection{Pipeline Replacement Programs}

PHMSA requires operators to replace, repair, or remove from service pipelines that are "unsafe." "However, as noted above, there is no definition of unsafe nor is a timeframe specified as to when replacement must occur. ${ }^{212}$ PHMSA has been engaged, however, in an effort to encourage states to accelerate remediation of high-risk gas pipeline infrastructure. ${ }^{213}$ Per this effort PHMSA has engaged with states, pipeline operators and technical experts to identify pipeline risks and expedite repairs of the highest risk pipelines. $^{214}$

Ultimately, as noted above in Section 2, states are primarily responsible for pipeline replacement. ${ }^{215}$ Generally, LDCs have discretion to design their own programs regarding distribution pipeline replacement, subject to approval by state PUCs. As discussed above, these programs can include a variety of mechanisms, such as cost trackers, infrastructure base rate surcharges, or deferred regulatory assets that the companies may use to cover the cost of pipeline replacement. For interstate transmission pipelines, cost-recovery for infrastructure replacement is subject to approval by FERC, in the context of a Section 4 rate case or settlement agreement (e.g., Columbia $\mathrm{Gas}^{216}$ ). However, given the competitive nature of the market - and the desire for pipeline companies to minimize costs to customers - plus the lack of clear guidelines from PHMSA, noted above, securing cost recovery for expensive safety-related investments can be very difficult; this helps to explain why FERC has proposed a new policy ${ }^{217}$ for cost-recovery.

\subsection{Section Summary}

To date, PHMSA has primarily focused on the risk that gas pipeline leaks and ruptures pose to public safety, with limited consideration of the threat that methane leaks pose to the environment. As a result, there are numerous gaps and limitations in PHMSA's pipeline requirements with regard to the goal of reducing methane emissions from

\footnotetext{
${ }^{208}$ Compendium, supra note 201; See also Pipeline Safety Trust website, http://pstrust.org/aboutpipelines1/regulators-regulations/state-pipeline-safety-policy. 
pipelines and associated infrastructure. Notably, PHMSA has indicated the possibility of addressing some of these gaps in recent ANPRMs and NPRs. Removing the exemptions for grandfathered pipelines, increasing the number of pipelines subject to IMP requirements, and extending pipeline safety and inspection requirements to a greater percentage of gathering lines would likely lead to additional methane emission reductions. Nevertheless, under the current regulatory framework, the following gaps or limitations exist:

- The vast majority of rural gathering lines have no reporting requirements and are not inspected at all, while many other miles of pipeline are only inspected once or twice a year.

- Operators have considerable discretion in determining how to conduct leak inspections and when to repair non-hazardous leaking pipelines and equipment.

- To detect leaks, most operators rely on their SCADA systems, which are not designed to detect small leaks. ${ }^{218}$

- There are limited incentives for operators to replace leaky pipe that does not pose an immediate threat to safety. This is particularly true where operators are not able to monetize the value of recovered methane because they must return the value of reduced losses to customers - as is often the case for transmission and distribution pipeline companies. ${ }^{219}$

- Federal and state safety rules mostly apply to pipelines and there are limited safety requirements that apply to other facilities, such as compressor stations or pressure-limiting and regulating stations. Yet, according to EPA Inventory data, ${ }^{220}$ most emissions are from above-ground facilities (i.e., not from the pipelines themselves).

As discussed above, most states have put safety standards into place that go beyond minimum federal requirements promulgated by PHMSA. The recent law passed in California recognizes the environmental importance of reducing pipeline leaks, which should lead to the adoption of stronger pipeline leak detection and repair requirements, as well as voluntary efforts elsewhere. Also, a desire to conserve their product, reduce litigation risk, and/or increase customer confidence may motivate some companies to go beyond regulatory requirements, particularly when rate recovery is assured.

\footnotetext{
218 Shaw, supra note 142, at 7-24.

${ }^{219} \mathrm{ICF}$, supra note 11 , at 2-7.

${ }^{220}$ Environmental Protection Agency. "Greenhouse Gas Inventory, Annex 3." Table A139 And Table A140. http://www.epa.gov/climatechange/Downloads/ghgemissions/US-GHG-Inventory-2014-Annex-3Additional-Source-or-Sink-Categories.pdf
} 


\section{Federal and State Air Pollution Requirements}

Congress and state legislatures have entrusted the protection and enhancement of air quality primarily to EPA and state environmental protection agencies, which act as delegated agents of EPA in most instances. ${ }^{221}$ With respect to emissions from oil and natural gas systems, until recently, federal and state air quality regulations have focused exclusively on controls aimed directly at reducing ozone precursor emissions (volatile organic compounds and oxides of nitrogen) and hazardous air pollutants. That is changing, however. While EPA has yet to regulate methane directly from oil and natural gas operations, the agency spent the better part of 2014 considering such regulation. ${ }^{222}$ In early 2015 , the White House announced ${ }^{223}$ that EPA will soon propose the first-ever federal regulations on methane emissions from "new and modified oil and gas production sources, and natural gas processing and transmission sources." Moreover, a few states have begun or proposed to directly regulate hydrocarbon emissions, including methane, from oil and gas sources, having determined that this can be accomplished both economically and technically. ${ }^{224}$ However, requirements for emissions sources downstream of processing plants - such as compressor stations, pneumatic controllers, and pipeline and equipment leaks — are notably lacking in state clean air measures.

Methane is the primary constituent of natural gas, comprising anywhere from $78 \%$ to $98 \%$ (see Table 1). ${ }^{225}$ Other compounds found in natural gas include natural gas liquids (e.g., pentane, ethane, and propane), volatile organic compounds (VOCs), and hazardous air pollutants (HAPs). The amount of methane and other compounds that occur in vented or leaked gas depends on the composition of the produced gas. Gas composition varies between geologic basins and sectors within the natural gas supply chain. Gas produced from basins that contain little to no crude oil or natural gas liquids, such as coal-bed methane basins, often contains upwards of $90 \%$ methane by mass and thus emit relatively few VOCs when leaked or vented to the atmosphere. Alternatively, basins that produce

\footnotetext{
${ }^{221}$ The purpose of the Clean Air Act is to "protect and enhance the air quality of the Nation's air resources" and to "encourage or otherwise promote reasonable Federal, State, and local governmental actions, consistent with the provisions of this chapter, for pollution prevention." 42 U.S.C. § 7401(b)(1),(c). State legislatures have included similar mandates in state air quality statues (see e.g., Colo. Rev. Stat. § 25-7106; 102. (vesting authority in the Colorado Air Quality Control Commission the powers to devise an air quality control program that achieves the "maximum practical degree of air purity in every portion of the state").

${ }^{222}$ U.S. EPA Office of Air Quality Planning and Standards White Papers:, Oil and Natural Gas Sector Compressors; Oil and Natural Gas Sector Hydraulically Fractured Oil Well Completions and Associated Gas during Ongoing Production; Oil and Natural Gas Sector Leaks; Oil and Natural Gas SectorLiquids Unloading Processes; Oil and Natural Gas Sector Pneumatic Devices (Apr. 2014), http://ww w.epa.gov/airquality/oilandgas/whitepapers.html; Climate Action Plan Strategy to Reduce

Methane Emissions (Mar. 2014), http://www.whitehouse.gov/sites/default/files/strategy to reduce methan e emissions 2014-03-28 final.pdf.

${ }^{223} \mathrm{http} / / / \mathrm{www} . w h i t e h o u s e . g o v /$ the-press-office/2015/01/14/fact-sheet-administration-takes-steps-forwardclimate-action-plan-anno-1.

${ }^{224}$ See e.g. 5 C.C.R. 1001-9, CO Reg. 7, § XVII-XVIII (Feb, 24, 2014). Applicable to oil and gas facilities located between the wellhead and the gas processing plant; Oil \& Natural Gas Regulatory Activities Update, Public Workshop, California Air Resources Board, Sacramento, CA (Aug. 25, 2014).

${ }^{225}$ EPA uses $78 \%$ methane content by mass for the production stage. Pipeline quality gas has closer to $93 \%$ methane by mass. NETL, 2012. Role of Alternative Energy Sources: Natural Gas Technology Assessment. See ICF, supra note 11 at 78 , fn. 40.
} 
crude oil and other natural gas liquids, such as the Bakken shale in North Dakota, produce natural gas that contains a higher ratio of VOCs to methane. ${ }^{226}$ Processed or pipeline-quality gas consists mostly of methane ${ }^{227}$ and thus natural gas emissions from sources that occur downstream of processing, namely in the storage, transmission, and distribution sectors, contain mostly methane.

\begin{tabular}{lll} 
Table 1. U.S. Average Natural Gas Composition on a Mass Basis & \\
\hline Component & Production & $\begin{array}{l}\text { Pipeline- } \\
\text { quality }\end{array}$ \\
\hline $\mathrm{CH}_{4}$ (Methane) & $78.3 \%$ & $92.8 \%$ \\
\hline $\begin{array}{l}\mathrm{NMVOC} \text { (Non-methane } \\
\text { VOCs) }\end{array}$ & $17.8 \%$ & $5.54 \%$ \\
$\mathrm{~N}_{\mathbf{2}}$ (Nitrogen) & $1.77 \%$ & $0.55 \%$ \\
$\mathrm{CO}_{2}$ (Carbon Dioxide) & $1.51 \%$ & $0.47 \%$ \\
$\mathrm{H}_{2} \mathrm{~S}$ (Hydrogen Sulfide) & $0.5 \%$ & $0.01 \%$ \\
$\mathrm{H}_{\mathbf{2}} \mathrm{O}$ (Water) & $0.12 \%$ & $0.01 \%$ \\
\hline
\end{tabular}

\subsection{EPA Requirements}

\subsubsection{New Source Performance Standards}

EPA has promulgated standards to reduce VOC emissions from new and modified oil and gas stationary sources under its Clean Air Act authority in Section 111(b). ${ }^{229}$ Pursuant to these requirements, oil and gas operators must limit emissions of VOCs from certain new and modified equipment and activities located in the production, processing, storage and transmission sectors. Specifically, owners and operators of storage tanks in the production, processing, transmission, and storage sectors must control emissions by $95 \%$ using modern control technology such as flares or vapor recovery units. ${ }^{230}$ Owners and operators of pneumatic controllers in the production and processing sectors must install controllers that vent at less than 6 standard cubic feet (scf)/hour or do not vent at all, respectively. ${ }^{231}$ With the exception of compressors located at well sites, owners and operators of compressors in the production and processing sectors are subject to equipment maintenance and control requirements. ${ }^{232}$ In addition, owners/operators of hydraulically fractured gas wells must control emissions during well completion and recompletion activities by either capturing or combusting emissions. ${ }^{233}$ Leaky equipment, such as connectors, valves, and pumps located at gas processing plants, is subject to a leak detection and repair program that requires monthly, quarterly, or annual inspections,

22677 Fed. Reg. 48,878 (Aug. 15, 2012).

227 See U.S. Dept. of Transportation, Fact Sheet: Natural Gas Processing Plants, http://primis.phmsa.dot.gov/comm/factsheets/fsnaturalgasprocessingplants.htm.

${ }^{228}$ NETL, 2012. Role of Alternative Energy Sources: Natural Gas Technology Assessment.

${ }^{229} 42$ U.S.C. $\S 7411($ b); 40 C.F.R. $\S 60.5360$ et seq.

23040 C.F.R. $\$ 60.5395$.

23140 C.F.R. $\$ 60.5390$.

23240 C.F.R. $\$ 60.5385$.

23340 C.F.R. $\S 60.5375$. 
depending on the component type and leak rate of the component ${ }^{234}$ (see Table B-5, Appendix B).

However, EPA's New Source Performance Standards (NSPS) for the oil and gas sector do not apply to most existing emission sources, most sources located downstream of a gas processing plant (i.e., those in the storage, transmission or distribution sectors), and certain sources in the production sector. Other than storage tanks, the NSPS does not apply to any facilities downstream of processing plants. In addition, EPA's NSPS applies directly to new, modified and reconstructed sources. ${ }^{235}$ New sources are those that commence construction or modification after the date EPA finalizes its standard. ${ }^{236}$ Existing sources may become subject to an NSPS whenever they undergo a modification or reconstruction. ${ }^{237}$ In addition, EPA has the authority to directly regulate existing sources by issuing "emission guidelines." 238 Emission guidelines prescribe standards of performance or design, equipment, work practice, or operational standards, or a combination thereof that are implemented by the states. ${ }^{239}$ EPA may also promulgate Control Technique Guidelines (CTGs) for existing sources, although these have limited applicability only to sources in nonattainment areas. ${ }^{240}$ EPA recently announced ${ }^{241}$ that they will soon issue new CTGs to assist states in reducing ozone-forming pollutants from existing oil and natural gas facilities in ozone nonattainment areas.

A second limitation of the current oil and gas NSPS is that it is pollutant-specific. In its 2012 rulemaking for the oil and gas sector, EPA chose to regulate VOCs as opposed to methane. Because of this, many of the NSPS do not apply to activities or equipment that emit little to no VOCs, including compressors and pneumatics located in the transmission, storage, and distribution sectors, ${ }^{242}$ as these "downstream" sources transport and store pipeline quality gas. EPA declined to regulate sources in these sectors because it determined that doing so was not cost-effective in light of these sources' low VOC emissions. ${ }^{243}$

A final limitation to the current oil and gas NSPS is that it is equipment or sourcespecific. As a result, certain significant sources of emissions are not regulated by the

${ }^{234} 40$ C.F.R. $\$ 60.5400$; see also 40 C.F.R. pt. KKK.

${ }^{235} 42$ U.S.C. $\S 7411(b)(4),(a)(2)$.

${ }^{236} \mathrm{Id}$. at $\S 7411(\mathrm{a})(2)$.

${ }^{237} 42$ U.S.C. $\$ 7411(a)(4),(b)(6)$.

${ }^{238} 42$ U.S.C. $\$ 7411(\mathrm{~d})$;

${ }^{239} \mathrm{Id}$. at $7411(\mathrm{~d}),(\mathrm{h})(1)$.

${ }^{240} \mathrm{See}$ http://www.epa.gov/groundlevelozone/SIPToolkit/ctgs.html.

${ }^{241} \mathrm{http}$ ://www.whitehouse.gov/the-press-office/2015/01/14/fact-sheet-administration-takes-steps-forwardclimate-action-plan-anno-1.

24277 Fed. Reg. 49490, 49498-99 (Aug. 16, 2012); see also EPA Response to Public Comments on Proposed Rule August 23, 2011, 225.

24377 Fed. Reg. 49490, 49498-99 (Aug. 16, 2012); see also EPA Response to Public Comments on Proposed Rule August 23, 2011, 225. The one requirement in the NSPS that does apply on its face to lowVOC emission sources is the reduced emission completion requirement. Certain commenters requested EPA exempt low- or no-VOC wells such as coal-bed methane wells from the reduced emission completion requirement. EPA declined to issue a blanket exemption for such wells. However, it noted that $85 \%$ of such wells would likely qualify as "low-pressure" wells and therefore be excepted through the exception for "low-pressure" wells. EPA Response to Public Comments at 383. 
rule, ${ }^{244}$ including equipment leaks at well sites and compressor stations, completion emissions from oil wells, associated gas co-produced with oil at oil wells, and well liquids unloading activities. Notably, EPA's decision not to regulate these sources turned on fact-specific determinations such as the amount of VOCs emitted from such sources, rather than a determination that the agency lacked authority to issue performance standards for these sources. ${ }^{245}$ Indeed, in its recent white papers, EPA signaled the possibility of controlling some or all of these sources in the future ${ }^{246}$ and most recently announced plans to directly regulate methane emissions from new and modified sources within the oil and natural gas sectors.

\subsubsection{EPA National Emission Standards for Hazardous Air Pollutants}

EPA also requires certain equipment to control HAPs emissions. According to EPA, the majority of air toxics emitted in 2008 are also VOCs, and/or particle pollution. ${ }^{247}$ As with controlling VOCs, some methane emission reduction co-benefits accrue from the reduction of HAP emissions. ${ }^{248}$ EPA HAP requirements apply to both new and existing storage tanks and glycol dehydrators in the production, processing, storage, and transmission sectors and leaky equipment at gas processing plants ${ }^{249}$ (see Table B-5, Appendix B).

\subsubsection{Reporting Requirements for GHG Emissions}

Since 2010, EPA has required certain operators to report their methane and other GHG emissions through their Greenhouse Gas Reporting Program (GHGRP). Specifically, operators with facilities that emit 25,000 metric tons or more of carbon dioxide equivalent per year in the United States must report their GHG emissions to EPA. ${ }^{250}$ EPA's reporting requirements apply to many oil and gas sources involved in the production, gas processing, transmission, storage, and distribution of oil and natural gas. Notable exceptions are gathering and boosting facilities and hydraulically fractured oil well completion emissions, which are not subject to reporting requirements. ${ }^{251}$

The GHG reporting rule is expected to help steadily improve understanding of the amount of methane that is emitted from natural gas infrastructure and activities. In December 2014, EPA proposed to amend the Petroleum and Natural Gas Systems source category (subpart W) of the GHGRP. This proposed rule would add reporting of GHG emissions from gathering and boosting systems, completions and workovers of oil wells using hydraulic fracturing, and blowdowns of natural gas transmission pipelines. ${ }^{252}$

\footnotetext{
24440 C.F.R. $\S 60.5365$.

${ }^{245}$ EPA Response to Public Comments on Proposed Rule August 23, 2011.

${ }^{246}$ EPA White Papers, supra note 222.

${ }^{247} \mathrm{http}: / /$ www.epa.gov/airtrends/aqtrends.html.

248 See 77 Fed. Reg. 49490 (Aug. 16, 2012).

24940 C.F.R. at $\S 60.5430$.

${ }^{250} 40$ C.F.R. $\$ 98.231$.

${ }^{251} 40$ C.F.R. $\$ 98.230$. Hydraulically fractured oil well completion emissions are not subject to reporting requirements unless the emissions are routed to a flare, in which case the emissions would be calculated as part of the flare stacks emission source, or the well testing emissions are vented or flared, in which case the emissions would be calculated as part of the well testing venting and flaring emission source.

25279 Fed. Reg. 73,148 (Dec. 9, 2014).
} 


\subsection{State Requirements}

A handful of states have promulgated state air quality regulations that go beyond the federal requirements described above. Most of these regulations are targeted at reducing VOC emissions as a pathway to achieving lower ambient ozone levels. Recently, however, Colorado adopted a comprehensive set of requirements that directly control methane as well as VOCs from oil and gas production sources. ${ }^{253}$ These rules, the first comprehensive set in the nation to directly regulate hydrocarbon emissions, including methane, from oil and gas sources, demonstrate the technical and economic feasibility of controlling methane and provide a possible framework for adoption by other jurisdictions. Following suit, the California Air Resources Board (CARB) recently announced its intent to develop methane rules for oil and natural gas sources. ${ }^{254}$

The following discussion highlights control requirements adopted by Colorado as well as a handful of other states aimed at reducing natural gas emissions from two of the largest sources of methane emissions from oil and natural gas activities: equipment leaks and pneumatic devices. ${ }^{255}$

\subsubsection{Leak Detection and Repair Requirements for Equipment Leaks}

A handful of states (Colorado, Wyoming, Ohio, Pennsylvania, and California) have promulgated leak detection and repair (LDAR) requirements that limit emissions from well sites and gathering sector compressor stations. Only two states' requirements (Colorado and Pennsylvania) directly regulate methane emissions - the other state programs directly regulate VOC emissions. However, all programs require frequent inspection and timely repair of discovered leaks. In addition, CARB recently announced that it is considering promulgating rules to reduce methane emissions from a suite of stationary oil and gas sources. The announcement notes a possible revision to the current California LDAR requirements for oil and gas facilities in order to require operators detect and repair methane leaks as well as VOC leaks, in addition to other direct methane standards for oil and gas sources. ${ }^{256}$

All five states require that operators utilize instrument-based detection methods that comply with EPA standard leak detection methods, such as infrared cameras or hydrocarbon analyzers. In most cases, the rules require robust recordkeeping and reporting. The following chart describes the scope and the basic requirements of the rules adopted by Colorado, ${ }^{257}$ Wyoming, ${ }^{258}$ Ohio, ${ }^{259}$ Pennsylvania, ${ }^{260}$ and California air districts ${ }^{261}$ for well sites.

\footnotetext{
${ }^{253} 5$ C.C.R. 1001-9, CO Reg. 7, § XVII-XVIII (Feb, 24, 2014). Applicable to oil and gas facilities located between the wellhead and the gas processing plant.

${ }^{254}$ Oil \& Natural Gas Regulatory Activities Update, Public Workshop, California Air Resources Board, Sacramento, CA (Aug. 25, 2014) .

${ }^{255}$ According to a March 2014, ICF report fugitive emissions from leaking equipment and existing highbleed pneumatic controllers are projected to be the largest sources of methane from oil and gas systems across all segments of the supply chain in 2018. See ICF, supra note 11 at 3-7.

${ }^{256}$ CARB Workshop Presentation August 25, 2014.

2575 C.C.R. 1001-9, CO Reg. 7, § XVII-XVIII (Feb, 24, 2014). Applicable to oil and gas facilities located between the wellhead and the gas processing plant.
} 
Table 2. State Leak Detection and Repair Requirements for Production Sources

\begin{tabular}{|c|c|c|c|c|}
\hline State & $\begin{array}{l}\text { Frequency of } \\
\text { instrument based } \\
\text { inspections }\end{array}$ & $\begin{array}{l}\text { Apply to } \\
\text { existing } \\
\text { facilities? }\end{array}$ & $\begin{array}{l}\text { Geographic } \\
\text { scope }\end{array}$ & $\begin{array}{l}\text { Exemption } \\
\text { for low-VOC } \\
\text { components }\end{array}$ \\
\hline Colorado & $\begin{array}{l}\text { Tiers ranging from one } \\
\text { time to monthly } \\
\text { depending on emissions } \\
\text { potential }\end{array}$ & Yes & Statewide & No \\
\hline Wyoming & Quarterly & $\begin{array}{l}\text { No } \\
\text { Proposal to } \\
\text { require quarterly } \\
\text { inspections at } \\
\text { well sites with at } \\
\text { least } 4 \text { Tpy of } \\
\text { fugitive VOCs. }\end{array}$ & $\begin{array}{l}\text { Upper Green } \\
\text { River Basin } \\
\text { Ozone } \\
\text { nonattainment } \\
\text { area }\end{array}$ & No \\
\hline Ohio & $\begin{array}{l}\text { Quarterly. Potential to } \\
\text { reduce to semi-annual } \\
\text { and then annual if less } \\
\text { than } 2 \% \text { of components } \\
\text { leaking after } 5 \\
\text { consecutive inspections }\end{array}$ & No & & No \\
\hline Pennsylvania & Annual & No & Statewide & No \\
\hline California & $\begin{array}{l}\text { Quarterly. Potential to } \\
\text { reduce to annual based } \\
\text { on \% of leaking } \\
\text { components. }\end{array}$ & Yes & County specific & Yes \\
\hline
\end{tabular}

Pennsylvania and Colorado also require periodic inspections of components at compressor stations. Pennsylvania requires quarterly inspections of all compressor

\footnotetext{
${ }^{258}$ Wyoming Department of Environmental Quality, Oil and Gas Production Facilities Permitting Guidance (Sept. 2013), http://deq.state.wy.us/aqd/Oil\%20and\%20Gas/September\%202013\%20FINAL_Oil $\% 20$ and $\% 20$ Gas $\% 20$ Revision_UGRB.pdf.

${ }^{259}$ Model General Permit 12.1 and 12.2 for High Volume Horizontal Hydraulic Fracturing, Oil and Gas Well Site Production Operations (Apr. 4, 2014). Applicable to well sites.

${ }^{260}$ Well site production requirements based on exemption criteria in Exemption 38 for Oil and Gas Exploration, Development, and Production Facilities and Associated Equipment (2013). To qualify for Exemption 38 operators must maintain emissions under specified thresholds (e.g., 2.7 Tpy of VOCs) and institute "above and beyond" control measures including LDAR and tank controls, Pa. Dep't of Envtl. Prot., Air Quality Permit Exemptions, No. 275-2101-003, http://www.elibrary.dep.state.pa.us/dsweb/Get/D ocument-96215/275-2101-003.pdf. Compression and processing requirements based on General Plan Approval and/or General Operating Permit BAQ-GPA-GP-5 (2013), Pa. Dep't of Envtl.

Prot., General Permit for Natural Gas Compression and/or Processing Facilities (GP-5), http://www.elibrar y.dep.state.pa.us/dsweb/Get/Document-94153/2700-FS-DEP4403.pdf.

${ }^{261}$ San Joaquin R. 4409 (2005); South Coast R. 1173 (1989); Santa Barbara Rule 331 (1991); Ventura Rule 74.10 (1989).
} 
stations in the gathering and boosting sector, ${ }^{262}$ while Colorado requires either annual, quarterly, or monthly inspections for gathering sector compressor facilities, depending on the emissions potential. ${ }^{263}$

\subsubsection{Pneumatic Controllers}

Venting from high-bleed pneumatic controllers is another significant source of methane emissions from the oil production and natural gas supply chains. ${ }^{264}$ While EPA requires that new continuous-bleed controllers in the production and processing sectors vent no more than six standard cubic feet of gas per hour or less, ${ }^{265}$ existing pneumatics across the natural gas supply chain, new controllers in the transmission, storage and distribution sectors, and intermittent bleed controllers remain significant emissions sources. Some states have enacted policies to address these gaps.

Specifically, Colorado requires retrofits of existing continuous high-bleed controllers with low-bleed controllers or better in the production and processing sectors. ${ }^{266}$ Utah recently passed a rule requiring retrofits of all high-bleed continuous controllers in the production and processing segments. ${ }^{267}$ Wyoming similarly proposed a requirement that operators in the Upper Green River Basin (UGRB) nonattainment area replace high-bleed pneumatic controllers with low-bleed controllers or better. ${ }^{268}$ If this requirement is finalized, Wyoming will be the third state to require operators to retrofit existing highbleed controllers. Wyoming's current requirements for new controllers and the proposed rules for existing controllers in the UGRB apply to both continuous and intermittent bleed controllers. CARB's recent announcement to develop rules to reduce methane emissions from oil and gas sources also applies to pneumatic devices. ${ }^{269}$

\subsection{Section Summary}

As discussed above, current federal regulatory frameworks for pollution controls address venting and leaking of natural gas from certain equipment and facilities. However, current rules to do not regulate methane directly. Most methane emissions from older equipment, sources downstream of processing plants, and other select sources across all segments, are currently not subject to federal emissions standards. The administration recently announced ${ }^{270}$ that EPA will soon propose the first-ever federal regulations on methane emissions from "new and modified oil and gas production sources, and natural gas processing and transmission sources." States have already begun to address gaps in

\footnotetext{
${ }^{262} \mathrm{~Pa}$. Dep't of Envtl. Prot., General Permit for Natural Gas Compression and/or Processing Facilities (GP5), http://www.elibrary.dep.state.pa.us/dsweb/Get/Document-94153/2700-FS-DEP4403.pdf.

2635 C.C.R. 1001-9, CO Reg. 7, § XVII-XVIII (Feb. 24, 2014).

${ }^{264} \mathrm{ICF}$, supra note 1 at 3-7.

26540 C.F.R. $\$ 60.5390$.

${ }^{266} 5$ COLO. CODE REGS. $§ 1001-9$, XVIII.C.2.

${ }^{267}$ UT Air Quality Board R307-502307-502.

${ }^{268}$ Wyoming Dept. of Env. Quality Air Quality Division Standards and Regs., Nonattainment Area Regs. (June 2014), http://deq.state.wy.us/aqd/proposedrules files/Chapter $\% 208 \% 20$ $\% 20$ Nonattainment $\% 20$ Area $\% 20$ Regulations-Oil $\% 20$ and $\% 20$ Gas $\% 20 \mathrm{draft} \% 206-4-14$.pdf.

${ }^{269}$ CARB Workshop Presentation August 25, 2014.

${ }^{270} \mathrm{http}$ :/www.whitehouse.gov/the-press-office/2015/01/14/fact-sheet-administration-takes-steps-forwardclimate-action-plan-anno-1.
} 
current federal requirements. A small number of states directly regulate, or have proposed to regulate, methane emissions, including requirements for new and existing sources concurrently under the same authorities. However, requirements for downstream emissions sources, such as compressor stations, pneumatic controllers, and pipeline and equipment leaks, are notably lacking in state clean air measures. 


\section{Federal Permitting Requirements}

\subsection{Overview of Bureau of Land Management Requirements}

The BLM has an affirmative duty to minimize waste and prevent natural gas emissions from oil and gas activities that occur on federal lands and tribal lands and rights-of-way. In 2013 , approximately $23 \%$ of crude oil and condensate and $15.9 \%$ of natural gas production occurred on federal and Indian lands, ${ }^{271}$ making emissions from these lands an important source of methane emissions. The BLM's duty to prevent and reduce methane emissions stems from the agency's responsibility to prevent waste and protect the environment from harmful air pollution.

The Mineral Leasing Act (MLA) provides the Department of the Interior (DOI) with authority to administer onshore leases and federal rights-of-way. ${ }^{272}$ The Secretary of the Interior has delegated this authority to the BLM. Pursuant to this grant of authority, the BLM is responsible for permitting the exploration and development of federal oil and gas reserves, supervising the construction and operation of gas wells and pipelines and collecting rents and royalties from companies. ${ }^{273}$ The BLM may attach stipulations to oil and natural gas leases ${ }^{274}$ and impose conditions on rights-of-way for oil and natural gas pipelines. $^{275}$

The MLA places an affirmative obligation on lessees to prevent waste and protect the environment. The MLA requires that all oil and gas leases "shall be subject to the condition that the lessee will, in conducting his explorations and mining operations, use all reasonable precautions to prevent waste..."276 The MLA also requires that DOI "determine reclamation and other actions as required in the interest of conservation of surface resources" when regulating surface-disturbing activities. ${ }^{277}$ Each lease must contain provisions, as the BLM may deem necessary, "for the safeguarding of the public welfare." ${ }^{278}$ Pursuant to these grants of authority, the BLM has authority to promulgate regulations requiring the capture and control of natural gas emissions from oil and gas activities on federal and tribal lands and rights-of-way.

Federal leases and rights-of-way are also governed by the Federal Land Policy and Management Act (FLPMA). Like the MLA, FLPMA requires the BLM to prevent waste and protect air quality. FLPMA requires the BLM take any action necessary to prevent "unnecessary or undue degradation of the lands." 279 The BLM has determined that protection of air quality through compliance with federal and state clean air requirements constitutes prevention of "unnecessary or undue degradation." ${ }^{280}$ FLPMA further requires

${ }^{271}$ EIA, Sales of Fossil Fuels Produced from Federal and Indian Lands, FY 2003 thought FY 2013, Table 1.

27230 U.S.C. $\$ 189$.

${ }^{273}$ Romany Webb \& Steven Weissman, Addressing Climate Change Without Legislation, Vol. 1: DOI, 4 (June 2014).

27443 C.F.R. $\S 3101.1-3 ; 1-2 ;$ See also Id. at 9.

27530 U.S.C. $\$ 185(f)$.

27630 U.S.C. $\$ 225$.

${ }^{277} I d$. at $\S 226(\mathrm{~g})$.

${ }^{278} I d$. at $\S 187$.

27943 U.S.C. $\$ 1732(b)$.

28043 C.F.R. $\S \S 3809.415(a), 3809.420(b)(4)$. 
the public lands be managed in a manner that will protect the quality of...environmental, air and atmospheric...values." 281 Lastly, FLPMA directs the BLM to manage leasing so that "the United States receives fair market value of the use of the public lands and their resources...."282

Thus far, the BLM's actions to limit venting, flaring and leaking on federal and tribal leases and rights-of-way historically have been limited. The agency has thus far relied primarily on its royalty policy contained in Notice to Lessees 4A and on the addition of select emissions control requirements in a limited number of Resource Management Plans. The Notice to Lessees 4A clarifies when royalties are due on "oil or gas lost or wasted," and waives royalties for natural gas that is put to "beneficial use," is "unavoidably lost," or is vented or flared under state rules or with prior authorization from DOI. In so doing, the royalty policy permits a significant amount of wasted gas due to "unavoidable" losses and allowable or authorized venting or flaring.

The BLM recently acknowledged that its current royalty policy, which was last updated in 1980, does not "reflect current best management practices" and suggested potential improvements. ${ }^{283}$ Specifically, the BLM has suggested strengthening policies related to venting and flaring from well completions, production tests, liquids unloading, associated gas from oil wells, storage tanks, pneumatic devices, and leaky equipment. ${ }^{284}$ The President's Climate Action Plan commits the BLM to issuing standards to reduce venting and flaring from oil and natural gas operations on public lands, and a proposed rule is anticipated in the near future. ${ }^{285}$

In addition to rules, notices to lessees and onshore orders, the BLM relies on Resource Management Plans (RMPs) "to establish guidance, objectives, policies and management actions" for specific federal lands. ${ }^{286}$ The BLM field officers must ensure that operations and activities on federal lands conform to RMPs. ${ }^{287}$ Historically, RMPs have not included measures aimed at reducing or preventing emissions from oil and gas sources. However, recently, the BLM has added specific emissions control requirements aimed at minimizing emissions of methane and ozone precursors into RMP amendments or revisions. ${ }^{288}$ Specifically, the Colorado Tres Rios RMP includes measures requiring leak detection and repair for valves and pipes in hydrocarbon liquid service, as well as guidelines for eliminating venting at existing wells. ${ }^{289}$ The New Mexico Farmington

\footnotetext{
28143 U.S.C. $\S 1701(\mathrm{a})(8)$.

${ }^{282} I d$. at $\$ 1701(\mathrm{a})(9)$.

${ }^{283}$ See BLM Public Events on Oil and Gas, Forums on Venting \& Flaring from Oil and Gas Operations and Indian Trust Lands, http://www.blm.gov/wo/st/en/prog/energy/public events on oil.html.

${ }^{284} \mathrm{Id}$.

${ }^{285}$ See BLM Public Events on Oil and Gas, Forums on Venting \& Flaring from Oil and Gas Operations and Indian Trust Lands, http://www.blm.gov/wo/st/en/prog/energy/public events on oil.html.

${ }^{286}$ See e.g., http://www.blm.gov/wy/st/en/programs/Planning/rmps/pinedale.html.

28743 C.F.R. $\S 3161.2$

${ }^{288}$ See Colorado Tres Rios RMP (containing methane emission reduction measures), New Mexico Farmington RMP (containing mandatory measures to reduce ozone precursor emissions) and Colorado White River Field Office Oil Gas Development RMP (authorizing the BLM to impose air quality controls and providing list of available mitigation measures).

289 See http://www.fs.usda.gov/main/sanjuan/landmanagement/planning.
} 
RMP contained mandatory measures to reduce ozone precursor emissions, including best management practices requirements to address compressor emissions. ${ }^{290}$ The Colorado White River Field Office Oil Gas Development RMP authorizes the BLM to impose air quality controls and provides a list of available mitigation measures. ${ }^{291}$

As a federal agency, the BLM must comply with NEPA before issuing a lease or right-of way. ${ }^{292}$ Pursuant to this review, the BLM must consider the environmental impacts of its actions and options for mitigating those impacts. ${ }^{293}$ Emissions associated with oil and gas equipment and activities squarely fall within the purview of a NEPA review for leasing. NEPA is designed to ensure federal agencies assess environmental impacts of federal projects, and GHG emissions - as a form of air pollution - are undoubtedly environmental impacts. ${ }^{294}$ Despite this, the BLM's regulations do not require a comprehensive assessment of the GHG emissions associated with a particular project, nor the climate effects to which such emissions may contribute. Accordingly, most NEPA reviews do not quantify the GHG emissions of a planned project, nor do the reviews attempt to identify the emissions' effects on the climate. ${ }^{295}$ Revisions to the NEPA guidance proposed by the CEQ, discussed above in Section 2.2.1.1, may change the manner in which the BLM conducts NEPA reviews, depending on how finalized.

\subsection{Section Summary}

While the current BLM waste and royalty policies provide limited incentives for operators to minimize methane emissions, the BLM is considering strengthening its requirements. As noted above, the BLM has acknowledged the need to update its outdated royalty policy that was last updated in 1980. The President's Methane Strategy commits the BLM to proposing "updated standards to reduce venting and flaring from oil and gas production on public lands". ${ }^{296}$ It is not clear, however, whether these standards will take the form of a revision to the current royalty policy or a wholly new rule.

In addition to the need to update current requirements, another limitation to the BLM's policies is that they only apply to leases on federal lands and Indian lands and rights-ofway. As noted above, roughly 16\% of natural gas production in 2013 occurred on federal and tribal lands. Thus, any updated standards will apply to only a select number of sources. For comparison, EPA's requirements apply nationally, including on all state, federal, and tribal lands.

\footnotetext{
290 See http://www.blm.gov/nm/st/en/fo/Farmington_Field_Office/ffo_planning/farmington_rmp/rmpa mancos.ht $\frac{\mathrm{ml}}{291}$.

${ }^{291}$ See http://www.blm.gov/co/st/en/BLM Programs/land use planning/rmp/white river.html.

292 See 42 U.S.C. $\$ 4321$ et seq.

${ }^{293} \mathrm{Id}$.

${ }^{294}$ See Massachusetts v. EPA, 549 U.S. 497 (2007) (holding that greenhouse gases are air pollutants under the Clean Air Act); See also High Country Conservation Advocates, et al. v. U.S. Forest Service, et al, U.S. Dist. LEXIS 127306 Sept. 11, 2014), (vacating decisions by Forest Service regarding coal exploration plan based on failure to consider social cost of carbon in NEPA review).

${ }^{295}$ Webb, supra note 273 at 5-7.

${ }^{296}$ President's Climate Action Plan, supra note 5 at 4.
} 


\section{Conclusions}

Historically, most federal and state regulatory agencies have not been charged with taking steps to minimize emissions of carbon dioxide or methane. Yet, there are many cases where existing federal and state agencies involved in regulation of the natural gas industry- including FERC, PHMSA, EPA, BLM, state public utility commissions (PUCs), state environmental and other agencies - have a wide array of existing authorities that could be leveraged to minimize emissions from the natural gas system. Moreover, state and federal air pollution regulators recently have begun to regulate methane emissions directly. For example, EPA has announced plans to propose rules to set standards for methane emissions from certain new and modified oil and gas facilities, including compressor stations. The BLM is expected to update its standards to reduce venting, flaring, and leaks from oil and gas wells. PHMSA is also expected to propose new transmission pipeline safety standards that could expand the number of facilities that need to meet the new requirements.

Economic regulators are also increasingly focused on approaches to reduce emissions. FERC's authority to site new interstate transmission pipelines, coupled with its oversight of rates charged by pipeline companies, present opportunities to improve the gas transmission system and reduce methane emissions. Most notably, by allowing pipeline companies to recover their costs associated with improvements in their pipeline infrastructure, FERC can accelerate efforts to further reduce methane emissions from the existing pipeline system. FERC and a handful of state utility commissions have adopted incentive rates in specific cases to encourage better pipeline performance, including infrastructure upgrades and reductions of LAUF gas. Ultimately, the investments made in system efficiency improvements or reducing LAUF gas will need to be judged as reasonable and prudent in terms of their impacts on the rates charged to natural gas consumers. To the extent that the costs associated with such investments outweigh the benefits that accrue to customers (e.g., for improved safety, reliability, or the environment), they are unlikely to be recoverable as prudently incurred costs. However, infrastructure improvements that address certain externalities and are required under other regulatory frameworks, such as pipeline safety or environmental regulations, would merit treatment as a basic cost-of-service in pipeline service regulation. 


\section{Glossary}

Cost of service: The amount of revenue the company will need in order to cover the fixed and variable costs of providing service; also referred to as the company's "revenue requirement."

Deferral account: Account holding deferred investment costs associated with eligible infrastructure replacement and improvements. These mechanisms treat these costs as regulatory assets to be amortized and recovered over a future period, typically when new base rates are established in a rate case. No recovery occurs until the new base rates are implemented.

Hazardous leaks: Leaks that represent an existing or probable hazard to persons or property and requires immediate repair or continuous action to remediate the hazard.

In-kind gas: Paid or given in gas instead of money.

Interstate pipelines: Pipeline systems that cross one or more states.

Intrastate pipelines: Pipelines that operate only within state boundaries.

Prudent investments or expenditures: The so-called "prudent investment standard" holds that only those investments prudently made will be eligible for inclusion in rate base and thus recoverable in rates. Likewise, the "prudent expenditure standard" holds that only those operating and maintenance costs that are prudent or reasonable will be eligible for recovery in rates.

Purchased Gas Adjustment (PGA): Mechanism used by many utilities wherein base rates include historical or projected LAUF gas costs and any deviations are recoverable pursuant to agreement.

Rate base: The value of property upon which a utility is permitted to earn a specified rate of return as established by a regulatory authority.

Rate of return: The ratio (percentage) of profits (or earnings) compared to capital or assets.

Rate regulation: A government activity in which the government or representatives of the government regulate rates charged to consumers. 


\section{Appendix A: FERC Experiments with Incentive Rates to Reduce Pipelines' Fuel Use and LAUF Gas}

\section{Further Background on 2007 Notice of Inquiry}

The 2007 FERC Fuel NOI was issued in response to concerns raised by some pipeline customers that from 2000-2005, a period of relatively high and rising natural gas prices, the gas retained by some pipelines for fuel and LAUF requirements was excessive and was leading to significant over-recovery (and profits) by the pipelines. ${ }^{297}$ The FERC Fuel NOI cited a study from the Natural Gas Supply Association estimating that 32 pipelines representing $80 \%$ of interstate throughput generated some $\$ 2.1$ billion in excess retained fuel over the five-year period ending in 2005. ${ }^{298}$ FERC's own review of information previously filed with the Commission by pipelines for 2005 indicated that a net of more than 97 Bcf of gas had been retained or carried over in the pipelines' accounts beyond what was consumed as fuel or LAUF, representing over \$711 million in value at average 2005 prices. ${ }^{299}$ Several complaints made under Section 5 during this time also alleged excessive fuel retention. ${ }^{300}$ In the context of rising natural gas prices at the time, pipeline charges for fuel and LAUF made up a significantly greater percentage of the overall costs of transporting natural gas. Accordingly, because of the "increasing significance of pipeline fuel charges in the overall cost of transportation and the concerns about pipeline cost over-recoveries," the Commission concluded that "further investigation of in-kind fuel retention practices [was] warranted."301

The FERC Fuel NOI thus sought comment on whether the Commission's current fuel retention policy (as articulated in the ANR Order) should be modified, "both for the purpose of providing pipelines a greater incentive to reduce their fuel use and LAUF and for the purpose of minimizing pipeline over-recoveries of these costs." 302 In particular, the FERC Fuel NOI posed a number of specific questions regarding different options, including the use of new incentive requirements to improve efficiency. ${ }^{303}$ With respect to such incentive requirements, FERC asked whether a decision to allow pipelines to continue using fixed percentages should be accompanied by an explicit incentive requirement, such as the RPI-X methodology, and whether the Commissions should develop such a requirement on either a standardized or case-by-case basis. ${ }^{304}$

\footnotetext{
${ }^{297}$ Fuel Retention Practices of Natural Gas Companies, FERC Stats. \& Regs. ๆ 35,556 at P 10 (2007); terminated, FERC Stats. \& Regs. ๆ 35,560 (2008). some X-factor deduction to provide incentives for improved efficiency and an implicit sharing of such efficiencies with ratepayers.
} 
During the comment period for the 2007 Notice of Inquiry, 32 parties responded with comments. Shippers and end-users generally argued that FERC should require all pipelines to use a tracker with a true-up in order to prevent over-recovery of costs. The pipelines, however, argued that FERC should retain its current policy and continue to permit pipelines to choose whether a fixed retention percentage established in a Section 4 rate case or a tracker is best suited to their particular circumstances. Most parties stated that including some form of incentive mechanism in a tracker with true-up mechanism could encourage greater efficiency, but the parties generally agreed that the Commission should consider such mechanisms on a case-by-case basis rather than imposing any generic requirements. ${ }^{305}$

At roughly the same time that FERC issued its NOI on fuel retention practices, it also initiated a separate proceeding on information and reporting requirements that addressed (among other things) the adequacy of FERC reporting requirements with respect to LAUF gas. ${ }^{306}$ This proceeding resulted in a formal rulemaking culminating in Order 710, which did provide for new and improved LAUF gas reporting requirements for pipelines. ${ }^{307}$ Several of the parties that submitted comments in response to the fuel retention NOI highlighted the importance of this parallel rulemaking and the need for improved transparency and standardized reporting on LAUF gas regardless of the outcome of the 2007 fuel retention NOI. As discussed below, FERC also cited Order 710 's improved reporting and transparency provisions in its decision to terminate the fuel retention NOI.

\section{More Background on 2008 Termination of Notice of Inquiry}

FERC terminated the Fuel Retention Notice of Inquiry in 2008, stating that it would continue to develop its fuel retention policies on a case-by-case basis. ${ }^{308}$ In terminating the NOI, FERC listed four main reasons:

1. Insufficient legal basis for generic Section 5 action: In the fuel retention NOI proceeding, shippers and end-users urged FERC to require all pipelines to recover their fuel costs through trackers with true-up mechanisms in order to minimize pipeline over-recovery of fuel costs. FERC concluded, however, that it did not have a sufficient basis under NGA Section 5 to require all pipelines currently using fixed-fuel charges to adopt trackers and true-up mechanisms. ${ }^{309}$ Because

\footnotetext{
${ }^{305}$ Fuel Retention Practices of Natural Gas Companies, Notice Terminating Proceeding, FERC Stats. \& Regs. at P 35,560 (2008) [hereinafter FERC Notice of Termination] (summarizing comments). Several pipelines and the major trade association representing interstate pipelines (INGAA) noted in their comments that in competitive markets, pipelines using trackers with true-up mechanisms did have incentives to reduce LAUF and retained gas used as fuel in order to reduce overall costs and maintain competitiveness. See, e.g., Comments of Interstate Natural Gas Association of America, Fuel Retention Practices of Natural Gas Pipelines, Docket No. RM07-20-000 (2007) at 7.

${ }^{306}$ See Assessment of Information Requirements for FERC Financial Forms, Notice of Inquiry, FERC Stats \& Regs 935,554 (Feb. 15, 2007).

${ }^{307}$ Revisions to Forms, Statements, and Reporting Requirements for Natural Gas Pipelines, FERC Stats. \& Regs. \ 31,267 (2008) (Order No. 710), order on reh'g and clarification, 123 FERC $\mid 61,278$ (2008) (Order No. 710-A), remanded, American Gas Ass'n v. FERC, 593 F.3d 14 (D.C. Cir 2010) .

${ }^{308}$ Fuel Notice of Termination, FERC Stats. \& Regs. at P 35,560 (2008).

${ }^{309}$ Id. $\mathrm{P} 8$.
} 
Section 5 imposes the burden of establishing that the challenged rates are unjust and unreasonable, FERC concluded that it would have had to find that all such fixed fuel charges were unjust and unreasonable and that the only just and reasonable method for pipelines to recover fuel costs was through a tracker with a true-up mechanism. ${ }^{310}$ FERC concluded in its Notice of Termination that the pipeline customers in favor of such a generic Section 5 action had failed to establish a sufficient basis for making the requisite finding as applied to all pipelines in the industry using a fixed percentage approach. ${ }^{311}$ Instead, FERC concluded that if a shipper believed that a particular pipeline was over-recovering its fuel costs, it could file a complaint under NGA Section 5, pursuant to the procedures in $\$ 385.206$ of FERC's regulations. ${ }^{312}$ In response to the argument from pipeline customers that remedying pipeline over-recoveries under individual Section 5 actions was too difficult, FERC concluded that "[r]equiring pipelines to recover their fuel costs through a tracker and true-up mechanism based solely on the alleged difficulty of remedying cost overrecoveries under NGA section 5, and without any other independent policy justification, would be contrary to the court's holding that the Commission may not order pipelines to make section 4 filings in order to avoid the 'insufficient protection' afforded by section 5, i.e. to avoid its procedural constraints." 313

2. Fixed percentage approach accords with general rate-making policy: FERC's general rate-making policy for open access pipelines is founded on a presumption (or at least a preference) against true-up mechanisms because such mechanisms are generally viewed as contrary to incentives to minimize costs and maximize service during the time period between general Section 4 rate cases (that is, during the time of "regulatory lag"). ${ }^{314}$ The fixed-percentage approach, in contrast, provides an incentive for pipelines to improve efficiency, so as to minimize the risk of under-recovery of costs by pipelines and maximize the possibility of overrecovery during the period between rate cases. ${ }^{315}$

\section{Improved reporting/transparency enhances individual Section 5 actions:}

FERC also stated that its changes to the financial reporting requirements for natural gas pipelines would assist shippers who wished to file a Section 5 complaint involving fuel cost over-recovery. ${ }^{316}$ In March 2008, the Commission issued Order No. 710 revising the financial forms and reporting requirements for natural gas pipelines in order to enhance the transparency of financial reporting by interstate natural gas pipelines and better reflect the current market and cost

${ }^{310} \mathrm{Id}$.

${ }^{311} \mathrm{Id}$.

${ }^{312}$ Id. P 12. (Section 5 only allows for prospective relief and does not allow for recovery of any past overrecovery.)

${ }^{313}$ Id.P 9 (citing Public Serv. Comm'n of New York v. FERC, 866 F.2d 487, 491 (D.C. Cir. 1989)). Parties opposed to utilizing Section 5 complaints point out these complaints require the complainant to carry the burden of proof, can be extremely expensive, and only offer prospective relief. Notice of Termination, at $\mathrm{n}$. 12 .

${ }^{314}$ Id. at n. 11.

${ }^{315}$ Id. $\mathrm{P} 3$.

${ }^{316}$ Id. PP 10-11. 
information. ${ }^{317}$ Among the changes were new reporting requirements that required natural gas companies to provide detailed information regarding the acquisition and disposition of fuel use and LAUF gas. FERC concluded that with this new information, shippers would be better able to use the Section 5 complaint process to address fuel cost over-recovery by a pipeline. ${ }^{318}$

\section{Incentive approaches should be developed in individual proceedings: FERC} acknowledged the need to improve the efficiency of existing pipelines and the merits of incentive mechanisms in doing so, but agreed with the general sentiment expressed by most of the parties to the proceeding that fuel savings incentive mechanisms should be developed in individual proceedings. ${ }^{319}$ FERC thus decided to take a case-by-case approach to reviewing proposed incentive mechanisms. To that effect, the termination notice noted that FERC had recently ordered a technical conference to consider a three-year experimental fuel incentive mechanism proposed by Texas Gas Transmission LLC, which is discussed below. ${ }^{320}$

In sum, FERC cited a mix of legal and practical constraints that prevented it from moving forward with a one-size-fits-all approach to pipeline fuel retention practices. In FERC's view, there was not a sufficient legal basis for a generic action under Section 5. Specifically, FERC did not view the concerns about over-recovery as sufficient to carry its burden under Section 5 and find that all fixed percentage rates, including those agreed to in settlements between pipelines and their customers, were unjust and unreasonable. At the same time, the revisions to reporting requirements under Order 710 made it easier to track LAUF and any over-recoveries, and therefore provided pipeline customers with better information so as to proceed on an individual basis under Section 5. Finally, FERC's policy interest in pursuing new incentive mechanisms to improve pipeline efficiency (and to reduce LAUF gas) was generally viewed by the parties to the proceeding as best pursued on a case-by-case basis.

\section{Background on Incentive Rates}

Since the early 1990s, FERC has experimented with alternatives to the traditional model of cost-of-service ratemaking for pipelines. ${ }^{321}$ Incentive rates are often used to encourage

\footnotetext{
${ }^{317}$ Revisions to Forms, Statements, and Reporting Requirements for Natural Gas Pipelines, FERC Stats. \& Regs. \ 31,267 (2008) (Order No. 710), order on reh'g and clarification, 123 FERC $\$ 61,278$ (2008) (Order No. 710-A), remanded, American Gas Ass'n v. FERC, 593 F.3d 14 (D.C. Cir 2010) . In Order 710, FERC revised its financial forms, statements, and reports for natural gas companies contained in FERC Form Nos. 2, 2-A and 3-Q. These changes addressed concerns that the Form 2 data was insufficient to support a complaint or FERC action under NGA Section 5.

${ }^{318}$ Notice of Termination at PP 10-11. Since the revisions to Form 2, FERC has initiated several NGA Section 5 actions against natural gas pipelines targeting potential over-recovery by those pipelines of rates and fuel. costs. See, e.g., Natural Gas Pipeline Co. of America, LLC, 129 FERC \ 61,158 (2009), reh'g denied, 130 FERC 91,133 (2010). NGPL reached a settlement with its shippers to resolve the Section 5 proceeding, which provided for reduced transportation rates and reduced fuel retention allowances. Natural Gas Pipeline Co. of America LLC, 132 FERC \ 61,082 (2010).

${ }^{319} I d$. at 8 .

${ }^{320}$ Id. at 8. See also Texas Gas Transmission, LLC, 125 FERC $\uparrow 61,134$ (2008).

${ }^{321}$ Although the concept of incentive or performance-based ratemaking has been around for a long time, FERC did not look seriously at such approaches until the 1990s. FERC first endorsed the idea of incentive
} 
more investments in new equipment, operations and maintenance, to optimize safety, affordability and reliability of the interstate natural gas pipeline network. FERC's current policy on incentive ratemaking for natural gas pipelines is contained in the 1996 Incentive Ratemaking Policy Statement. ${ }^{322}$ The 1996 Policy Statement requires incentive ratemaking proposals to specify performance standards, the mechanism for sharing benefits with customers, and a method for evaluating the proposal. ${ }^{323}$ Incentive rates must also be prospective, voluntary, and understandable to all parties. ${ }^{324}$ The overall goal is to provide better service options at lower rates for consumers while providing regulated companies with the opportunity to earn higher returns. ${ }^{325}$

While a competitive market creates some incentive for pipeline companies to conserve natural gas, the most common tariff structure (i.e., "tracker with true-up") allows pipeline companies to pass through costs associated with natural gas used as fuel or lost through leakage. Incentive mechanisms have the potential to alleviate some of the issues that have historically prevented pipeline companies from making capital investments in their infrastructure and reducing LAUF gas and fuel use.

In terminating the 2007 NOI, FERC determined to proceed on a case-by-case basis. The following summarizes the most important cases in which FERC has considered specific incentive mechanisms regarding fuel use and LAUF gas by pipelines.

\section{Texas Gas Experimental Fuel Savings Sharing Mechanism}

As noted in the Termination Notice of the Fuel Retention NOI, FERC ordered a technical conference in 2008 to explore a proposal by Texas Gas Transmission to use a fuel savings sharing mechanism in its tariff. ${ }^{326}$ In making its proposal, Texas Gas maintained that one of the weaknesses of its then-current fuel tracker was that it had little economic incentive to invest in capital projects for the purpose of reducing fuel use and LAUF gas as long as its rates were competitive, because all such fuel costs were passed directly through to the customers. ${ }^{327}$

Under the proposed fuel savings sharing mechanism, until Texas Gas recovered the capital investments it made to improve efficiency, Texas Gas would receive $80 \%$ of any fuel savings and customers would receive $20 \%{ }^{328}$ Once it had recovered its investment, and until the end of the experimental period, Texas Gas and its customers would share

ratemaking in 1992. See Incentive Ratemaking for Interstate Natural Gas Pipelines, Oil Pipelines, and Electric Utilities, Policy Statement for Incentive Regulation, 61 FERC |61,168 (1992).

${ }^{322}$ See Alternatives to Traditional Cost-of-Service Ratemaking for Natural Gas Pipelines and Regulation of Negotiated Transportation Services of Natural Gas Pipelines; Statement of Policy and Request for Comments, 61 Fed. Reg. 4,633, 4,641-42 (Feb. 7, 1996).

${ }^{323}$ Id.

${ }^{324}$ Id.

${ }^{325} \mathrm{Id}$.

${ }^{326}$ On October 1, 2008, Texas Gas filed tariff sheets to implement an experimental fuel savings sharing mechanism to promote fuel savings and increase long-term fuel efficiency on its system. Texas Gas Transmission, LLC, Tariff Filing with FERC, Docket RP09-7-000 (Oct. 1, 2008) [hereinafter Texas Gas Tariff Filing].

${ }^{327}$ Order on Technical Conference and Contested Settlement, 126 FERC 161,235 (2009).

328 Texas Gas Tariff Filing at 3. 
50-50 in any fuel savings. ${ }^{329}$ After the end of the experimental period, $100 \%$ of the fuel and LAUF savings would be passed on to Texas Gas's customers. ${ }^{330}$ Texas Gas would not be able to include any projects included in the sharing mechanism in any future rate cases. $^{331}$

A number of protests were filed to the Texas Gas proposal raising concerns that the proposed mechanism would not ensure accurate measurement of fuel savings, that the approach would create a disincentive for Texas Gas to file a new Section 4 rate case, and that it violated the field rate doctrine. ${ }^{332}$ FERC staff convened a technical conference on December 2, 2008 to discuss the issues raised by the protests. ${ }^{333}$ After the technical conference, on February 13, 2009, Texas Gas filed an Offer of Settlement to resolve some of the issues raised by the protest. ${ }^{334}$ The following month, FERC rejected the Offer of Settlement, finding that Texas Gas's proposed Settlement and its original incentive savings proposal were unjust and unreasonable. ${ }^{335}$

Specifically, FERC found that the proposed fuel savings sharing mechanism lacked any reasonably accurate standard for measuring the savings attributable to Texas Gas's capital investments. ${ }^{336}$ According to FERC, Texas Gas's proposal was inconsistent with the requirements of FERC's 1996 Incentive Ratemaking Policy Statement that an incentive ratemaking proposal must specify performance standards and define a method for evaluating whether those standards were being met. ${ }^{337}$ FERC also pointed out that other pipeline companies had put forth incentive rate proposals that calculated fuel savings using performance standards and evaluation methods that were more consistent with the 1996 Incentive Ratemaking Policy Statement, based upon the savings generated by the pipeline's investments. ${ }^{338}$

${ }^{329} \mathrm{Id}$.

${ }^{330} \mathrm{Id}$. at 4.

${ }^{331} I d$. at 3

332 Order on Technical Conference and Contested Settlement, 126 FERC 9 61,235, at paras. 19-22 (Mar. 19, 2009) (discussing concerns raised by various parties).

${ }^{333}$ FERC Notice of Technical Conference for Texas Gas Transmission LLC, Docket Nos. RP09-3-000, RP09-7-000, RP09-7-001 (Nov. 13, 2008).

${ }^{334}$ Texas Gas Transmission LLC, Fuel Savings Sharing Mechanism Offer of Settlement, Docket No. RP097-002 (Feb. 13, 2009).

335 Order on Technical Conference and Contested Settlement, 126 FERC \ 61,235 (Mar. 19, 2009).

${ }^{336} I d$.

${ }^{337}$ Id. FERC found that Texas Gas's proposal did not include any reasonable standards for measuring fuel and LAUF savings specifically attributable to Texas Gas's capital improvements, or method for evaluating whether such standards are being met. Therefore, FERC found, it would be impossible to determine with reasonable accuracy if Texas Gas's investments were in fact reducing fuel use and LAUF on its system or whether such reductions were due to factors other than Texas Gas's capital improvements. As a result, FERC found it would be impossible to determine with any reasonable accuracy if Texas Gas's fuel incentive mechanism was fulfilling its stated purpose, promoting fuel savings and increasing fuel efficiency on its system. Because the purpose of a fuel incentive mechanism is to encourage a pipeline to make investments to reduce fuel use, the mechanism should only allow the pipelines to share savings reasonably attributable to those investments.

${ }^{338}$ FERC also noted that "in a contemporaneous order, [it was] approving El Paso Natural Gas Company's fuel savings sharing mechanism, under which projected fuel savings are based upon the design conditions of the capital improvement adjusted for reasonably expected operating conditions." FERC also pointed to 
FERC also objected to Texas Gas's proposal to consider under the incentive mechanism investment projects that were either completed or in-service prior to Texas Gas's October 1, 2008 filing for Commission approval of the program.

Accordingly, FERC rejected the Settlement. However, FERC disagreed with certain opposing parties' contentions that pipelines should only be permitted to implement fuel savings sharing mechanisms in general Section 4 rate cases. FERC stated "We want to encourage pipelines to develop fuel incentive mechanisms that contribute to pipeline fuel efficiency and we believe that requiring pipelines to implement fuel incentive mechanisms only in a general section 4 rate case may discourage Texas Gas, and other pipelines, from proposing such mechanisms.",339

\section{El Paso Natural Gas Co.'s Proposed Fuel Savings Sharing Mechanism}

In 2009, El Paso Natural Gas Company proposed an incentive mechanism whereby customers would share capital project costs and savings that result from efficiency improvements and reduced LAUF gas. ${ }^{340}$ As FERC pointed out in its discussion of El Paso's previous use of a fuel tracker with a true-up mechanism:

Fuel trackers and true-up mechanisms permit pipelines to recover their exact fuel costs and no more. This reduces any incentive for a pipeline to make capital improvements to reduce fuel usage and LAUF, because the pipeline is guaranteed to recover all its fuel costs regardless of how efficiently (or inefficiently) it operates and it cannot retain any of the cost savings resulting from fuel savings projects. El Paso's proposal remedies this issue by creating an incentive mechanism under which El Paso and its customers share the cost savings from various specified types of capital improvements intended to reduce fuel usage and LAUF. ${ }^{34}$

Despite FERC's support for El Paso's incentive mechanism, El Paso did not comply with all elements of FERC's Incentive Ratemaking policy and the plan was not approved. ${ }^{342}$ Specifically, FERC stated that El Paso's proposal lacked any method for evaluating whether the performance standard was being met, which is required under FERC's 1996 Incentive Ratemaking Policy Statement. ${ }^{343}$ El Paso seems to have abandoned the

Colorado Interstate Gas Company's (CIG) mechanism. Under CIG's fuel savings sharing mechanism, CIG shares in fuel consumption savings if CIG "experiences an identifiable reduction in fuel consumption on its system (excluding [LAUF] savings or other changes) that is directly related to a new qualifying capital project placed into service under th[e] mechanism...." Id. at para. 30 .

339 Id.

${ }^{340}$ See El Paso Natural Gas Co., 126 FERC 61,247 (2009). FERC accepted El Paso's proposal subject to certain conditions, despite opponents of the plan, who maintained El Paso should recover the cost of any fuel savings project through the base rates it would establish in general Section 4 rate cases.

${ }^{341} I d$.

${ }^{342}$ El Paso Natural Gas Co., 128 FERC 61,196 (2009).

${ }^{343}$ In its Incentive Ratemaking Policy Statement, the Commission stated that an incentive ratemaking proposal must specify the performance standards it defines and a method for evaluating whether those standards were being met. Incentive Ratemaking Policy Statement, 74 FERC 9 61,076, at 61,237-38 (1996). 
proposed Fuel Savings Sharing Mechanism, as subsequent filings do not indicate acceptance by FERC of any revised proposal.

\section{Colorado Interstate Gas Company's Fuel Savings Sharing Mechanism}

In 2006, Colorado Interstate Gas Co. (CIG) adopted a fuel mechanism that contains a true-up for amounts over or under retained. CIG's Incentive Fuel Sharing Mechanism provides CIG an incentive to reduce the amount of fuel consumed on its system. CIG and its shippers share in the savings created. ${ }^{344}$ FERC approved CIG's settlement on August 7, $2006 .^{345}$

\section{Columbia Gulf Transmission Company's Incentive Fuel Mechanism}

In 2009, Columbia Gulf Transmission Company (Columbia Gulf) filed an experimental incentive fuel mechanism utilizing fixed fuel retainage percentages (Incentive Fixed Fuel or IFF mechanism) as an alternative to its then-existing fuel tracker and true-up mechanism. ${ }^{346}$ In response, FERC clarified its policy concerning permissible incentive fuel mechanisms. FERC stated that it would permit a pipeline to establish, in a limited Section 4 filing fixed fuel rates that are significantly below the cost-based level that the pipeline could otherwise justify. The pipeline could then, in exchange, keep a share of the fuel usage savings that result from the capital improvements it makes in order to reduce its fuel usage. FERC sated that this policy would assure customers an immediate, real rate reduction, as well as encouraging pipelines to make investments to improve fuel efficiency of their systems. Consistent with this policy, FERC required Columbia Gulf to recalculate the IFF rates such that those rates would be significantly below the recalculated current cost-based retainage rates. FERC set the proposal for technical conference and thereafter Columbia Gulf filed a revised IFF proposal. FERC accepted and suspended Columbia's tariff record finding that the IFF mechanism was just and reasonable, subject to certain conditions. ${ }^{347}$ FERC conditioned its approval on Columbia Gulf: (1) providing additional information to support its projection of the CUG it would incur absent the investments it intends to make as part of the IFF mechanism; and (2) revise the allocation of savings between itself and its customers to increase the customer share to $33 \%$. Columbia Gulf withdrew its IFF proposal, rather than comply with these conditions.

\section{Columbia Gas's CCRM}

In 2013, FERC approved a settlement addressing the base rate treatment for planned actions to overhaul the aging Columbia Gas Transmission pipeline system. The settlement established a capital cost recovery mechanism (CCRM) for Columbia,

\footnotetext{
${ }^{344}$ Petition Of Colorado Interstate Gas Company To Amend Filing Requirement And For Approval of Stipulation and Agreement (Jun. 20, 2006).

345116 FERC $\mid 61,126$ (2006).

${ }^{346}$ Columbia Gulf Transmission Co., 131 FERC $\$$ 61,156 (2010), order on technical conference and proposed fuel rates, 132 FERC \ 61,009 (2010) (Columbia Gulf).

347 Columbia Gulf, 132 FERC $961,009$.
} 
structured as an annually updated rate surcharge, effective through 2018 . Through the rate surcharge, Columbia will recover the costs (up to a $\$ 300$ million annual cap, subject to a $15 \%$ tolerance) of upgrading certain facilities on the Columbia system. ${ }^{348}$ Columbia also committed to $\$ 100$ million in annual capital maintenance expenditures that would not be recouped through the CCRM. ${ }^{349}$

\footnotetext{
${ }^{348}$ Columbia Gas Transmission, LLC, 142 FERC 61,062, at p. 22 (2013). The CCRM was coupled with annual base rate reductions and the payment of $\$ 50$ million in refunds to firm shippers. The settlement also included a number of features designed to provide Columbia with the incentive to perform the upgrades efficiently (e.g., specific identification of the facilities for which costs could be recovered in the CCRM, a billing determinant floor, caps on recoverable amounts, and shipper oversight).

${ }_{349}$ Columbia Gas Transmission, LLC, 142 FERC 61,062, at p. 22 (2013). The Maryland Public Service Commission opposed the settlement, citing FERC's general policy against the use of rate trackers to recover costs incurred to comply with pipeline safety requirements. Although acknowledging its policy disfavoring trackers for pipeline safety infrastructure spending, FERC approved the settlement and CCRM. FERC found that "the settlement and the CCRM provide a reasonable means for Columbia to recover the substantial costs of addressing urgent public safety and reliability concerns, without undercutting Columbia's incentives to operate efficiently and to maximize service to the extent that previously proposed and rejected surcharges would have done."
} 


\section{Appendix B: Tables}

\section{Table B-1: Leak Classification and Action Criteria for Transmission and Distribution Piping Systems ${ }^{350}$}

\begin{tabular}{|c|c|c|c|}
\hline Class & Definition & Action Criteria & Examples \\
\hline 1 & $\begin{array}{l}\text { A leak that represents an existing or } \\
\text { probable hazard to persons or } \\
\text { property, and requires immediate } \\
\text { repair or continuous action until the } \\
\text { conditions are no longer hazardous. } \\
\text { See } \$ 192.703 \text { (c). }\end{array}$ & $\begin{array}{l}\text { Requires prompt action* to protect life and } \\
\text { property, and continuous action until the } \\
\text { conditions are no longer hazardous. } \\
\text { *The prompt action in some in-stances may } \\
\text { require one or more of the following: } \\
\text { a. Implementation of emergency plan } \\
\text { (\$192.615). } \\
\text { b. Evacuating premises. } \\
\text { c. Blocking off an area. } \\
\text { d. Rerouting traffic. } \\
\text { e. Eliminating sources of ignition. } \\
\text { f. Venting the area by removing manhole } \\
\text { covers, barholing, installing vent holes, or } \\
\text { g. Sther means. } \\
\text { other means. } \\
\text { h. Notifying police and fire departments. }\end{array}$ & $\begin{array}{l}\text { 1. Any leak which, in the judgment of } \\
\text { operating personnel at the scene, is } \\
\text { regarded as an immediate hazard. } \\
\text { 2. Escaping gas that has ignited. } \\
\text { 3. Any indication of gas which has } \\
\text { migrated into or under a building, or } \\
\text { into a tunnel. } \\
\text { 4. Any reading at the outside wall of a } \\
\text { building, or where gas would likely } \\
\text { migrate to an out-side wall of a } \\
\text { building. } \\
\text { 5. Any reading of } 80 \% \text { LEL, or greater, } \\
\text { in a confined space. } \\
\text { 6. Any reading of } 80 \% \text { LEL, or greater } \\
\text { in small substructures (other than } \\
\text { gas associated substructures) from } \\
\text { which gas would likely migrate to } \\
\text { the outside wall of a building. } \\
\text { 7. Any leak that can be seen, heard, or } \\
\text { felt, and which is in a location that } \\
\text { may endanger the general public or } \\
\text { property. }\end{array}$ \\
\hline
\end{tabular}

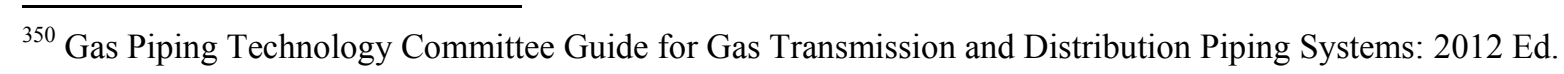




\begin{tabular}{|c|c|c|c|}
\hline Class & Definition & Action Criteria & Examples \\
\hline 2 & $\begin{array}{l}\text { A leak that is recognized as being } \\
\text { non-hazardous at the time of } \\
\text { detection, but justifies scheduled } \\
\text { repair based on probable future } \\
\text { hazard. }\end{array}$ & $\begin{array}{l}\text { Leaks should be repaired or cleared within one } \\
\text { calendar year, but no later than } 15 \text { months from } \\
\text { the date the leak was reported. In determining the } \\
\text { repair priority, criteria such as the following should } \\
\text { be considered. } \\
\text { a. Amount and migration of gas. } \\
\text { b. Proximity of gas to buildings and subsurface } \\
\text { structures. } \\
\text { c. Extent of pavement. } \\
\text { d. Soil type, and soil conditions, such as frost } \\
\text { cap, moisture and natural venting. } \\
\text { e. Grade } 2 \text { leaks should be reevaluated at least } \\
\text { once every six months until cleared. The } \\
\text { frequency of reevaluation should be } \\
\text { determined by the location and magnitude of } \\
\text { the leakage condition. }\end{array}$ & $\begin{array}{l}\text { A. Leaks Requiring Action Ahead of Ground } \\
\text { Freezing or Other Adverse Changes in } \\
\text { Venting Conditions. } \\
\text { Any leak which, under frozen or other } \\
\text { adverse soil conditions, would likely } \\
\text { migrate to the outside wall of a building. } \\
\text { B. Leaks Requiring Action Within Six } \\
\text { Months } \\
\text { 1. Any reading of } 40 \% \text { LEL, or greater, } \\
\text { under a sidewalk in a wall-to-wall paved } \\
\text { area that does not qualify as a Grade } 1 \\
\text { leak. } \\
\text { 2. Any reading of } 100 \% \text { LEL, or greater, } \\
\text { under a street in a wall-to-wall paved } \\
\text { area that has significant gas migration } \\
\text { and does not qualify as a Grade } 1 \text { leak. } \\
\text { 3. Any reading less than } 80 \% \text { LEL in small } \\
\text { substructures (other than gas associated } \\
\text { substructures) from which gas would } \\
\text { likely migrate creating a probable future } \\
\text { hazard. } \\
\text { 5.4 Any reading between } 20 \% \text { LEL and } 80 \% \\
\text { LEL in confined space. } \\
\text { 5. Any reading on a pipeline operating at } 30 \\
\text { percent SMYS, or greater, in a class } 3 \text { or } \\
4 \text { location, which does not qualify as a } \\
\text { Gradeleak. } \\
\text { 4.6 Any reading of } 80 \% \text { LEL, or greater, in } \\
\text { gas associated sub-structures. } \\
\text { 7. Any leak which, in the judgment of } \\
\text { operating personnel at the scene, is of } \\
\text { sufficient magnitude to justify scheduled } \\
\text { repair. }\end{array}$ \\
\hline
\end{tabular}




\begin{tabular}{|c|c|c|c|}
\hline Class & Definition & Action Criteria & Examples \\
\hline 3 & $\begin{array}{l}\text { A leak that is nonhazardous } \\
\text { at the time of detection and can be } \\
\text { reasonably expected to remain non- } \\
\text { hazardous. }\end{array}$ & $\begin{array}{l}\text { These leaks should be reevaluated during the } \\
\text { next scheduled survey, or within } 15 \text { months of the } \\
\text { date reported, whichever occurs first, until the } \\
\text { leak is regraded or no longer results in a reading. }\end{array}$ & $\begin{array}{l}\text { Leaks Requiring Reevaluation at Periodic } \\
\text { Intervals } \\
\text { 1. Any reading of less than } 80 \% \text { LEL in } \\
\text { small gas associated substructures. } \\
\text { 2. Any reading under a street in areas } \\
\text { without wall-to-wall paving where it is } \\
\text { unlikely the gas could migrate to the out- } \\
\text { side wall of a building. } \\
\text { 3. Any reading of less than } 20 \% \text { LEL in a } \\
\text { confined space. }\end{array}$ \\
\hline
\end{tabular}


Table B-2: Leak Survey and Patrol Requirements for Distribution Lines

\begin{tabular}{lll}
\hline Location & Patrol Requirements & Leak Survey Requirements \\
\hline Business Districts & $\begin{array}{l}\text { Intervals not exceeding 4 } 1 / 2 \\
\text { months, but at least four } \\
\text { times each calendar year }\end{array}$ & $\begin{array}{l}\text { Leakage survey with leak detector equipment, including tests of the atmosphere in gas, } \\
\text { electric, telephone, sewer, and water system manholes, at cracks in pavement and } \\
\text { sidewalks, and at other locations providing an opportunity for finding gas leaks, at intervals } \\
\text { not exceeding } 15 \text { months, but at least once each calendar year. }\end{array}$ \\
$\begin{array}{l}\text { Outside Business } \\
\text { Districts }\end{array}$ & $\begin{array}{l}\text { Intervals not exceeding } 71 / 2 \\
\text { months, but at least twice } \\
\text { each calendar year }\end{array}$ & $\begin{array}{l}\text { A leakage survey with leak detector equipment must be conducted as frequently as } \\
\text { Necessary, but at least once every } 5 \text { calendar years at intervals not exceeding } 63 \text { months. } \\
\text { However, for cathodically unprotected distribution lines subject to } \S 192.465(e) \text { on which } \\
\text { electrical surveys for corrosion are impractical, a leakage survey must be conducted at least } \\
\text { once every 3 calendar years at intervals not exceeding 39 months. }\end{array}$ \\
\hline
\end{tabular}


Table B-3. Leak Survey and Patrol Requirements for Transmission Pipelines

\begin{tabular}{|c|c|c|c|}
\hline \multirow{2}{*}{$\begin{array}{l}\text { Class } \\
\text { Location of } \\
\text { Line }^{351}\end{array}$} & \multicolumn{2}{|c|}{$\begin{array}{l}\text { Patrol Requirement } \\
\text { (maximum Interval Between Patrols) }\end{array}$} & \multirow[t]{2}{*}{ Leak Survey } \\
\hline & $\begin{array}{l}\text { At highway and railroad } \\
\text { crossings }\end{array}$ & At all other places & \\
\hline 1 & $\begin{array}{l}71 / 2 \text { months; but at least twice } \\
\text { each calendar year }\end{array}$ & $\begin{array}{l}15 \text { months; but at least } \\
\text { once each calendar } \\
\text { year }\end{array}$ & $\begin{array}{l}\text { Intervals not exceeding } 15 \text { months, but at least once each } \\
\text { calendar year }\end{array}$ \\
\hline 2 & $\begin{array}{l}71 / 2 \text { months; but at least twice } \\
\text { each calendar year }\end{array}$ & $\begin{array}{l}15 \text { months; but at least } \\
\text { once each calendar } \\
\text { year }\end{array}$ & $\begin{array}{l}\text { Intervals not exceeding } 15 \text { months, but at least once each } \\
\text { calendar year }\end{array}$ \\
\hline 3 & $\begin{array}{l}41 / 2 \text { months; but at least four } \\
\text { times each calendar year }\end{array}$ & $\begin{array}{l}71 / 2 \text { months; but at } \\
\text { least twice each } \\
\text { calendar year }\end{array}$ & $\begin{array}{l}\text { Transmission line which transports gas in conformity with } \S \\
192.625 \text { without an odor or odorant, leakage surveys using leak } \\
\text { detector equipment must be conducted at intervals not } \\
\text { exceeding } 71 / 2 \text { months, but at least twice each calendar year }\end{array}$ \\
\hline 4 & $\begin{array}{l}41 / 2 \text { months; but at least four } \\
\text { times each calendar year }\end{array}$ & $\begin{array}{l}41 / 2 \text { months; but at } \\
\text { least four times each } \\
\text { calendar year }\end{array}$ & $\begin{array}{l}\text { Transmission line which transports gas in conformity with } \S \\
192.625 \text { without an odor or odorant, leakage surveys using leak } \\
\text { detector equipment must be conducted at intervals not } \\
\text { exceeding } 4 \frac{1}{2} \text { months, but at least four times each calendar } \\
\text { year }\end{array}$ \\
\hline
\end{tabular}

\footnotetext{
${ }^{351}$ A "class location unit" is an onshore area that extends 220 yards (200 meters) on either side of the centerline of any continuous 1 - mile (1.6 kilometers) length of pipeline. Each separate dwelling unit in a multiple dwelling unit building is counted as a separate building intended for human occupancy. A Class 1 location is: (i) An offshore area; or (ii) Any class location unit that has 10 or fewer buildings intended for human occupancy. A Class 2 location is any class location unit that has more than 10 but fewer than 46 buildings intended for human occupancy. A Class 3 location is: (i) Any class location unit that has 46 or more buildings intended for human occupancy; or (ii) An area where the pipeline lies within 100 yards (91 meters) of either a building or a small, well-defined outside area (such as a playground, recreation area, outdoor theater, or other place of public assembly) that is occupied by 20 or more persons on at least 5 days a week for 10 weeks in any 12-month period. (The days and weeks need not be consecutive.) A Class 4 location is any class location unit where buildings with four or more stories above ground are prevalent. The length of Class locations 2, 3, and 4 may be adjusted as follows: (1) A Class 4 location ends 220 yards (200 meters) from the nearest building with four or more stories above ground. (2) When a cluster of buildings intended for human occupancy requires a Class 2 or 3 location, the class location ends 220 yards (200 meters) from the nearest building in the cluster. 49 C.F.R. $\$ 192.5$.
} 
Table B-4. Leak Detection Requirements for Gathering Lines

\begin{tabular}{ll}
\hline Type of Gathering Line & Requirements \\
\hline Type A Regulated Onshore Gathering Lines ${ }^{352}$ & Transmission line requirements, except requirement to install smart pig and develop IMP. \\
\hline Type B Regulated Onshore Gathering Lines & $\begin{array}{l}\text { Design, installation, construction, initial inspection, and initial testing requirements for } \\
\text { transmission lines apply for new, replaced, or relocated gathering lines. }\end{array}$ \\
\hline
\end{tabular}

35249 C.F.R. § 192.9. Type A Regulated Gathering Lines are metallic lines with a maximum allowable operating pressure (MAOP) of 20\% or more of specified minimum yield strength (SMYS), as well as nonmetallic lines with an MAOP of more than 125 psig, in a Class 2, 3, or 4 location.

${ }^{353} \mathrm{Id}$. Metallic lines with an MAOP of less than $20 \%$ of

SMYS, as well as nonmetallic lines with an MAOP of

125 psig or less, in a Class 2 location (as determined under one of three formulas) or in a Class 3 or Class 4 location. 
Table B-5. Table of EPA Regulations

\begin{tabular}{|c|c|c|c|}
\hline Source & Section 111 & Section 112 & Notes \\
\hline Equipment leaks & Periodic inspections at gas plants. ${ }^{354}$ & $\begin{array}{l}\text { Periodic inspections at gas } \\
\text { plants. }\end{array}$ & New and existing. \\
\hline $\begin{array}{l}\text { Leaks from } \\
\text { centrifugal } \\
\text { compressor seals }\end{array}$ & $95 \%$ control from wet seals. ${ }^{356}$ & & $\begin{array}{l}\text { New. } \\
\text { Not apply to storage and transmission } \\
\text { sector. } \\
\text { Note apply to well sites. }\end{array}$ \\
\hline $\begin{array}{l}\text { Well venting during } \\
\text { completions and re- } \\
\text { completions }\end{array}$ & $\begin{array}{l}\text { Reduced emission completion "REC" } \\
\text { for hydraulically fractured and re- } \\
\text { fractured gas wells except exploratory, } \\
\text { delineation wells and low-pressure } \\
\text { wells. Otherwise, must combust gas } \\
\text { unless safety concerns. }{ }^{357}\end{array}$ & & $\begin{array}{l}\text { New and existing. } \\
\text { Not apply to oil wells. }\end{array}$ \\
\hline $\begin{array}{l}\text { Pneumatic } \\
\text { controllers }\end{array}$ & $\begin{array}{l}\text { Low bleed at wellheads. }{ }^{358} \\
\text { No bleed at gas processing plants. }{ }^{359}\end{array}$ & & $\begin{array}{l}\text { New sources. } \\
\text { Not apply to storage and transmission } \\
\text { sector. } \\
\text { Not apply to intermittent bleed devices. }\end{array}$ \\
\hline $\begin{array}{l}\text { Leaks from } \\
\text { reciprocating } \\
\text { compressors }\end{array}$ & $\begin{array}{l}\text { Replace rod-packing every } 26,000 \\
\text { hours. }\end{array}$ & & $\begin{array}{l}\text { New sources. } \\
\text { Not apply to storage and transmission } \\
\text { sector. } \\
\text { Not apply to well sites. }\end{array}$ \\
\hline Storage Tanks & $\begin{array}{l}95 \% \text { control of VOCs from tanks with } \\
\text { at least } 6 \text { Tpy VOCs. }\end{array}$ & $\begin{array}{l}\text { Large tanks with the potential for } \\
\text { flash emissions that are, or are } \\
\text { located at, major sources. }{ }^{362}\end{array}$ & $\begin{array}{l}\text { New and existing. } \\
\text { Not apply to distribution. }\end{array}$ \\
\hline
\end{tabular}

\footnotetext{
${ }^{354} 40$ C.F.R. Subpart KKK (1986); 40 C.F.R. Subpart OOOO (2012).

35540 C.F.R. Subpart KKK (1986); 40 C.F.R. Subpart OOOO (2012).

${ }^{356} \mathrm{Id}$.

35740 C.F.R. Subpart OOOO (2012).

35840 C.F.R. Subpart OOOO (2012).

${ }^{359} \mathrm{Id}$.

36040 C.F.R. Subpart OOOO (2012).
} 


\begin{tabular}{|c|c|c|c|}
\hline Source & Section 111 & Section 112 & Notes \\
\hline \multirow{5}{*}{\multicolumn{2}{|c|}{ Glycol Dehydrators }} & $95 \%$ control from large ${ }^{363}$ & \multirow{5}{*}{$\begin{array}{l}\text { New and existing. } \\
\text { Not apply to distribution. } \\
\text { Non-major ("area") sources subject to } \\
\text { least stringent requirements. }\end{array}$} \\
\hline & & dehydrators that are or are located & \\
\hline & & $\begin{array}{l}\text { at major sources. }{ }^{04} \\
\text { Small }{ }^{365} \text { production dehydrators } \\
\text { located at major sources must meet } \\
\text { unit specific BTEX limits. }\end{array}$ & \\
\hline & & $\begin{array}{l}\text { "Large" area source production } \\
\text { dehydrators located within near } \\
\text { populated areas must reduce HAPs } \\
\text { by } 95 \% \text { or more to output } \\
\text { concentration of } 20 \text { ppmv. }\end{array}$ & \\
\hline & & $\begin{array}{l}\text { All other large production area } \\
\text { source dehydrators must optimize } \\
\text { glycol circulation rate. }\end{array}$ & \\
\hline
\end{tabular}

36140 C.F.R. Subpart OOOO (2012).

${ }^{362}$ Vessels that contain a hydrocarbon liquid with a storage tank gas to oil ratio equal to or greater than $.31 \mathrm{~m} 3 /$ liter, an API gravity equal to or greater than 40 degrees. 63 Fed. Reg. 6288 (Feb. 6, 1998).

${ }^{363}$ Large means a glycol dehydration unit with an actual flowrate of natural gas greater than 85 thousand $\mathrm{m} 3 / \mathrm{d}$ or the actual average benzene emissions from the glycol dehydration units are more than $.9 \mathrm{mg} / \mathrm{yr}$.

${ }^{364}$ National Emission Standards for Hazardous Air Pollutants: "Oil and Natural Gas Production and Natural Gas Transmission and Storage”, 64 Fed. Reg. 32610 (June 17, 1999).

${ }^{365}$ Those with an actual flowrate of natural gas less than 85 thousand $\mathrm{m} 3 / \mathrm{d}$ or the actual average benzene emissions from the glycol dehydration units are less than $.9 \mathrm{mg} / \mathrm{yr}$.

${ }^{366}$ National Emission Standards for Hazardous Air Pollutants for Oil and Natural Gas Production Facilities, 72 Fed. Reg. 26 (Jan. 3, 2007). Urban Area is a densely populated area of at least 50,000 people. An Urban Cluster is an area with between 10,000 and 50,000 people. Id.

${ }^{367} I d$. at 29 . 
Table B-6. PHMSA Funded Leak Detection Research Since 2002

\begin{tabular}{|c|c|c|c|c|c|c|c|}
\hline Seq. & $\begin{array}{l}\text { Prj } \\
\#\end{array}$ & $\begin{array}{l}\text { Program } \\
\text { Category }\end{array}$ & $\begin{array}{l}\text { Pipeline } \\
\text { Type }\end{array}$ & Project ID and Title & Status & Contractor & PHMSA \\
\hline 1. & 93 & $\begin{array}{l}\text { Leak } \\
\text { Detection }\end{array}$ & $\begin{array}{l}\text { GasGather } \\
\text { GasTrans } \\
\text { Dist-Steel } \\
\text { Dist-Non- } \\
\text { Metal }\end{array}$ & $\begin{array}{l}\text { DTRS56-01-X-0023, Airborne LIDAR Pipeline } \\
\text { Inspection System (ALPIS) Mapping Tests }\end{array}$ & Closed & $\begin{array}{l}\text { LaSen and U.S. Air } \\
\text { Force Research } \\
\text { Laboratory }\end{array}$ & $\$ 2,245,204$ \\
\hline 2. & 136 & $\begin{array}{l}\text { Leak } \\
\text { Detection }\end{array}$ & $\begin{array}{l}\text { HazLiq } \\
\text { GasGather } \\
\text { GasTrans } \\
\text { Dist-Steel } \\
\text { Dist-Non- } \\
\text { Metal }\end{array}$ & $\begin{array}{l}\text { DTRS57-04-C-10012, Intrinsic Distributed Fiber } \\
\text { Optic Leak Detection }\end{array}$ & Closed & Prime Research & $\$ 99,706$ \\
\hline 3. & 137 & $\begin{array}{l}\text { Leak } \\
\text { Detection }\end{array}$ & $\begin{array}{l}\text { HazLiq } \\
\text { GasGather } \\
\text { GasTrans } \\
\text { Dist-Steel } \\
\text { Dist-Non- } \\
\text { Metal }\end{array}$ & $\begin{array}{l}\text { DTRS57-04-C-10016, Piezo Structural Acoustic } \\
\text { Pipeline Leak Detection System }\end{array}$ & Closed & $\begin{array}{l}\text { Midé Technology } \\
\text { Corporation }\end{array}$ & $\$ 100,000$ \\
\hline 4. & 153 & $\begin{array}{l}\text { Leak } \\
\text { Detection }\end{array}$ & $\begin{array}{l}\text { HazLiq } \\
\text { GasGather } \\
\text { GasTrans } \\
\text { Dist-Steel } \\
\text { Dist-Non- } \\
\text { Metal }\end{array}$ & $\begin{array}{l}\text { DTRS56-04-T-0012, Hazardous Liquids Airborne } \\
\text { Lidar Observation Study (HALOS) }\end{array}$ & Closed & $\begin{array}{l}\text { ITT Industries } \\
\text { Space Systems, } \\
\text { LLC }\end{array}$ & $\$ 553,114$ \\
\hline 5. & 234 & $\begin{array}{l}\text { Leak } \\
\text { Detection }\end{array}$ & $\begin{array}{l}\text { HazLiq } \\
\text { GasGather } \\
\text { GasTrans }\end{array}$ & $\begin{array}{l}\text { DTPH56-08-T-000007, Development of a Free- } \\
\text { Swimming Acoustic Tool for Liquid Pipeline Leak } \\
\text { Detection Including Evaluation for Natural Gas } \\
\text { Pipeline Applications }\end{array}$ & Closed & $\begin{array}{l}\text { Arizona State } \\
\text { University }\end{array}$ & $\$ 388,332$ \\
\hline 6. & 363 & $\begin{array}{l}\text { Leak } \\
\text { Detection }\end{array}$ & $\begin{array}{l}\text { Dist-Steel } \\
\text { Dist-Non- } \\
\text { Metal }\end{array}$ & DTPH56-10-T-000018, Odorant Effectiveness & Closed & $\begin{array}{l}\text { Gas Technology } \\
\text { Institute }\end{array}$ & $\$ 408,653$ \\
\hline
\end{tabular}




\begin{tabular}{|c|c|c|c|c|c|c|c|}
\hline Seq. & $\begin{array}{l}\text { Prj } \\
\#\end{array}$ & $\begin{array}{l}\text { Program } \\
\text { Category }\end{array}$ & $\begin{array}{l}\text { Pipeline } \\
\text { Type }\end{array}$ & Project ID and Title & Status & Contractor & PHMSA \\
\hline 7. & 367 & $\begin{array}{l}\text { Leak } \\
\text { Detection }\end{array}$ & $\begin{array}{l}\text { GasGather } \\
\text { GasTrans } \\
\text { Dist-Steel } \\
\text { Dist-Non- } \\
\text { Metal }\end{array}$ & $\begin{array}{l}\text { DTPH56-10-T-000022, Development and Field } \\
\text { Testing of a Highly Sensitive Mercaptans } \\
\text { Instrument }\end{array}$ & Closed & $\begin{array}{l}\text { Northeast Gas } \\
\text { Association }\end{array}$ & $\$ 246,496$ \\
\hline 8. & 442 & $\begin{array}{l}\text { Leak } \\
\text { Detection }\end{array}$ & $\begin{array}{l}\text { HazLiq } \\
\text { GasGather } \\
\text { GasTrans } \\
\text { Dist-Steel }\end{array}$ & $\begin{array}{l}\text { DTRT57-12-C-10050, Smart Pipeline Network - } \\
\text { Seal Sensor System }\end{array}$ & Closed & $\begin{array}{l}\text { Odyssian } \\
\text { Technology LLC }\end{array}$ & $\$ 150,000$ \\
\hline 9. & 443 & $\begin{array}{l}\text { Leak } \\
\text { Detection }\end{array}$ & $\begin{array}{l}\text { HazLiq } \\
\text { GasGather } \\
\text { GasTrans } \\
\text { Dist-Steel }\end{array}$ & $\begin{array}{l}\text { DTRT57-12-C-10048, Smart Pipeline Network - } \\
\text { Cased Pipe for Monitoring and Sensor System }\end{array}$ & Closed & $\begin{array}{l}\text { Odyssian } \\
\text { Technology LLC }\end{array}$ & $\$ 150,000$ \\
\hline 10. & 444 & $\begin{array}{l}\text { Leak } \\
\text { Detection }\end{array}$ & $\begin{array}{l}\text { HazLiq } \\
\text { GasGather } \\
\text { GasTrans } \\
\text { Dist-Steel }\end{array}$ & $\begin{array}{l}\text { DTRT57-12-C-10049, Smart Pipeline Network - } \\
\text { Pipe \& Repair Sensor System }\end{array}$ & Closed & $\begin{array}{l}\text { Odyssian } \\
\text { Technology LLC }\end{array}$ & $\$ 150,000$ \\
\hline 11. & 495 & $\begin{array}{l}\text { Leak } \\
\text { Detection }\end{array}$ & $\begin{array}{l}\text { Dist-Steel } \\
\text { Dist-Non- } \\
\text { Metal }\end{array}$ & $\begin{array}{l}\text { DTPH56-13-T-000005, Advanced Development } \\
\text { and Technology Transfer of a Methane/Natural } \\
\text { Gas Microsensor }\end{array}$ & Active & $\begin{array}{l}\text { Northeast Gas } \\
\text { Association }\end{array}$ & $\$ 412,388$ \\
\hline 12. & 560 & $\begin{array}{l}\text { Leak } \\
\text { Detection }\end{array}$ & $\begin{array}{l}\text { HazLiq } \\
\text { GasTrans }\end{array}$ & $\begin{array}{l}\text { DTPH56-14-H-00007, Improving Leak Detection } \\
\text { System Design Redundancy \& Accuracy }\end{array}$ & Active & Kiefner Applus RTD & $\$ 832,036$ \\
\hline
\end{tabular}

